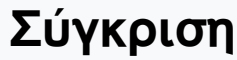

Tó 23 (2013)

\section{3-2014}

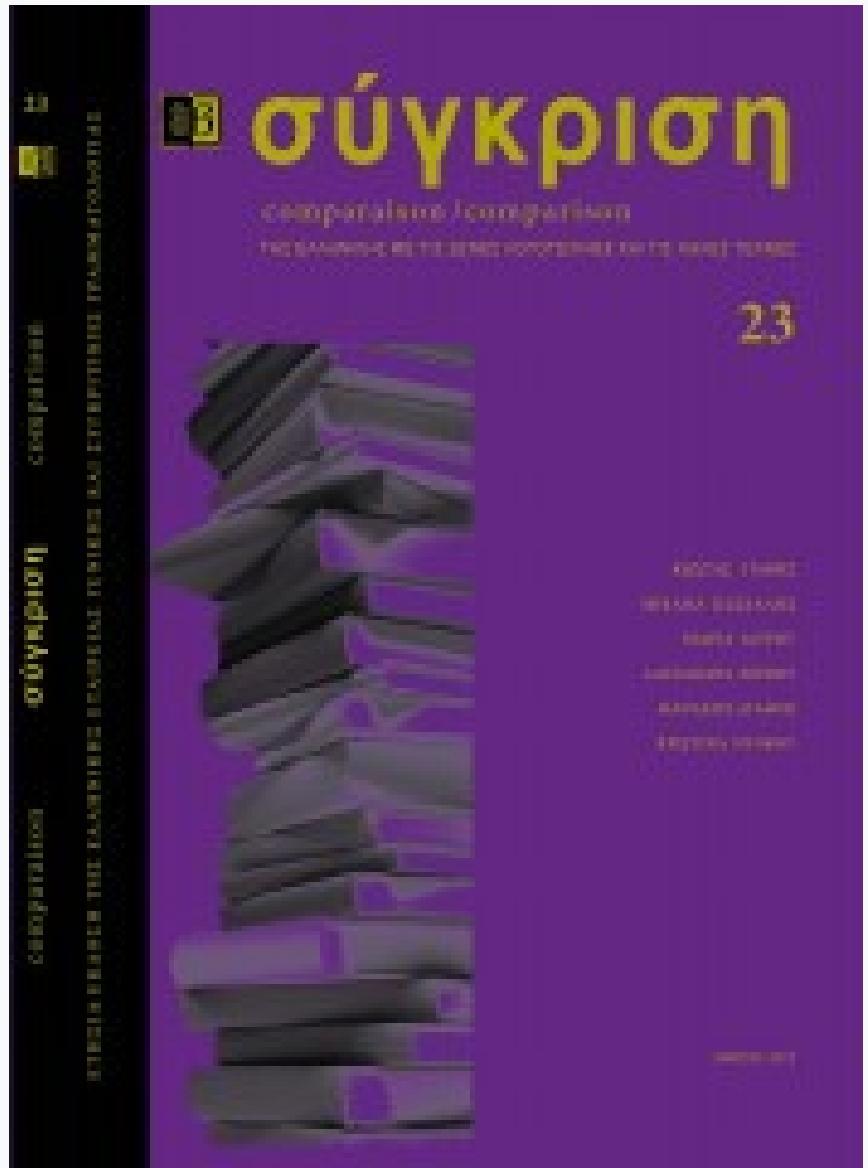

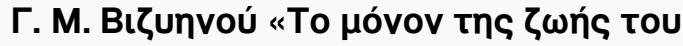

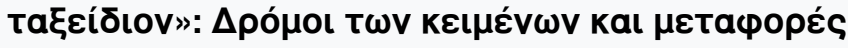
Tou Өavátou

\section{Mapía latpoú}

doi: $10.12681 /$ comparison.22

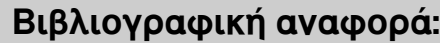

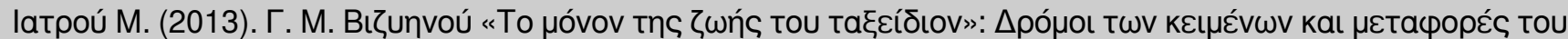

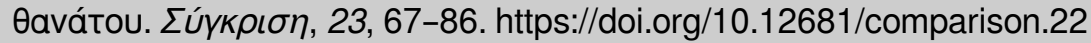




\title{
MAPIA IATPOY
}

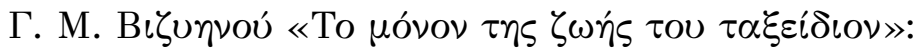

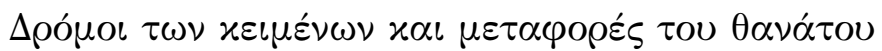

\section{Anton Reiser: $\tau o \delta \iota \alpha \kappa \varepsilon i ́ \mu \varepsilon v o$}

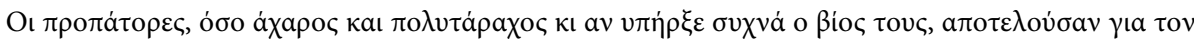

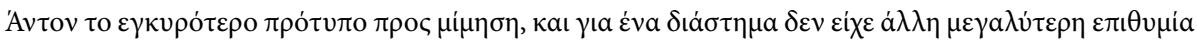

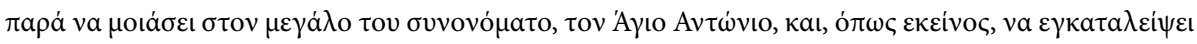

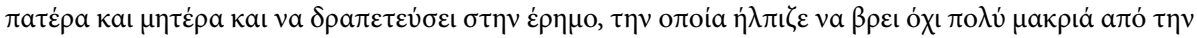

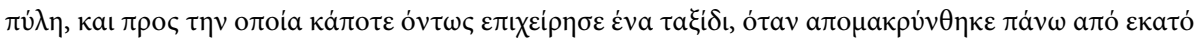

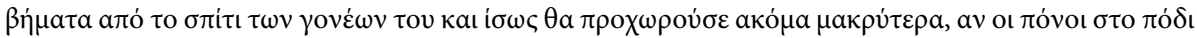

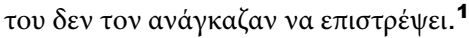

$\mathbf{T}$

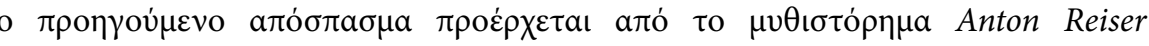

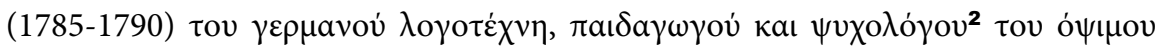

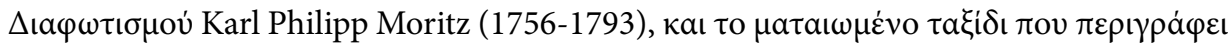

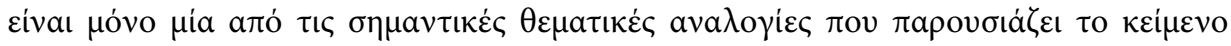

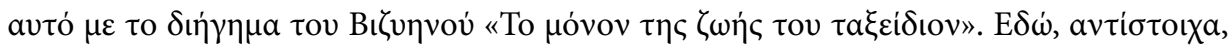

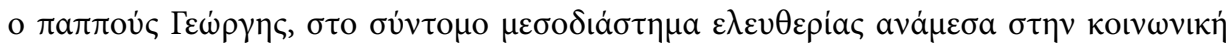

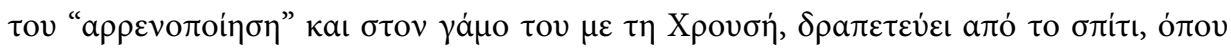

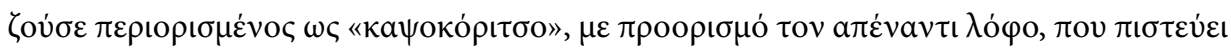

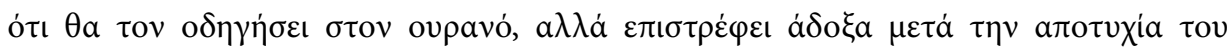

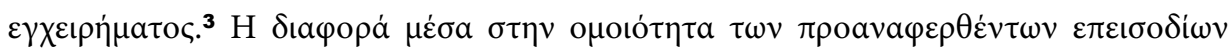

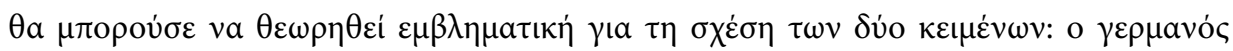

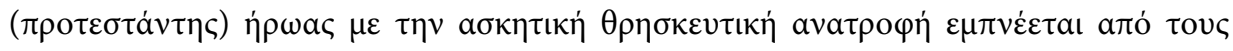

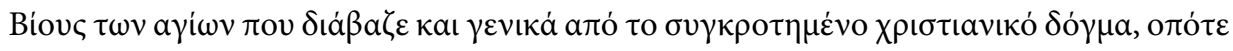

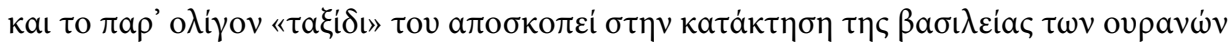

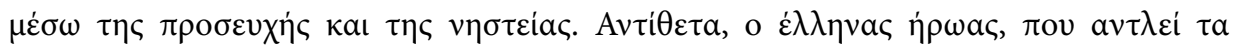

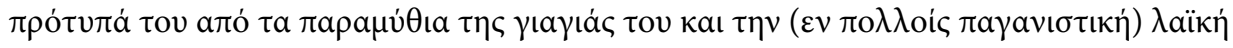

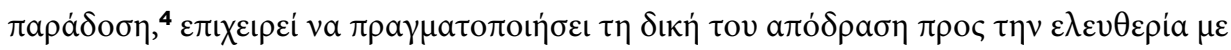

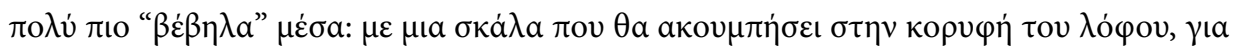

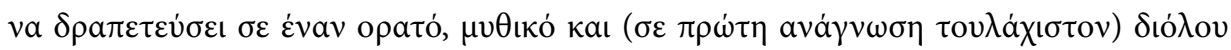

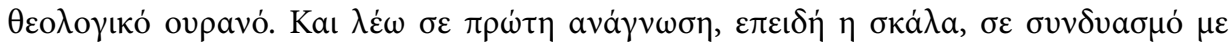

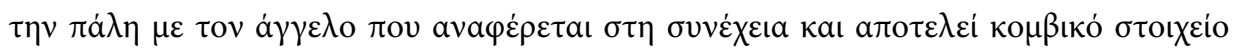

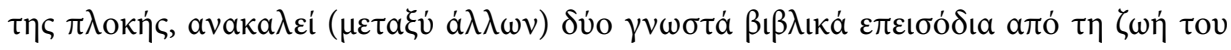




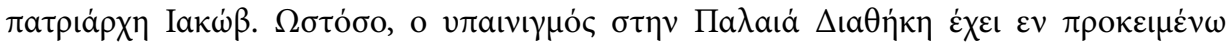

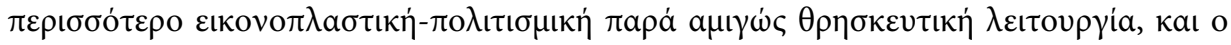

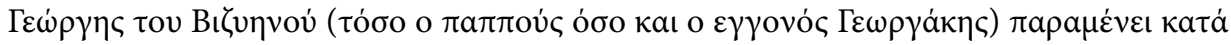

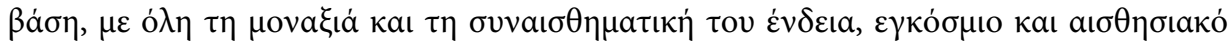

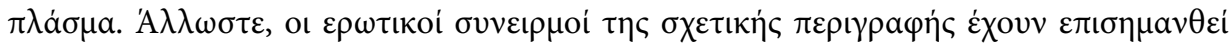

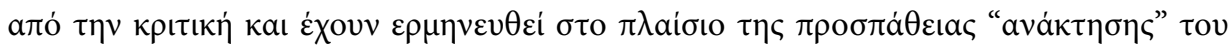

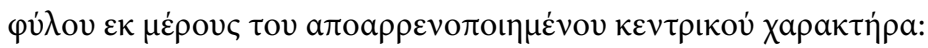

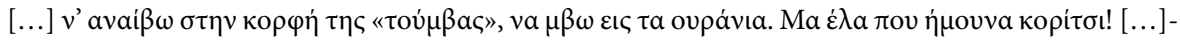

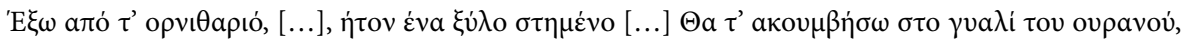

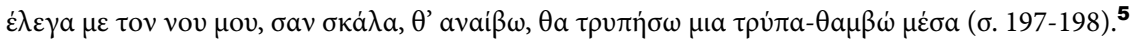

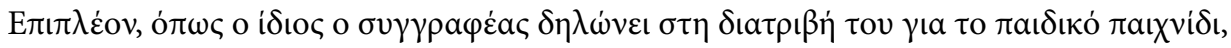

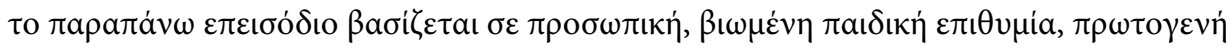

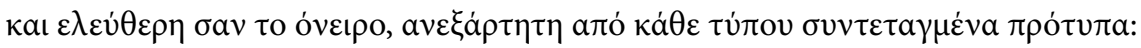

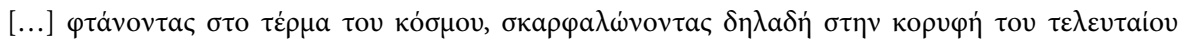

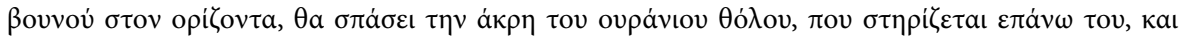

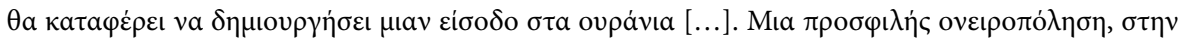

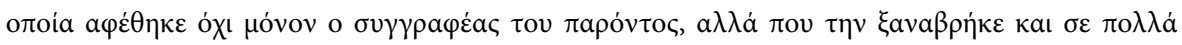

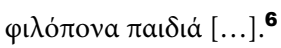

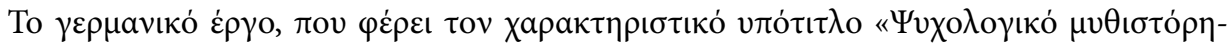

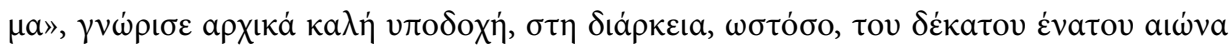

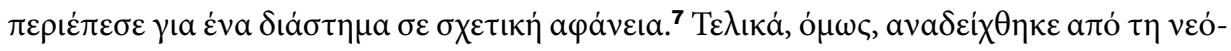

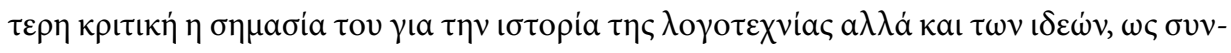

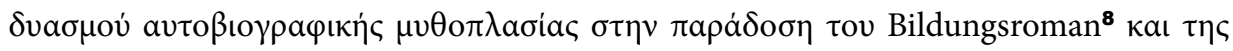

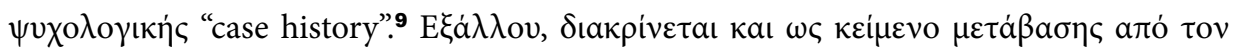

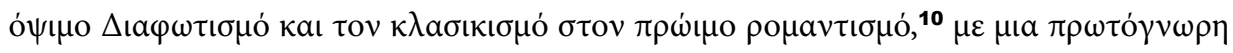

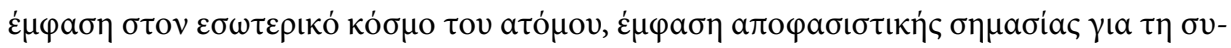

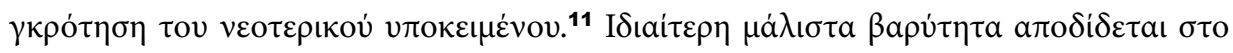

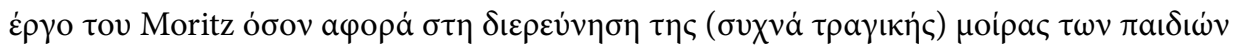

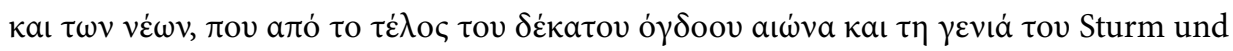
Drang a

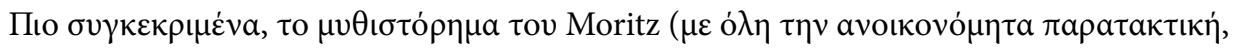

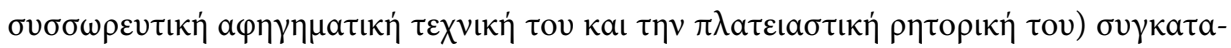

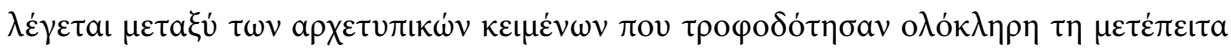

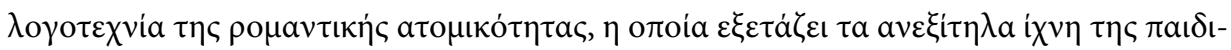

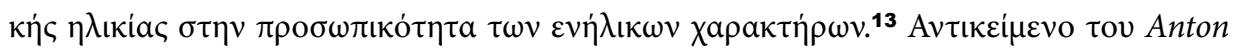

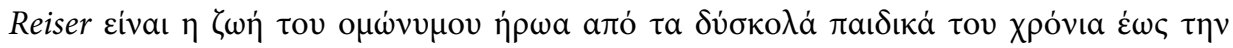




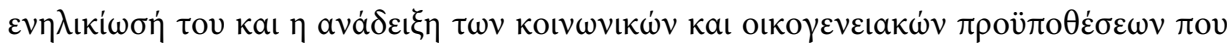

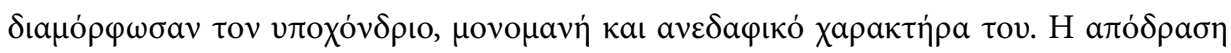

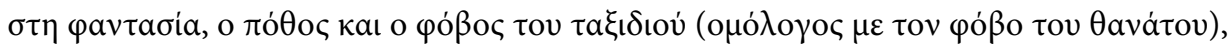

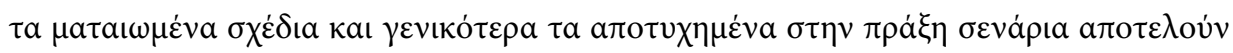

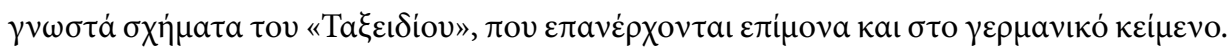

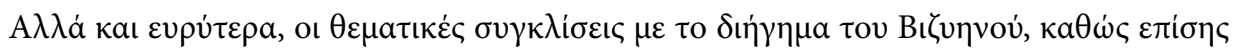

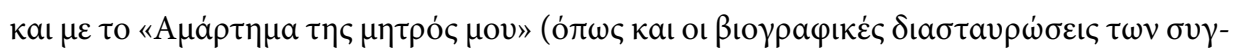

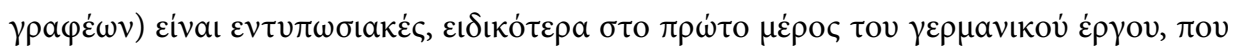

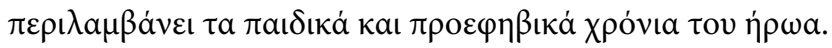

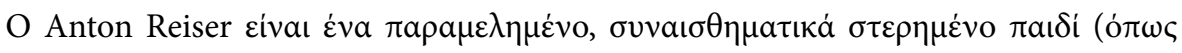

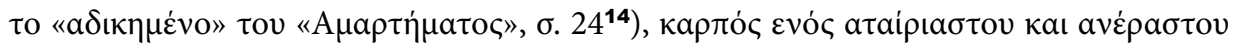

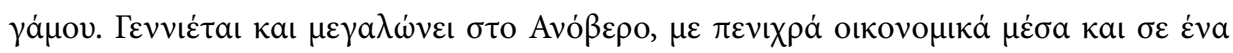

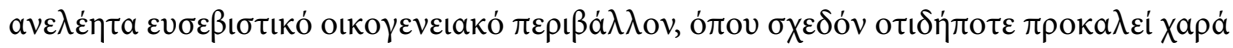

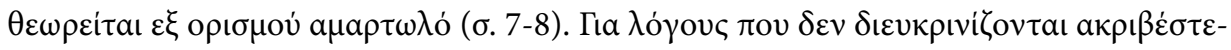

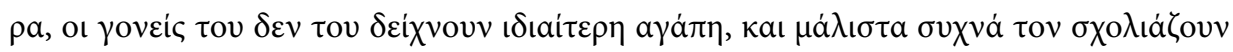

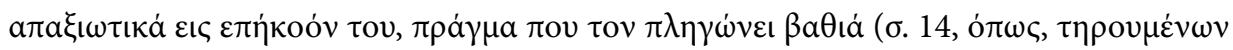

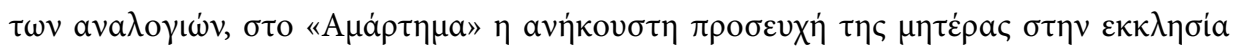

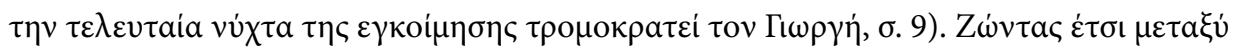

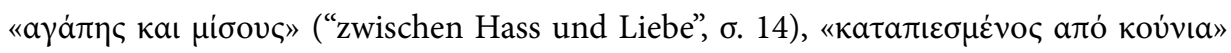

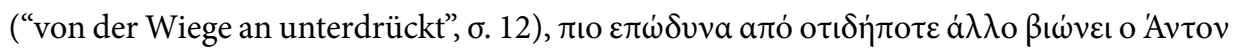

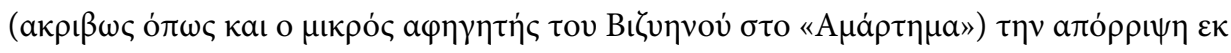

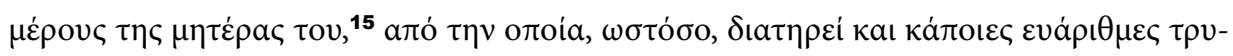

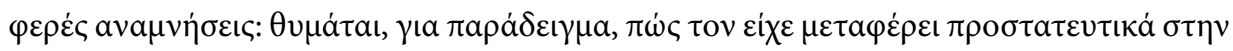

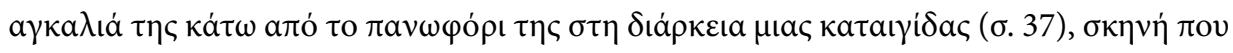

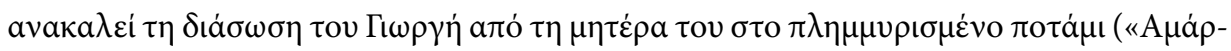

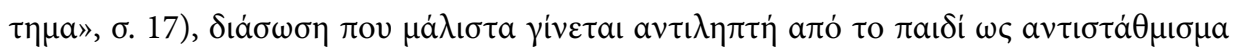

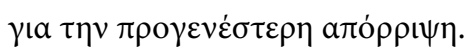

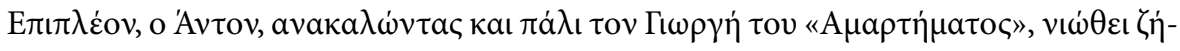

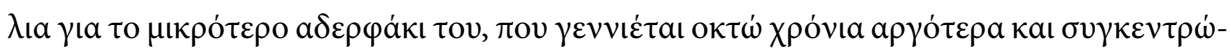

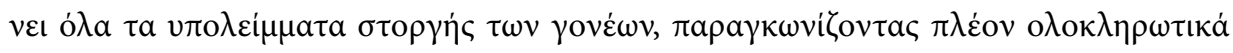

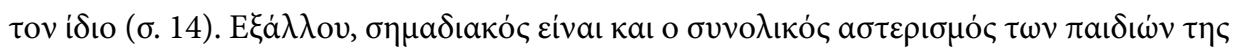

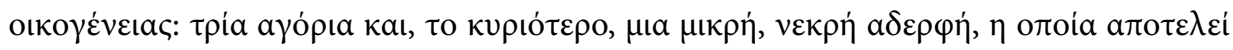

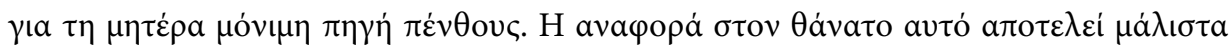

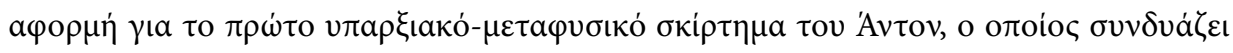

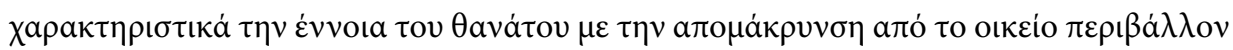

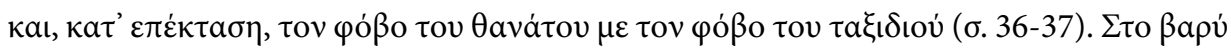

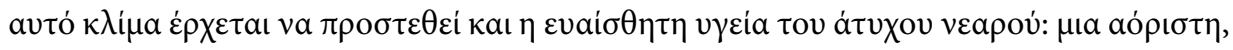




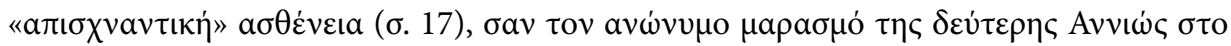

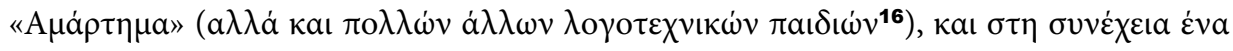

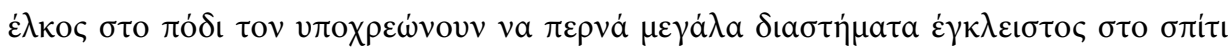

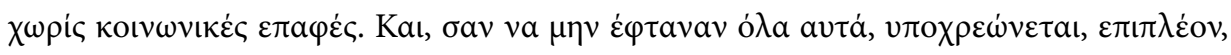
бvXvá a

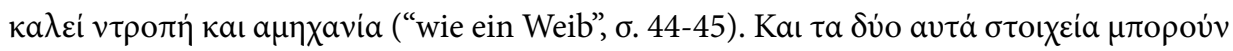

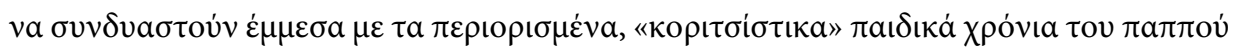

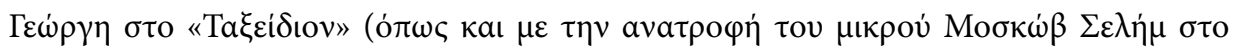

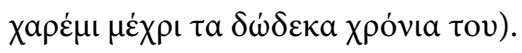

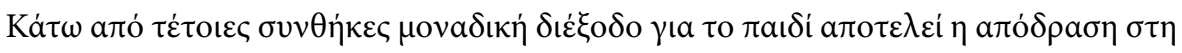

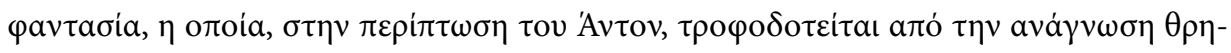

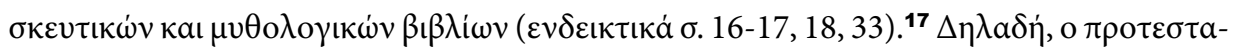

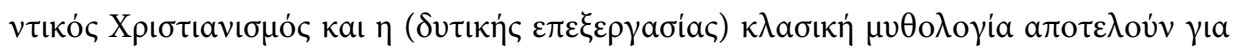

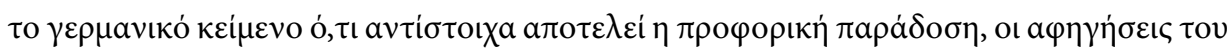

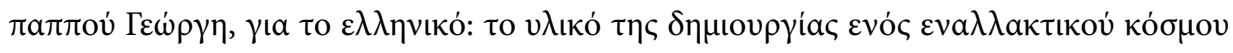

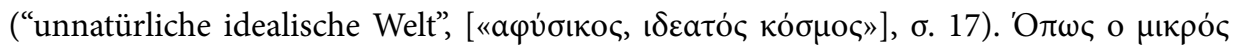

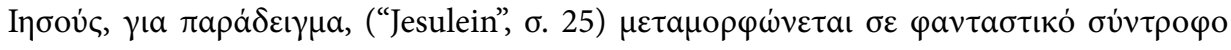

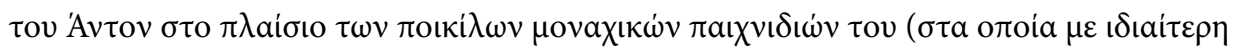

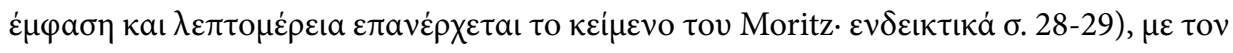

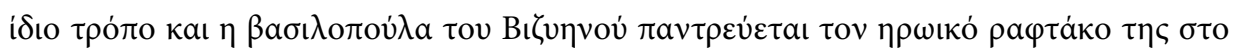

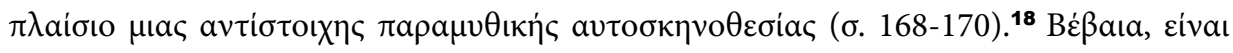

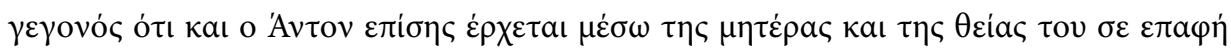

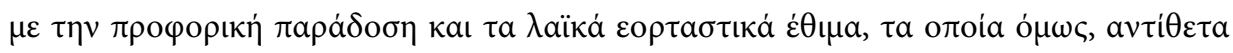

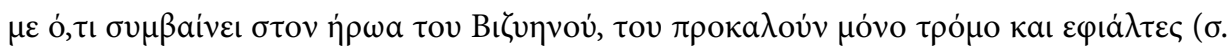

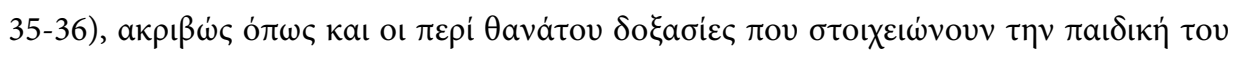

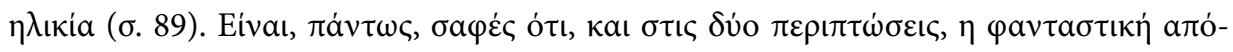

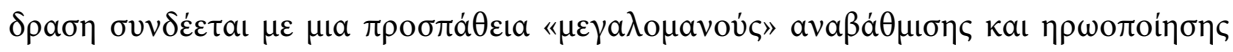

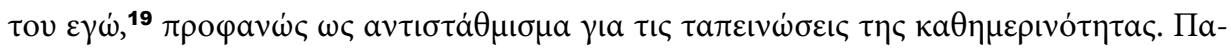

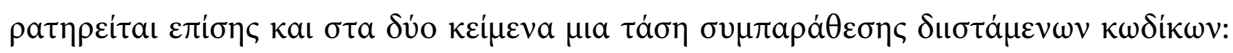

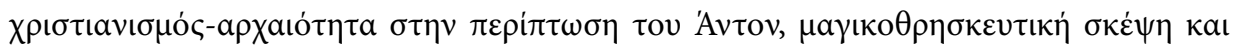

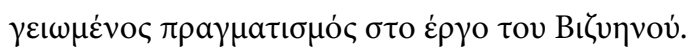

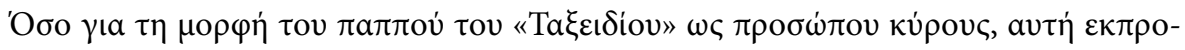

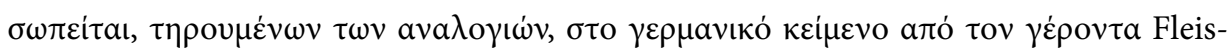

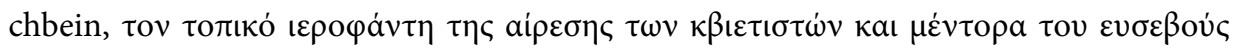

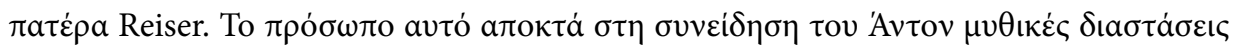

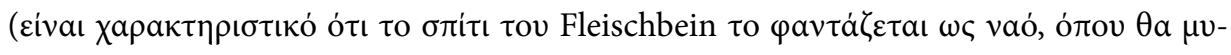

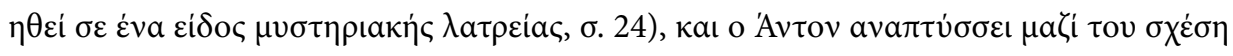

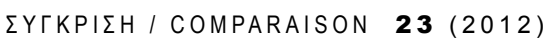


a

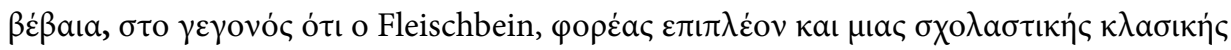

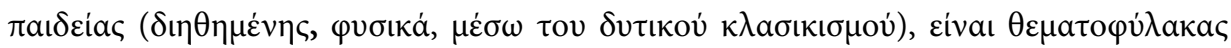

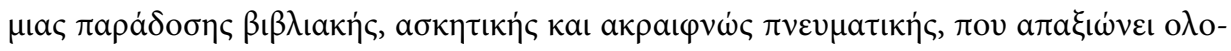

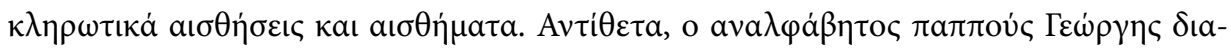

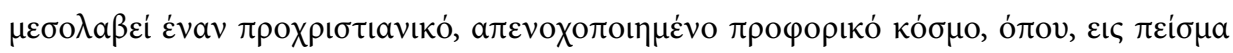

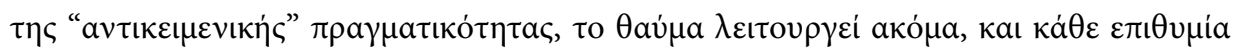

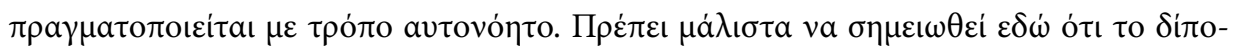

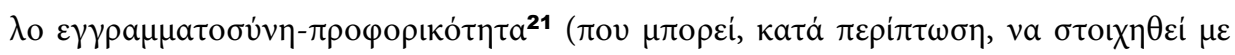

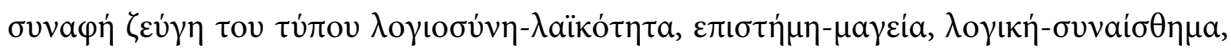

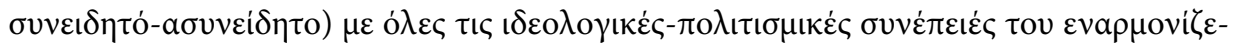
$\tau \alpha \iota$ a

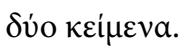

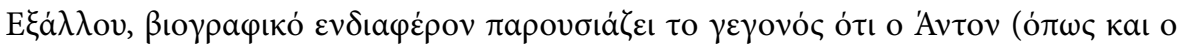

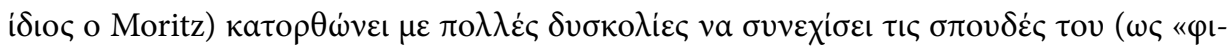

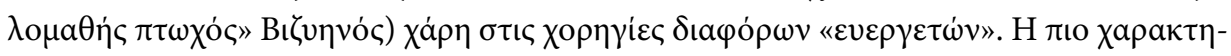

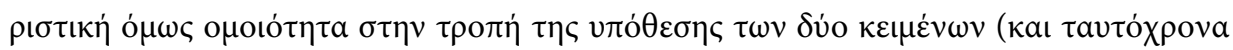

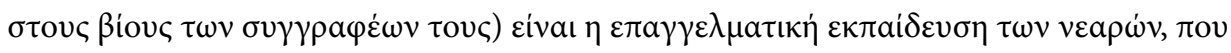

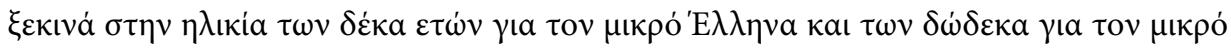

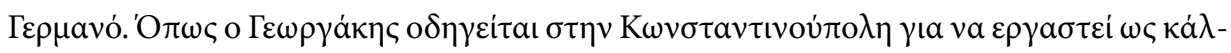

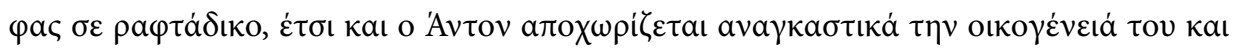

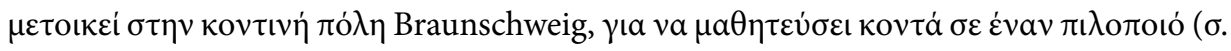

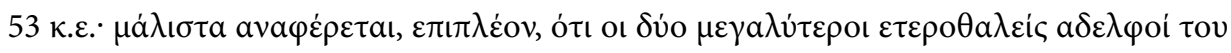

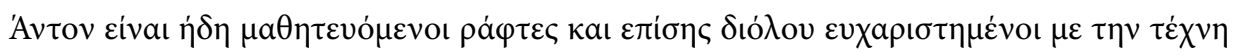

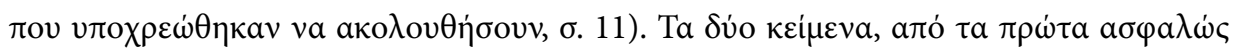

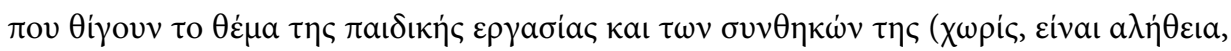

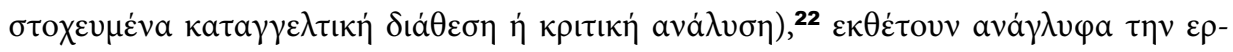

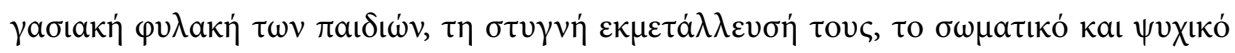

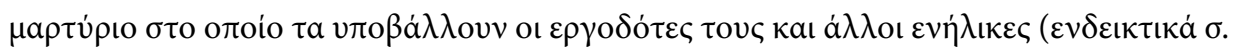

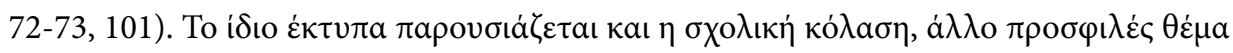

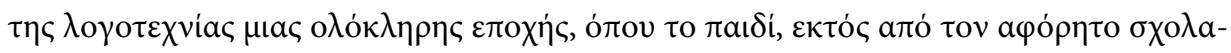

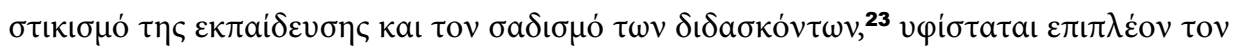

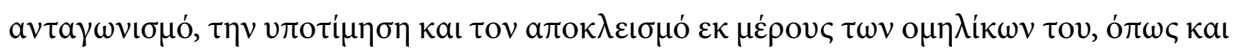

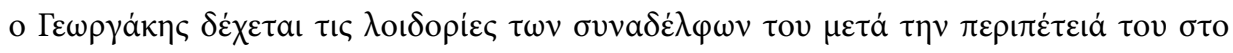

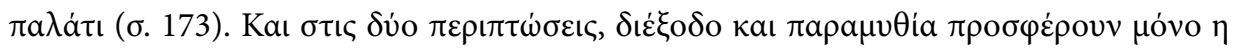

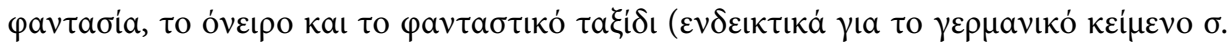

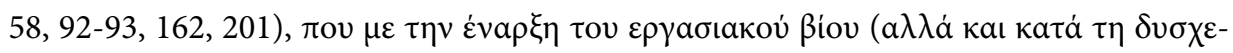




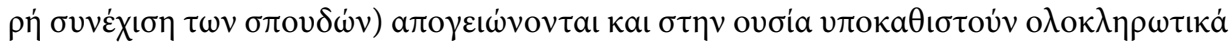

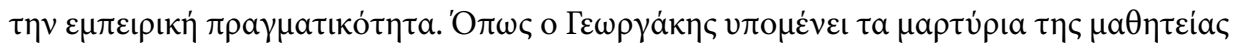

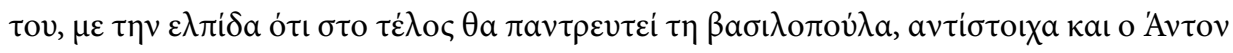

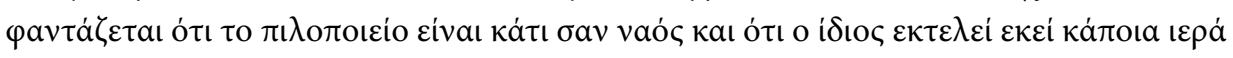

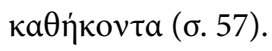

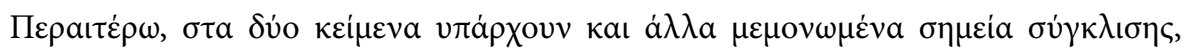

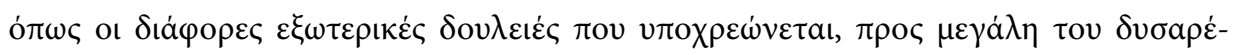

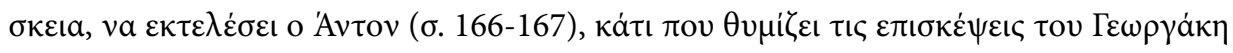

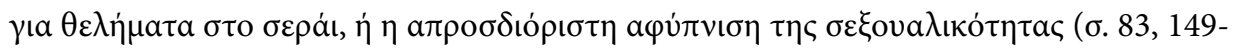

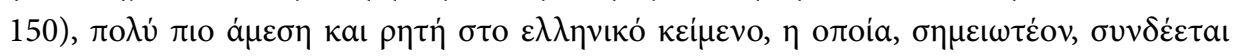

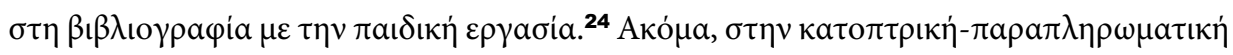

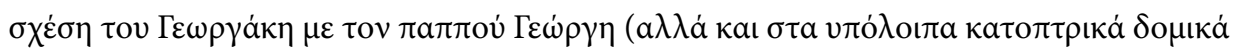

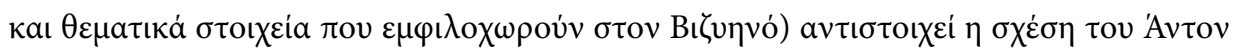

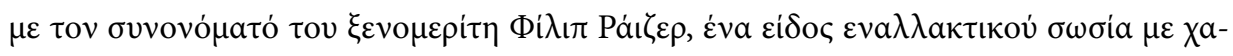

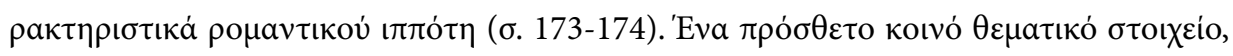

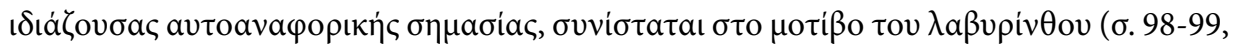

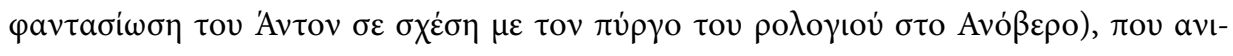

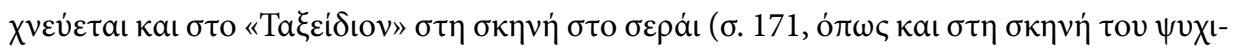

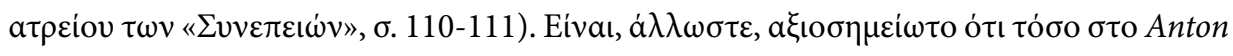

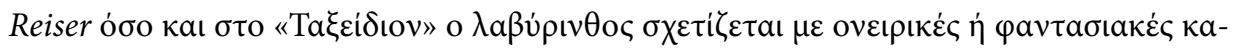

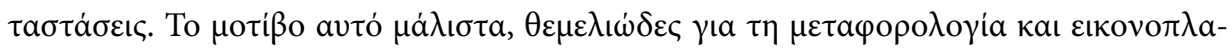

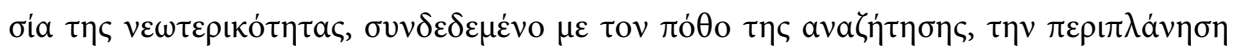

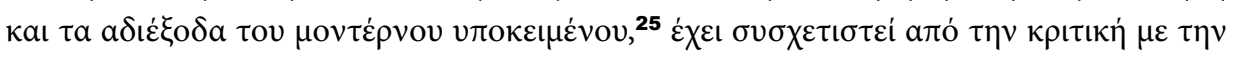

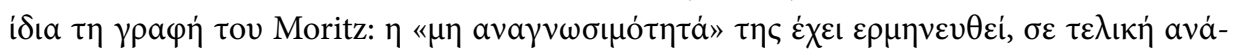

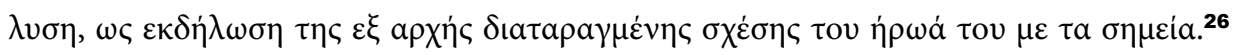

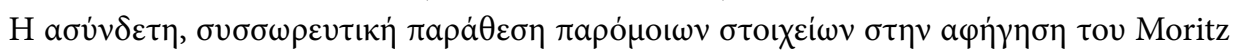

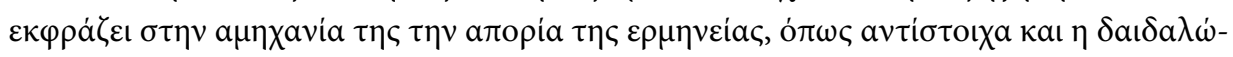

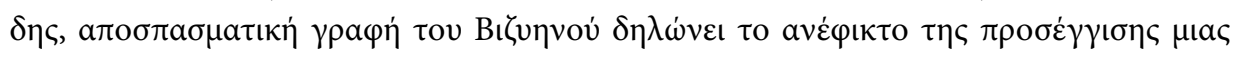

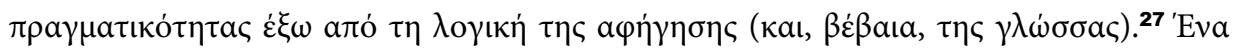

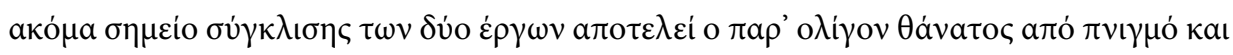

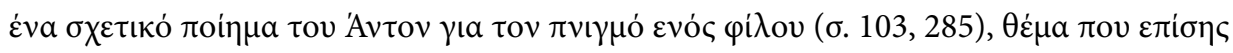

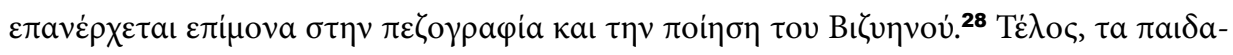

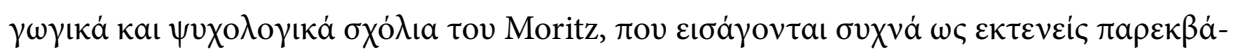

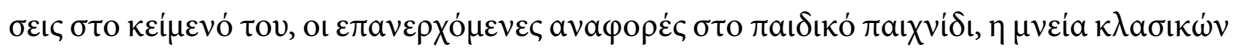

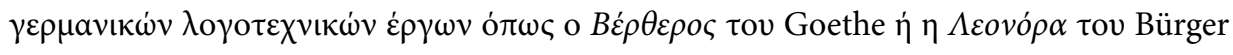

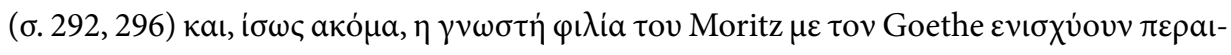

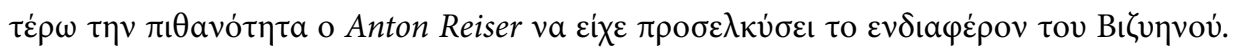

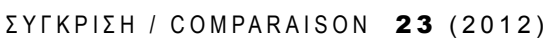




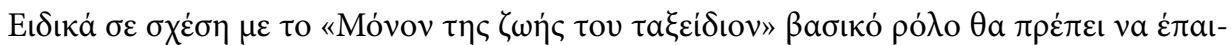

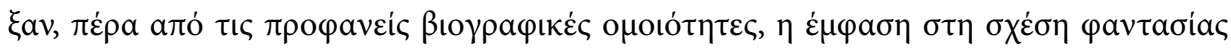

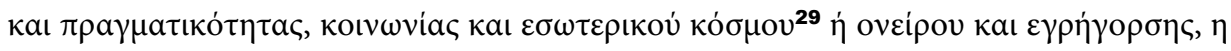

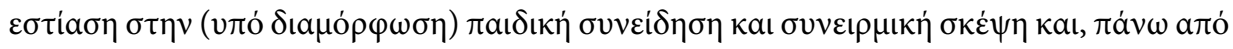

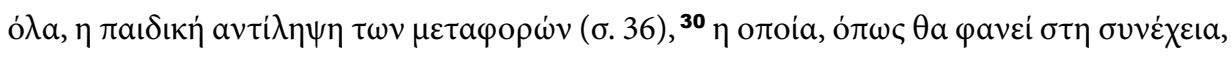

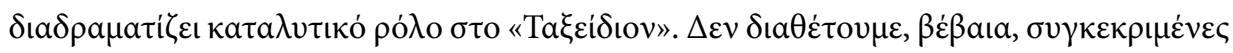

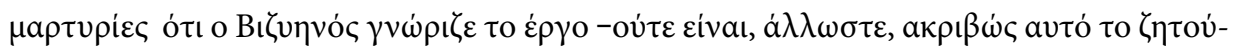

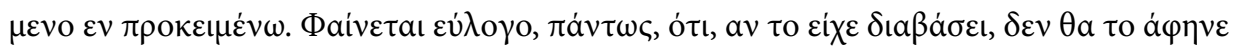

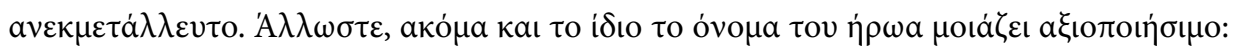

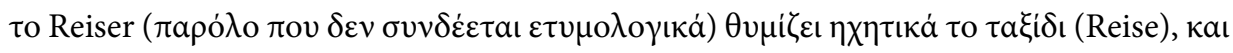

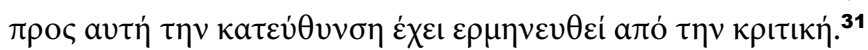

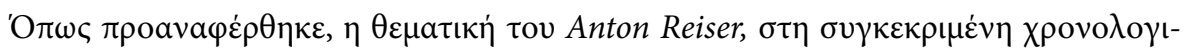

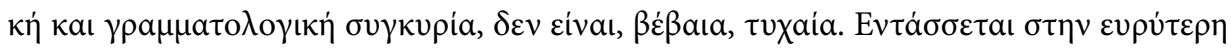

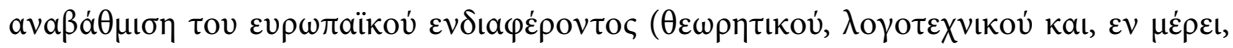

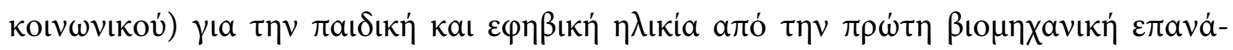

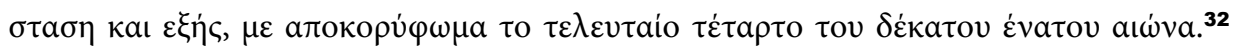

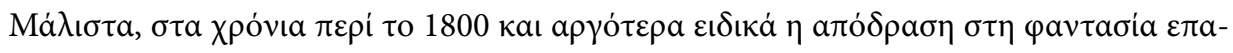

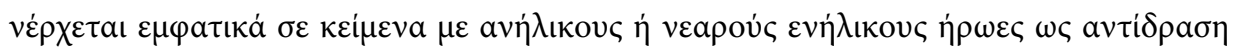

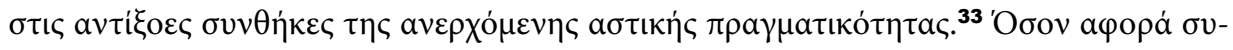

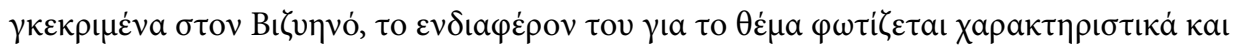

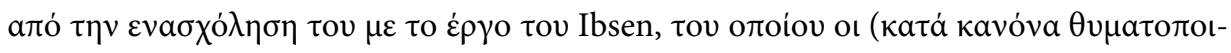

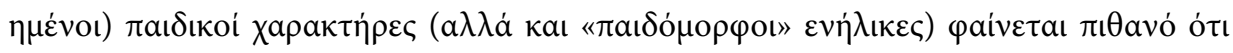

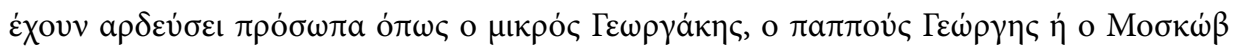

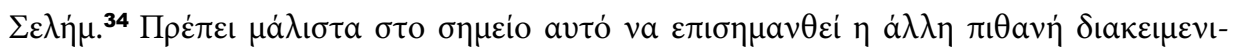

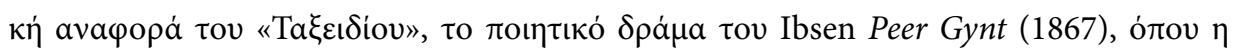

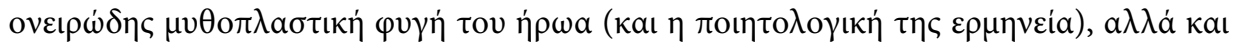

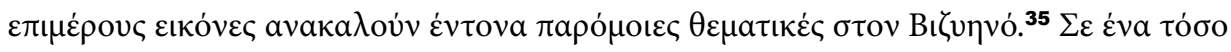

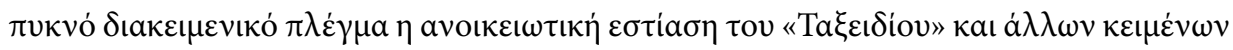

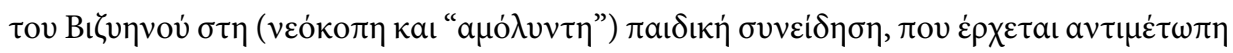

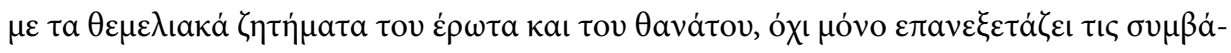

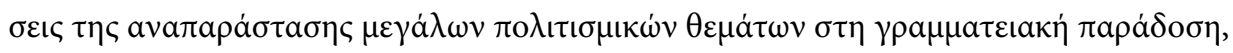

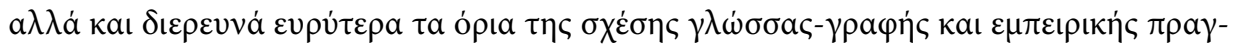

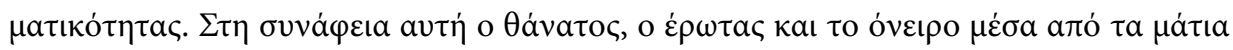

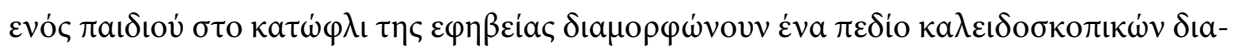

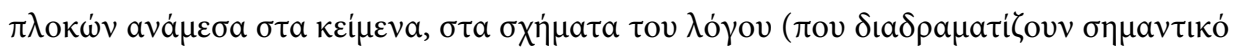

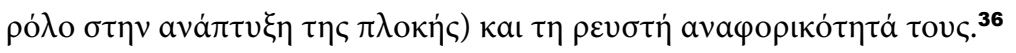




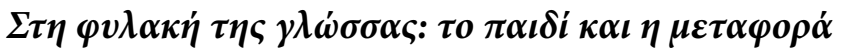

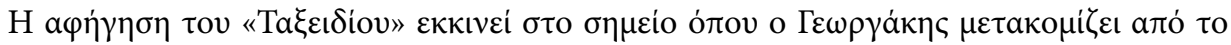
$\chi \omega \rho ı$

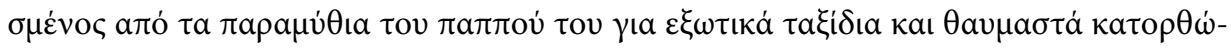

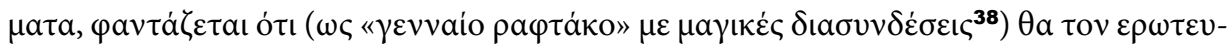

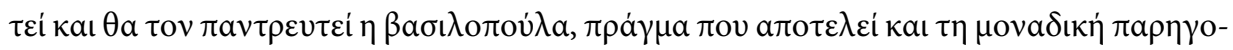

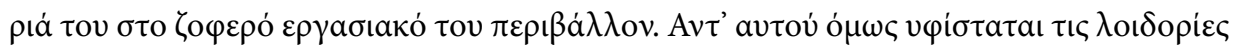

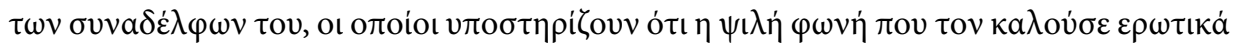

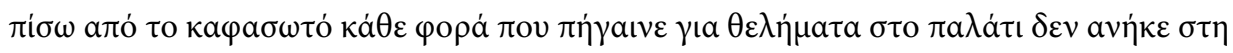

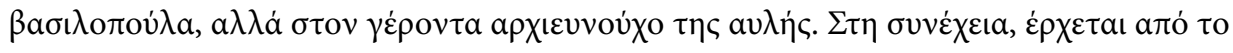

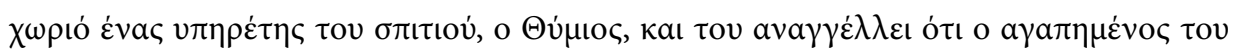

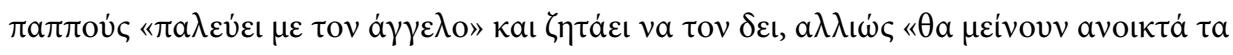

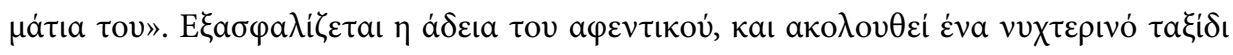

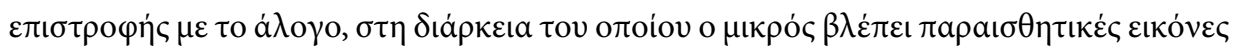

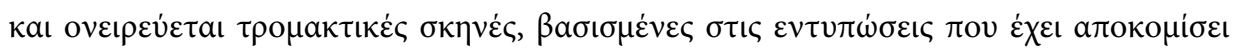

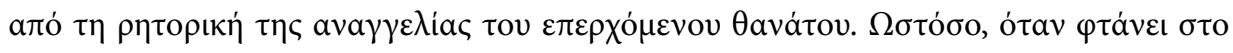

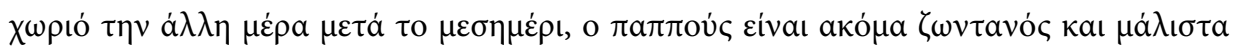

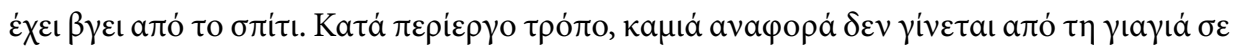

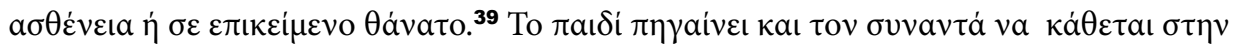

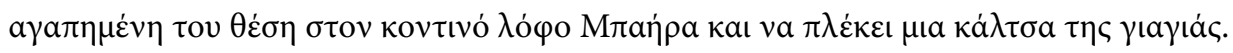

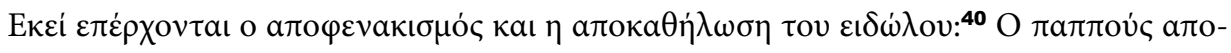

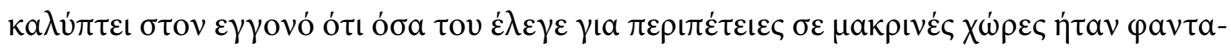

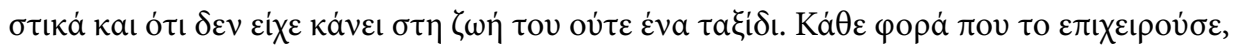

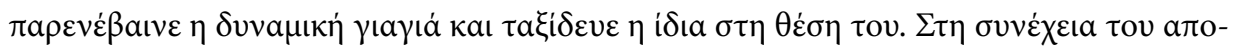

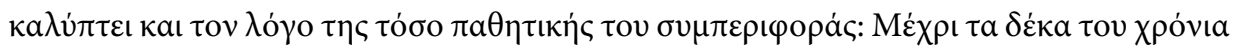

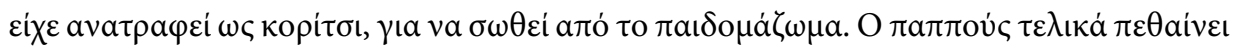

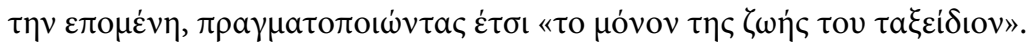

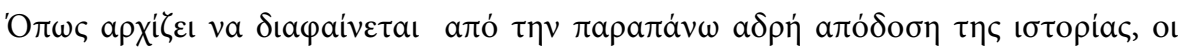

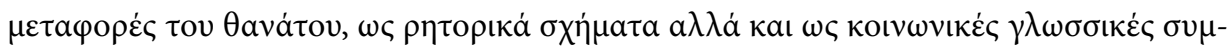

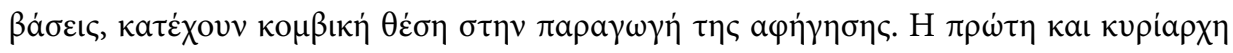

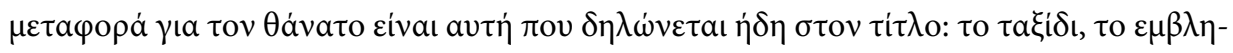

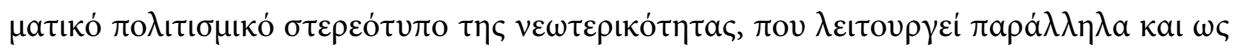

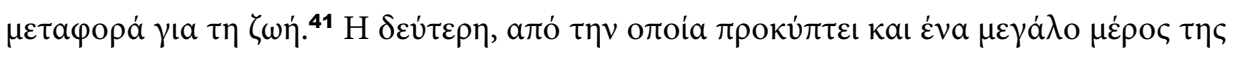

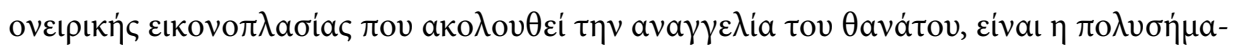

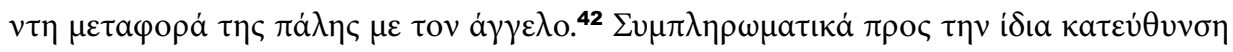

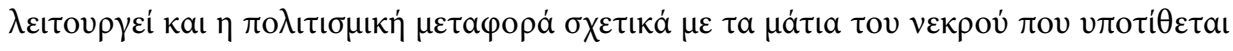

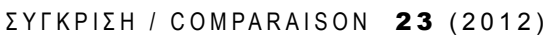




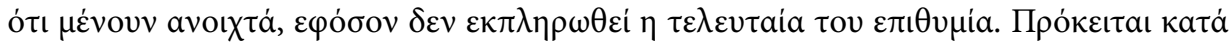

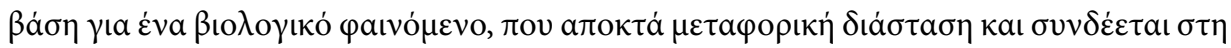

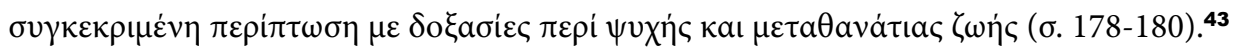

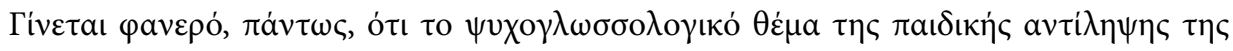

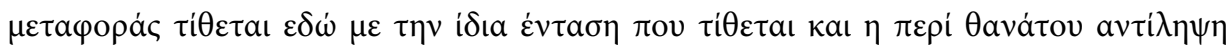

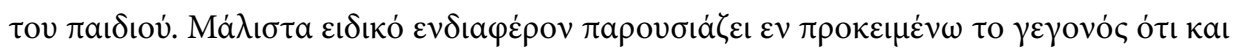

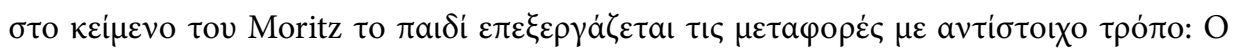

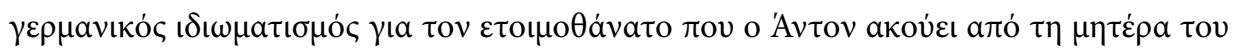

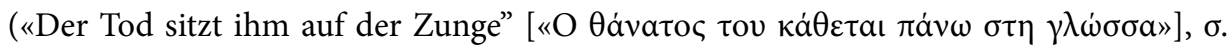

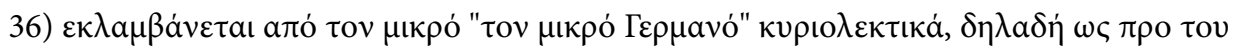

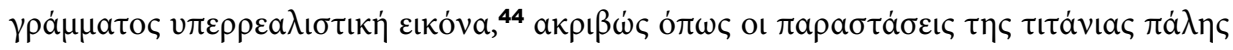

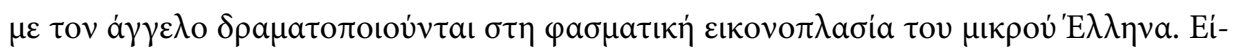

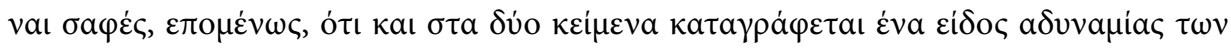

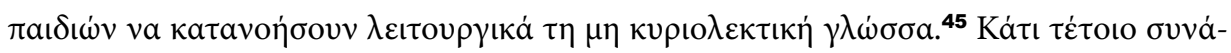

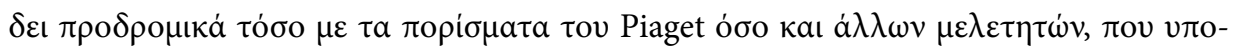

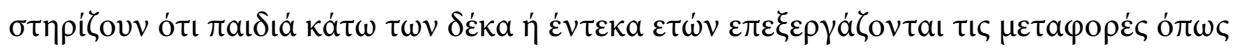

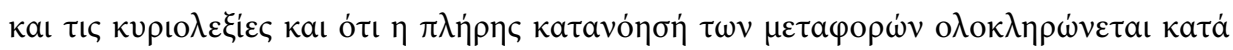

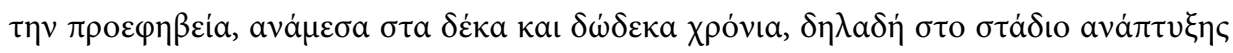

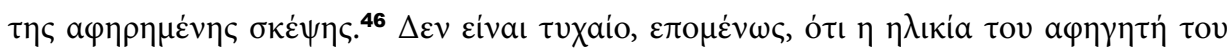

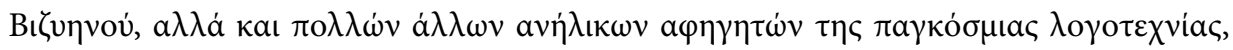

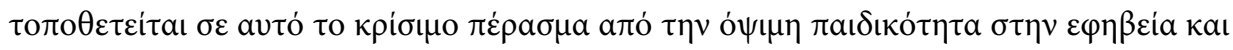

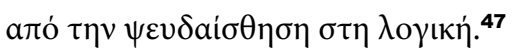

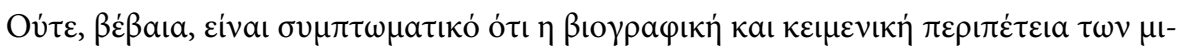

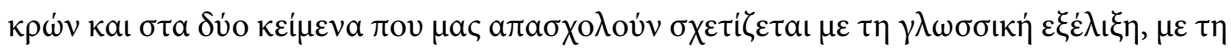

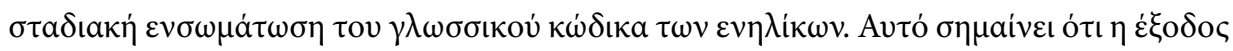

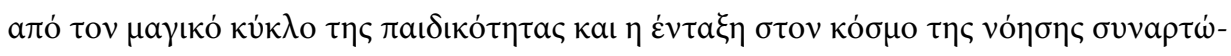

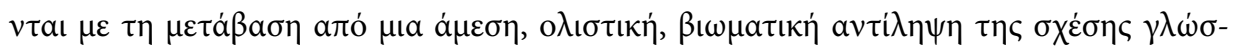

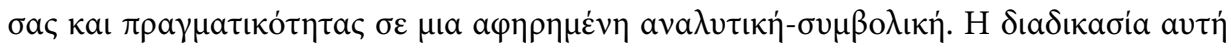

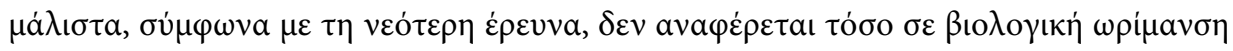

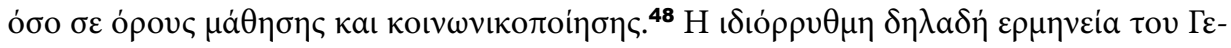

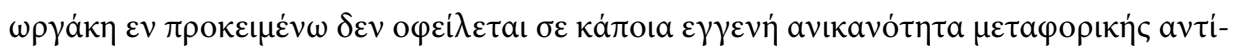

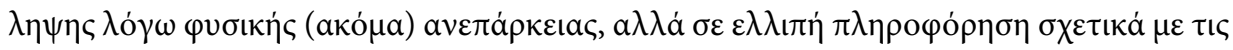

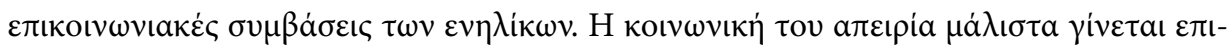

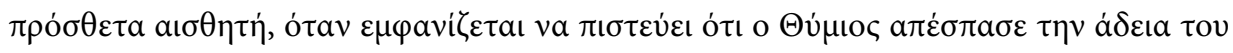

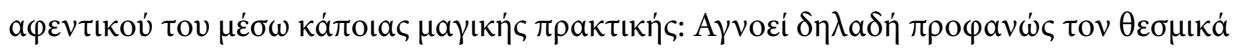

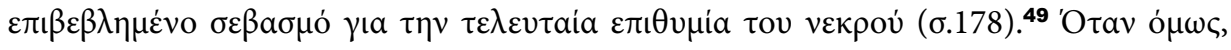

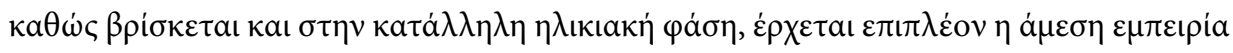




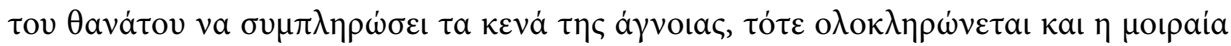

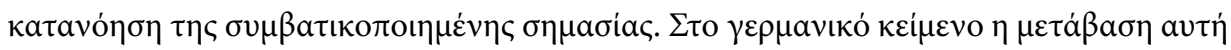

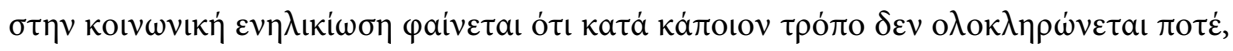

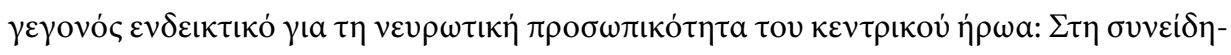

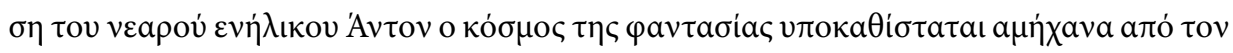

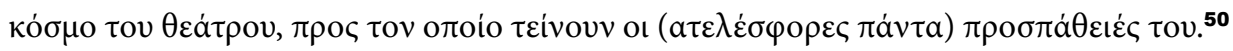

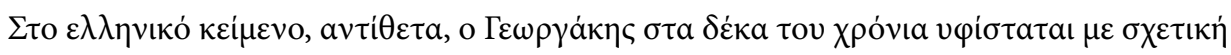

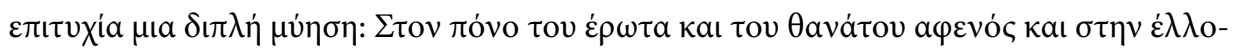

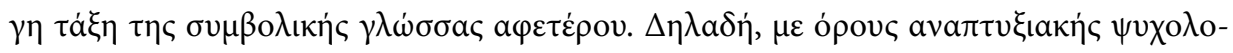

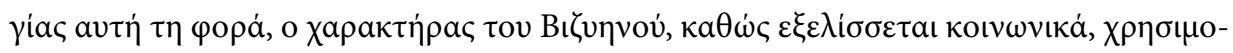

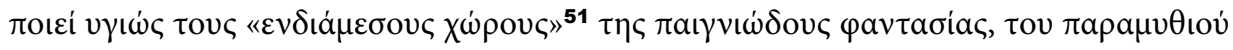

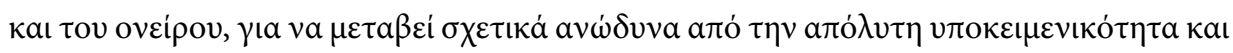

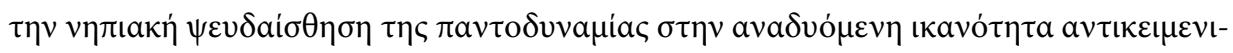

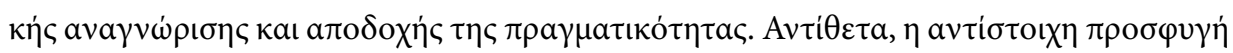

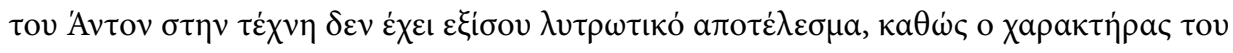

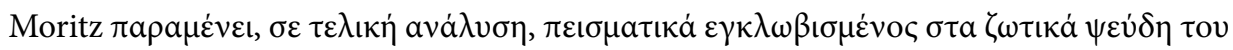

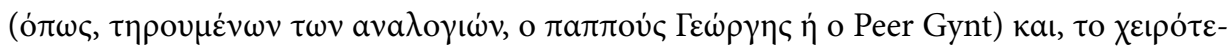

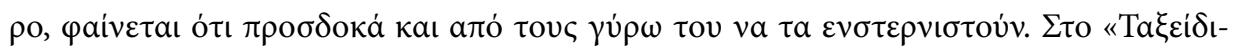

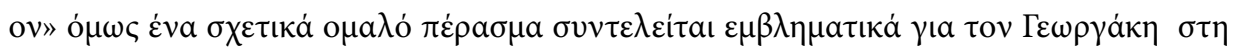

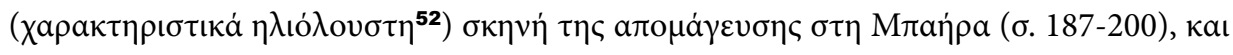

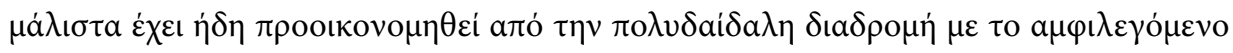

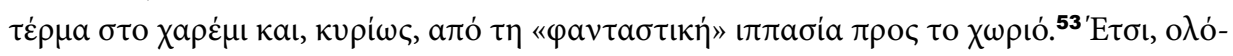

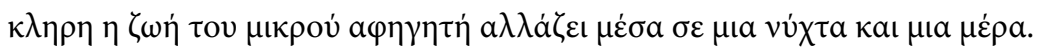

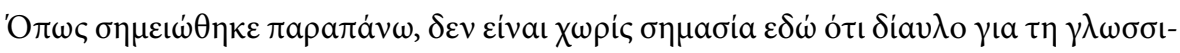

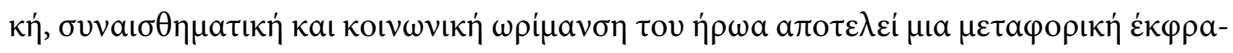

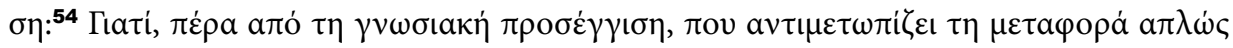

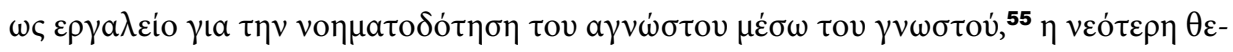

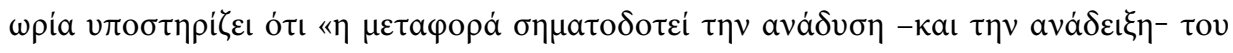

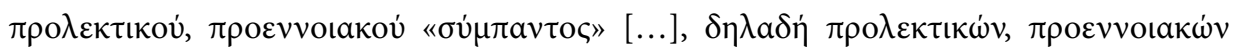

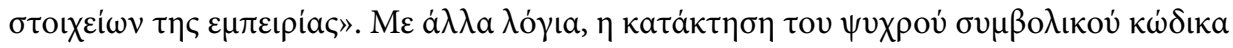

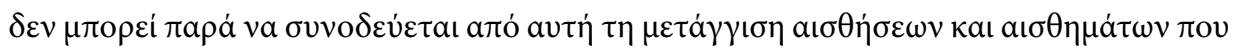

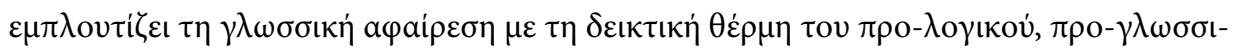

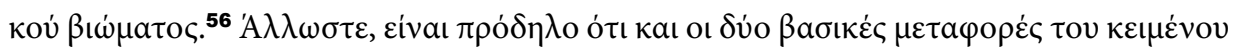

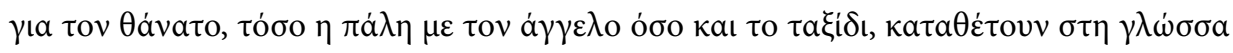

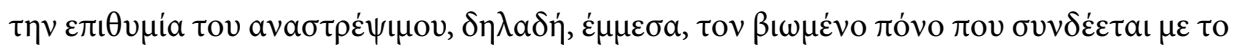

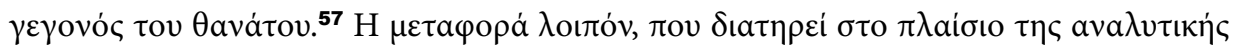

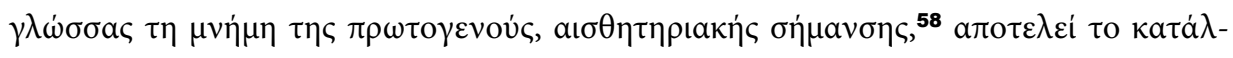

EYTKPIEH / COMPARAISON 23 (2012) 


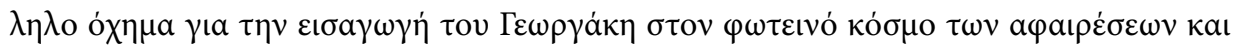

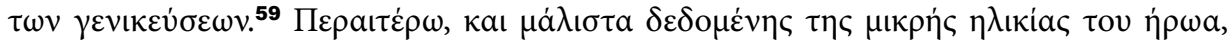

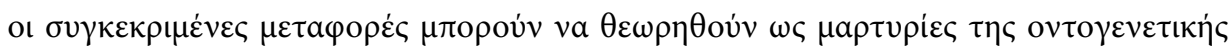

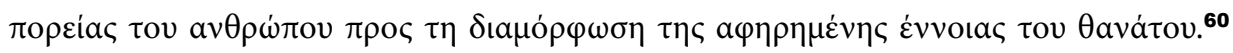

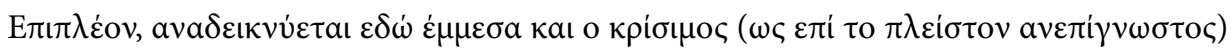

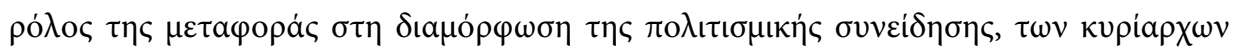

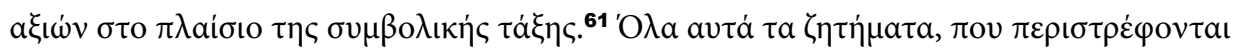

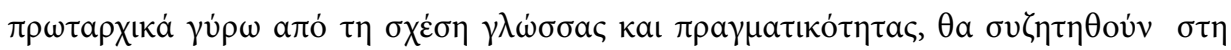

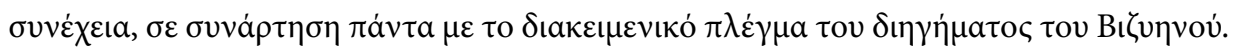

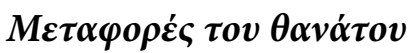

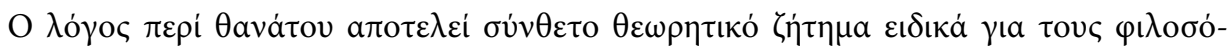

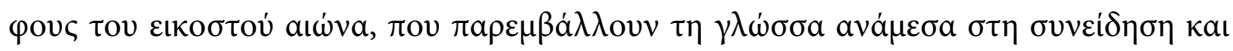

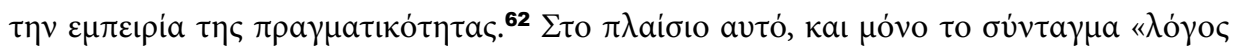

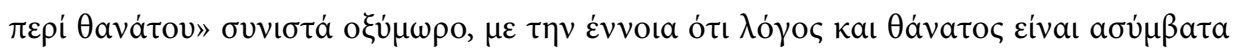

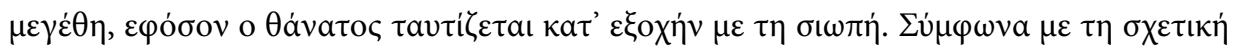

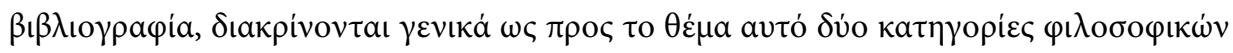

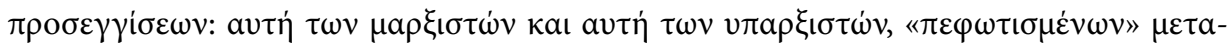

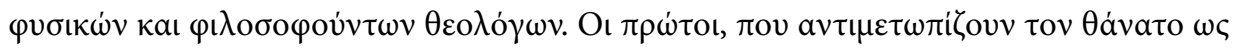

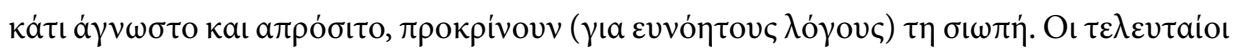

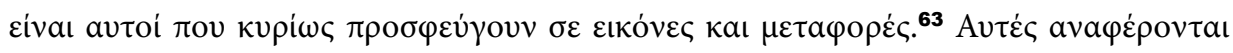

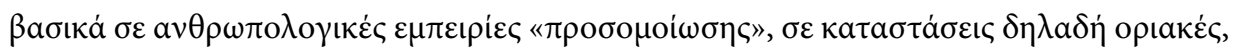

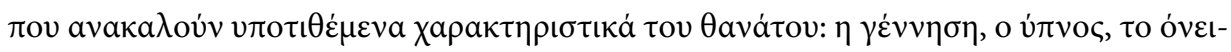

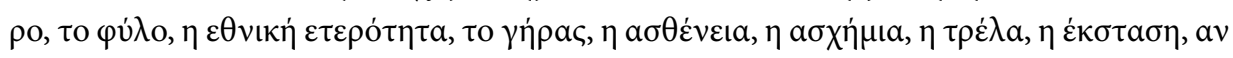

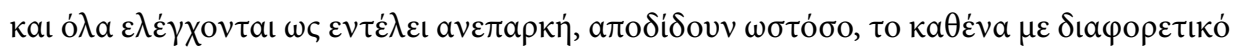

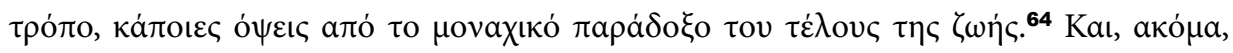

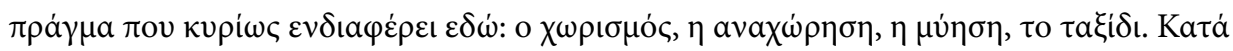

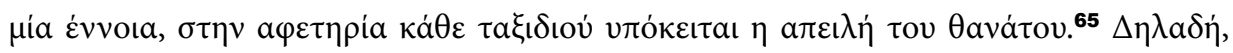

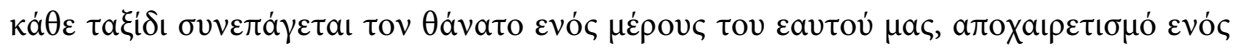

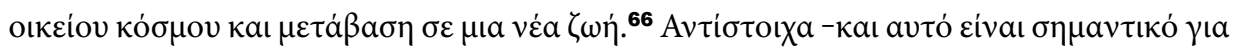

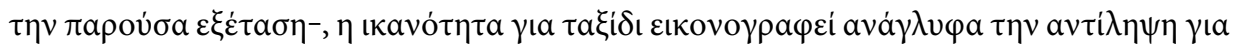

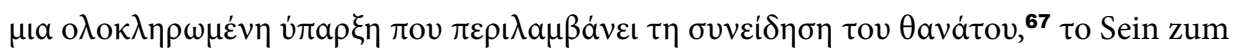
Tode tov Heidegger. ${ }^{68}$

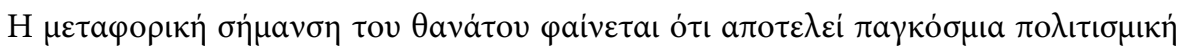

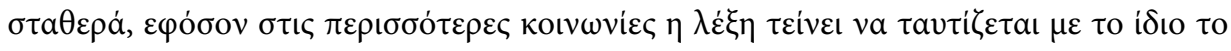

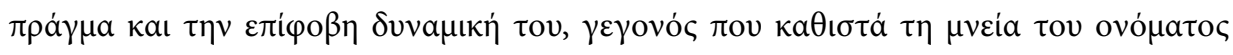




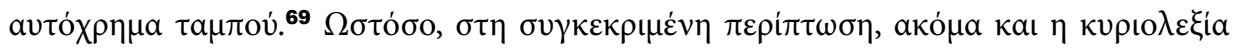
a

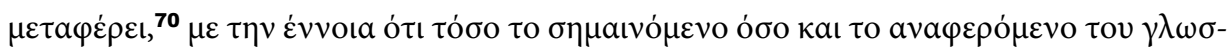

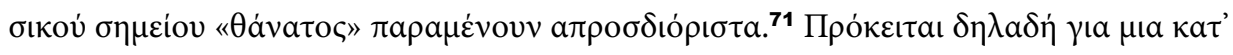

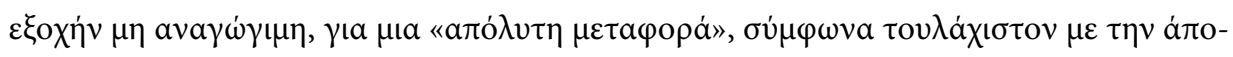

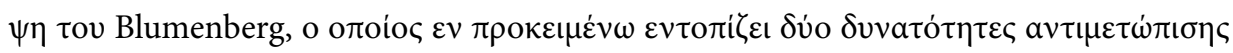

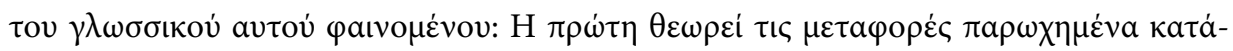

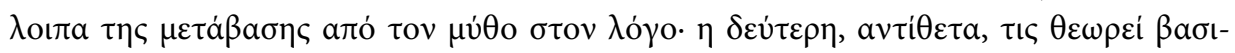

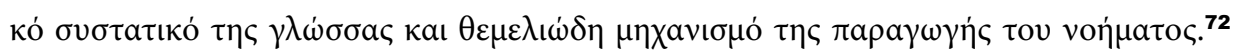

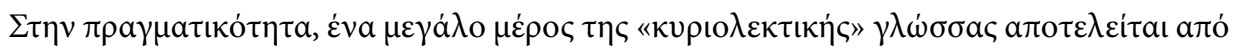

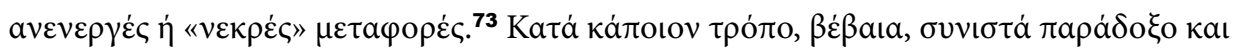

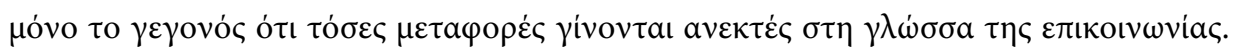

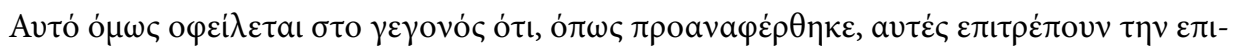

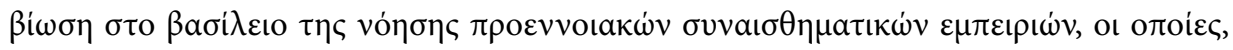

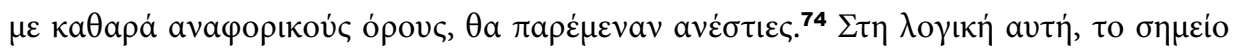

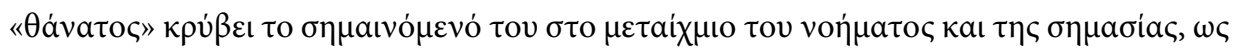

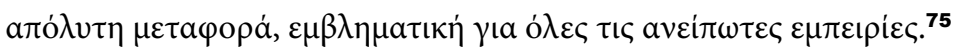

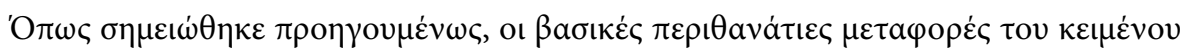

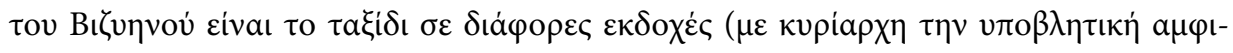

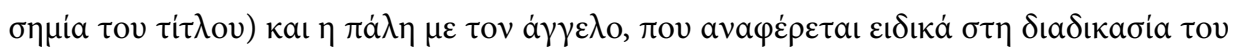

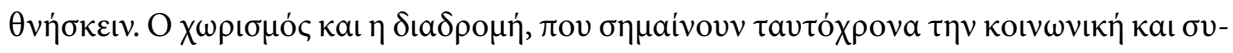

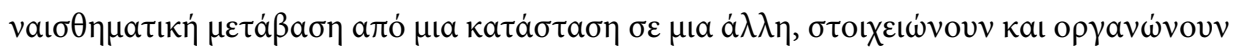

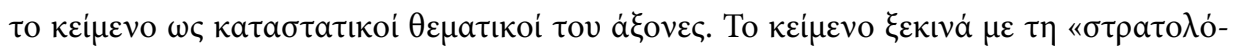

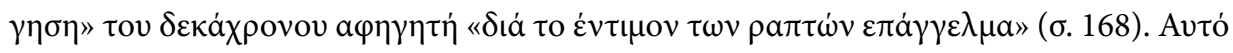

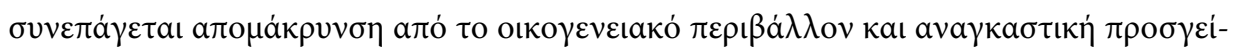

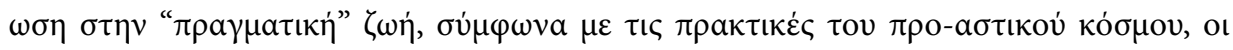

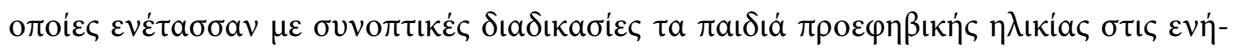

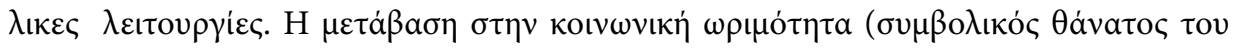

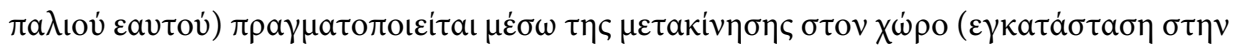

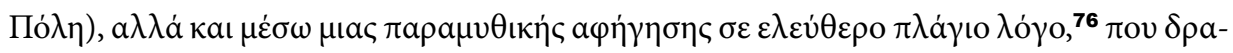

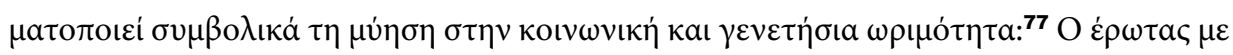

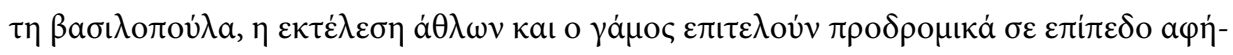

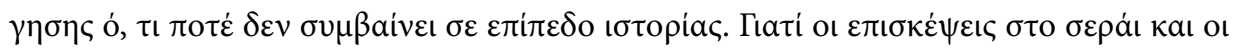

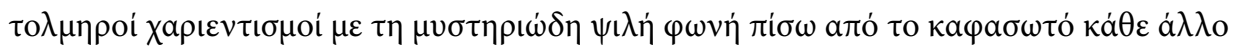

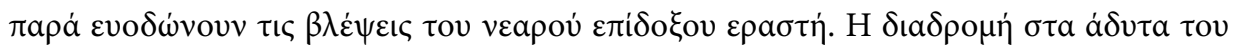

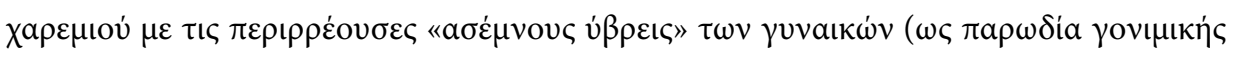

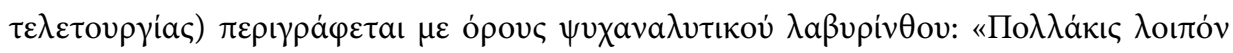

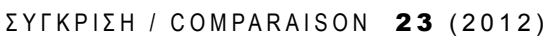




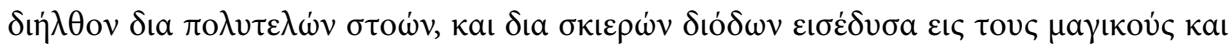

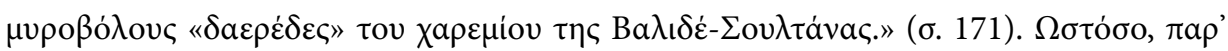

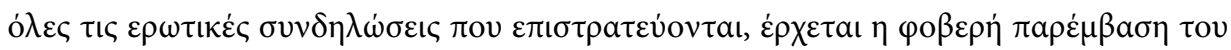

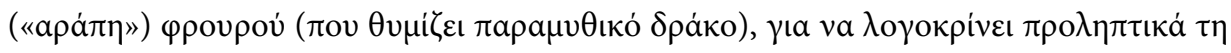

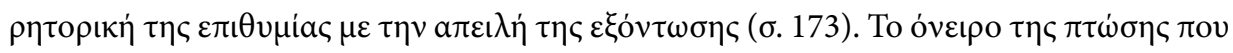

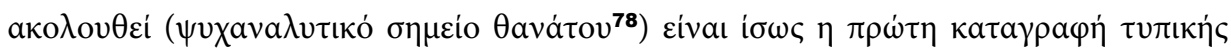

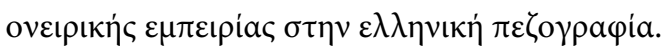

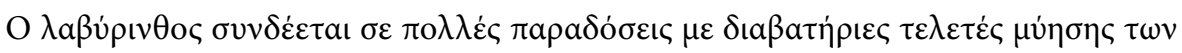

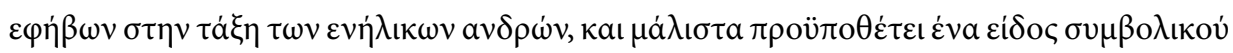

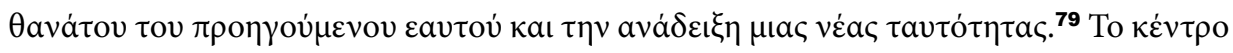

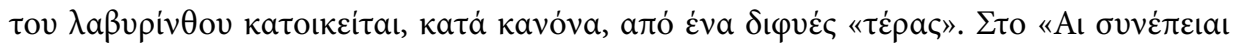

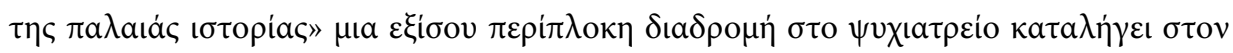

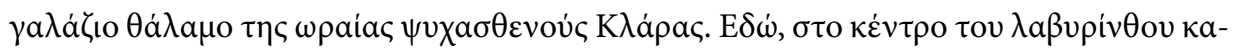

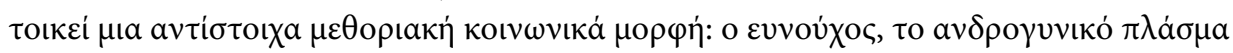

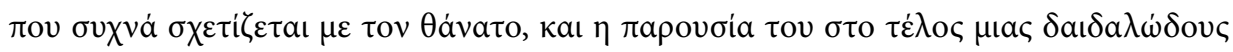

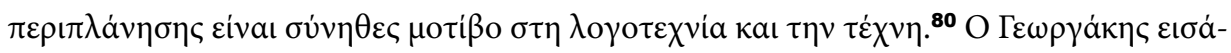

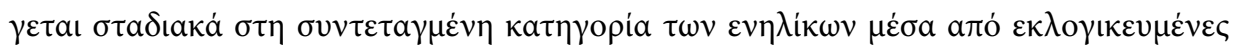

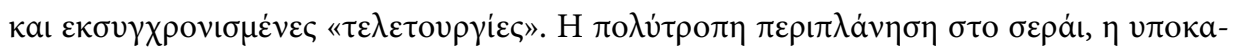

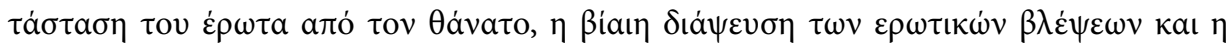

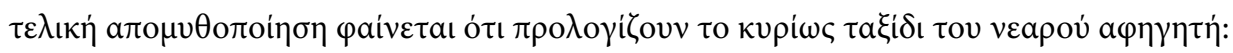

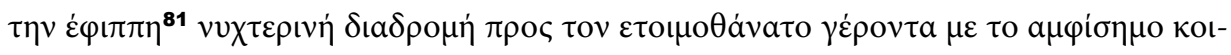

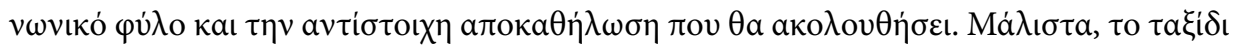

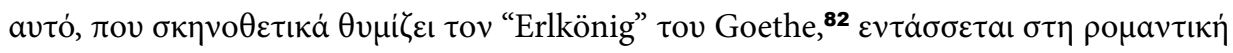

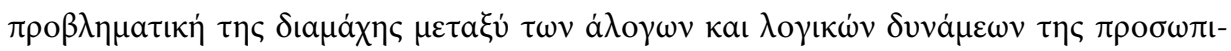

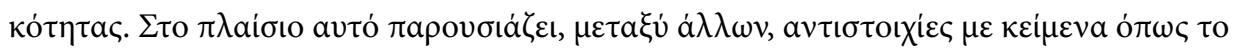

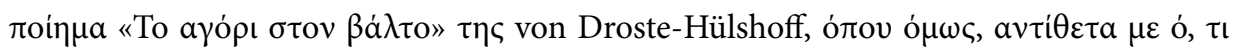

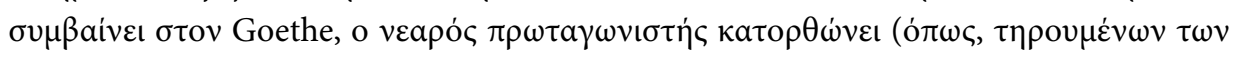

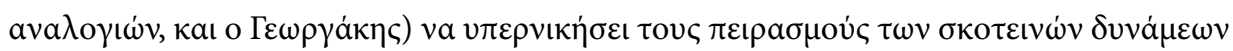

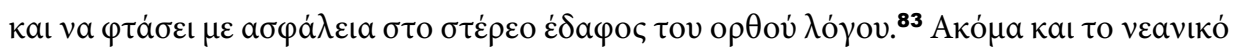

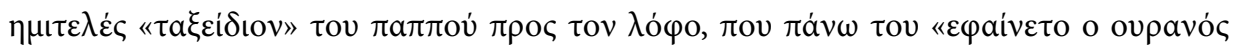

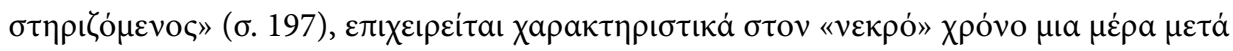

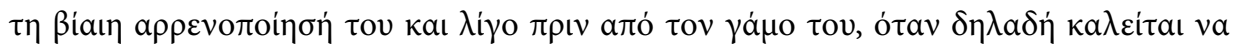

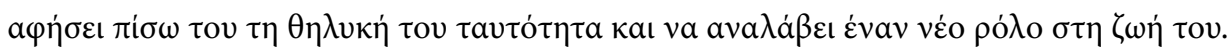

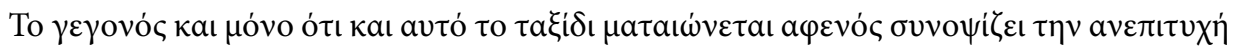
a

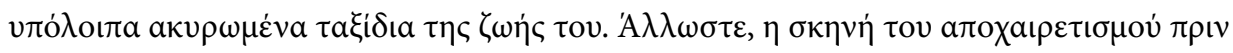

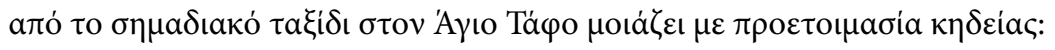




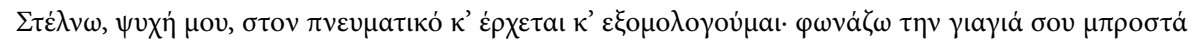

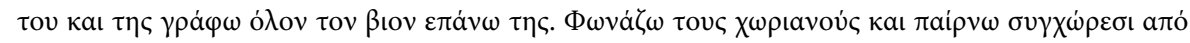

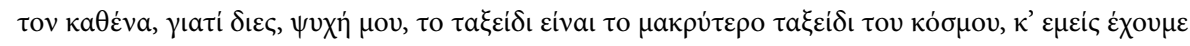
$\zeta \omega \eta \dot{~ \kappa a ı ~ \theta a ́ v a \tau o ! ~}$

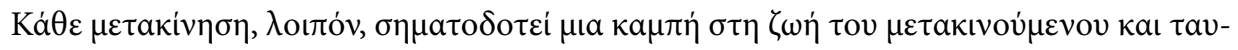

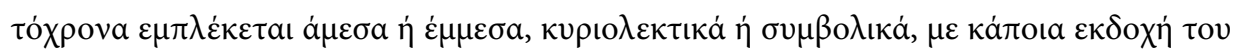
Өavátov.

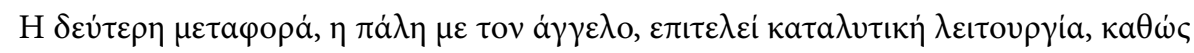
a

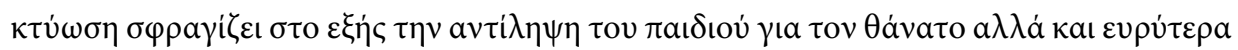

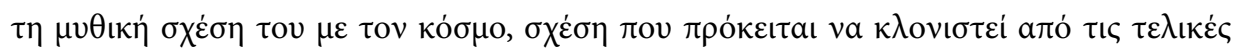

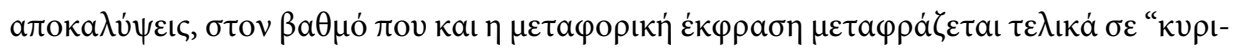

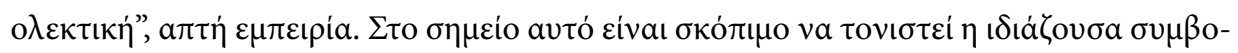

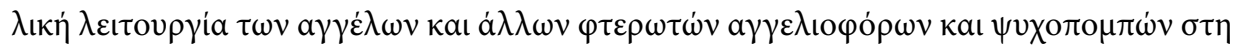

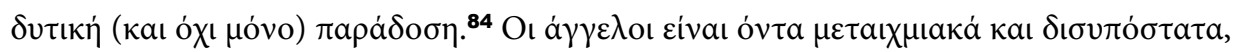

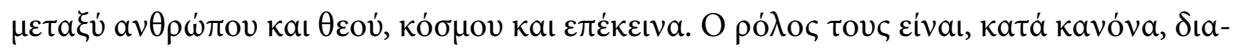

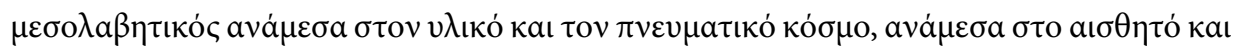

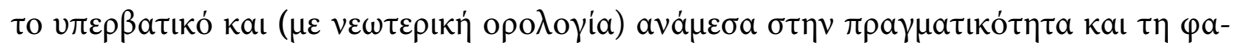

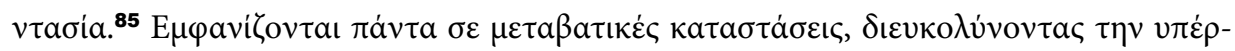

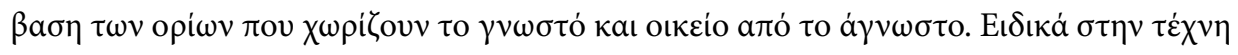

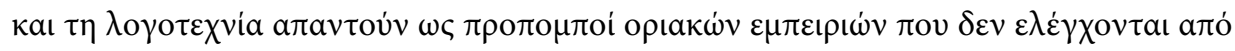

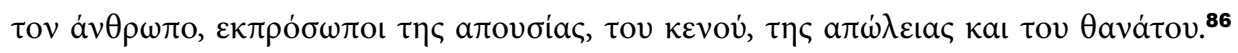

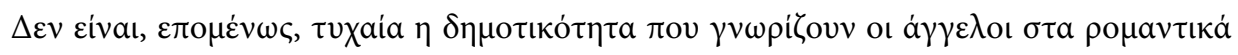

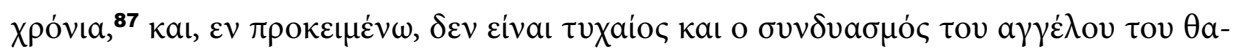

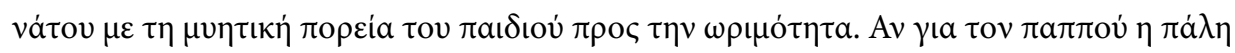

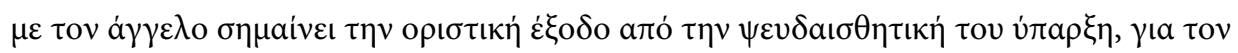

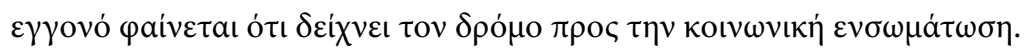

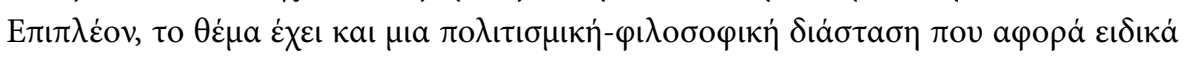

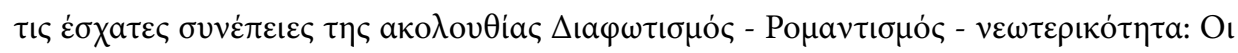

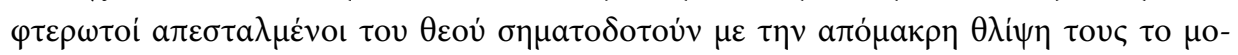

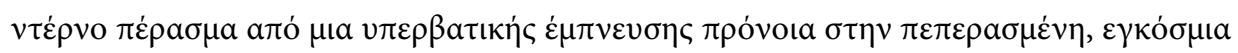

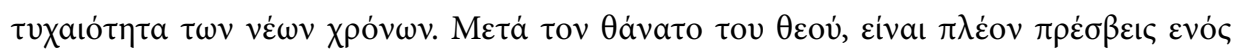

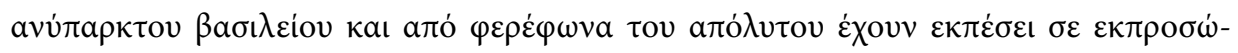

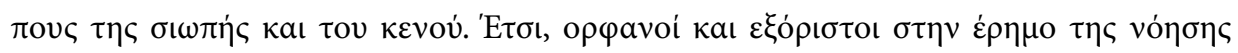

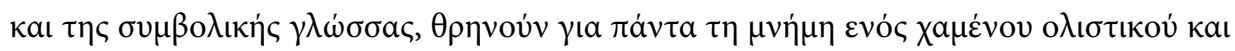

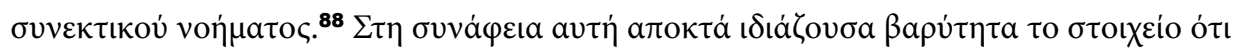

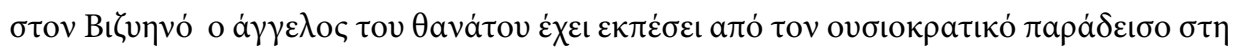

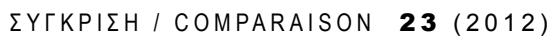




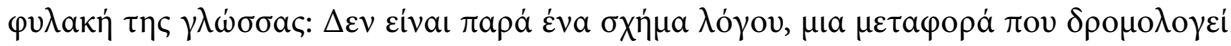

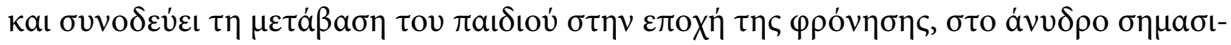

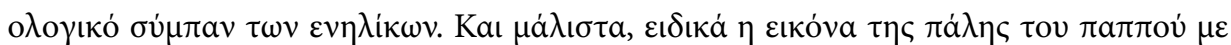

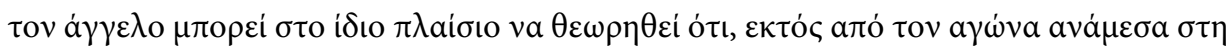

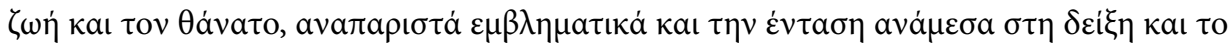

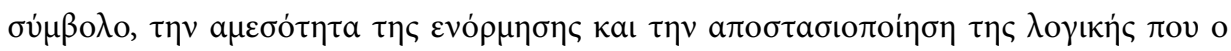

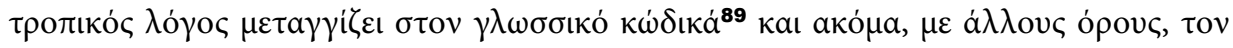

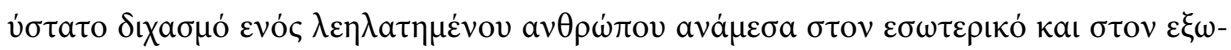

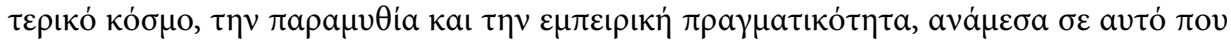

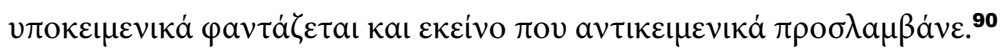

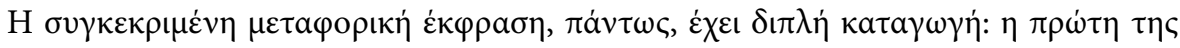

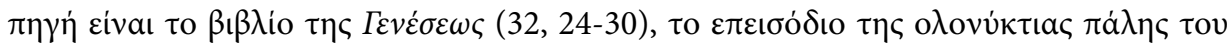

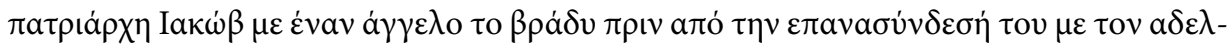

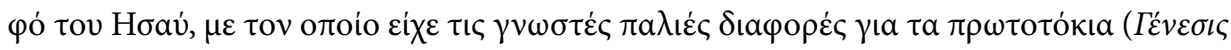

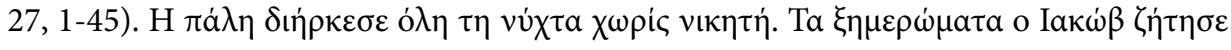

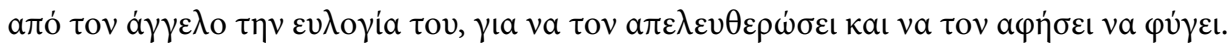

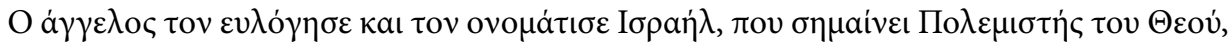

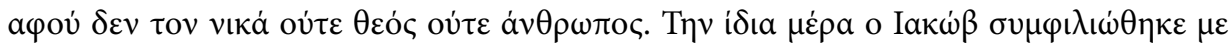

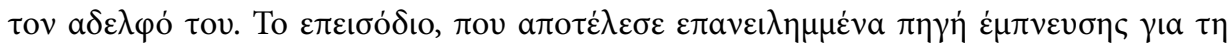

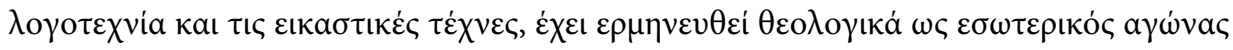

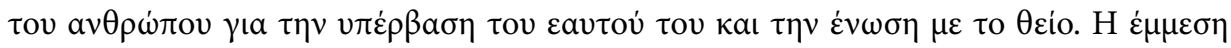

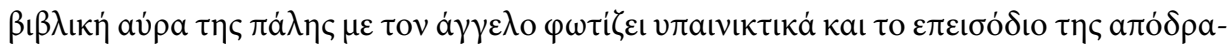

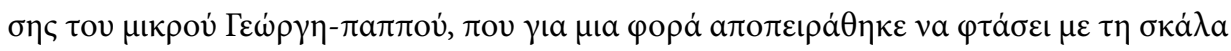

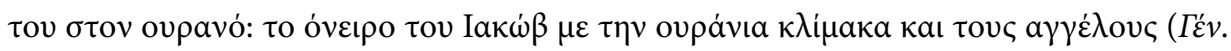

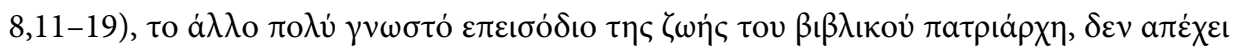

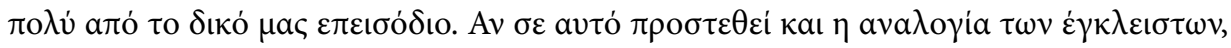

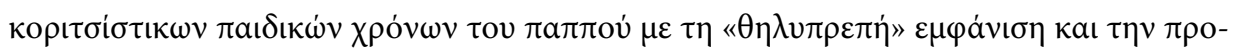

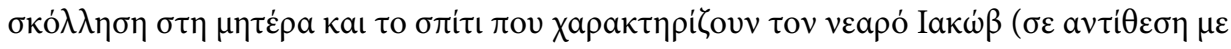

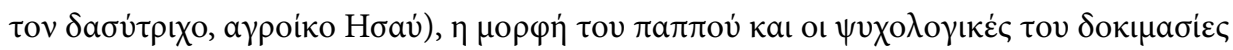
a

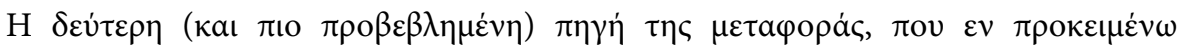

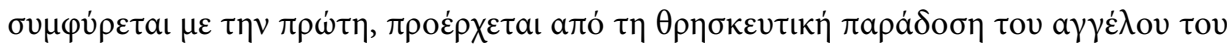

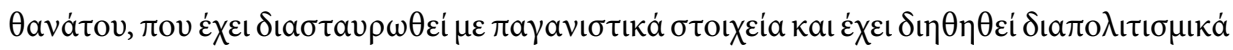

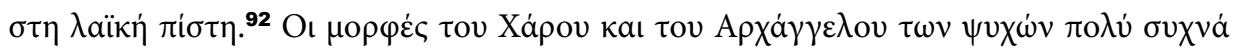

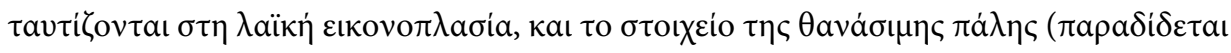

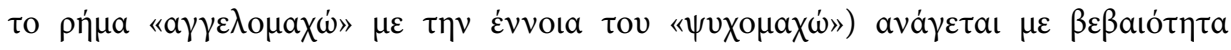

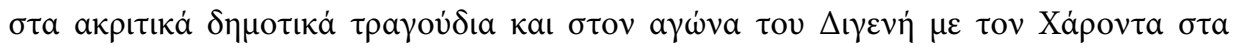




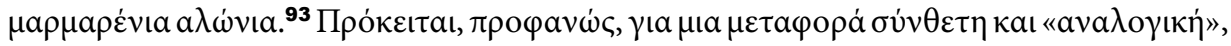

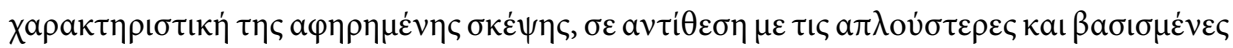

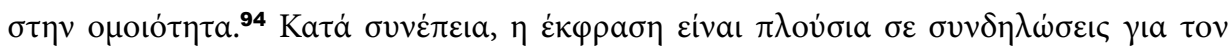

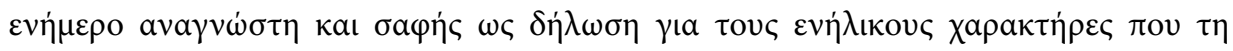

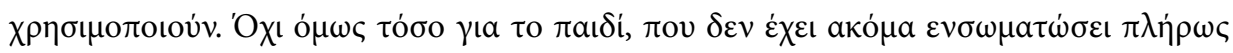

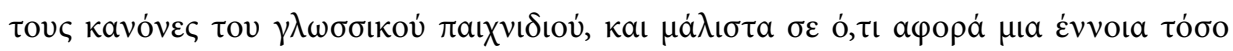

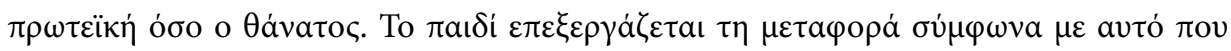

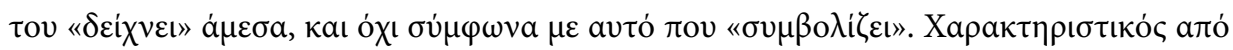

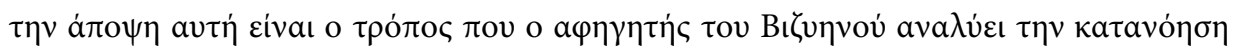

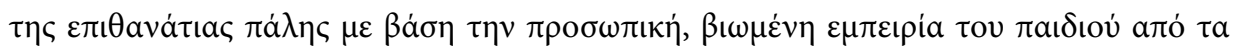

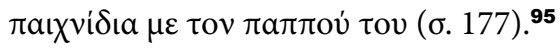

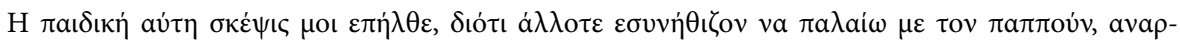

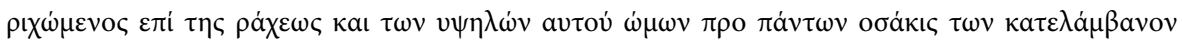

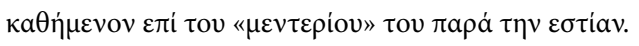

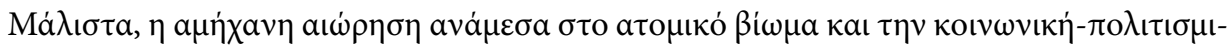

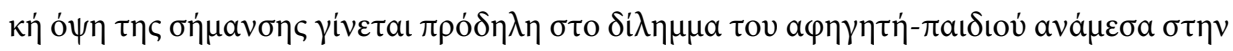

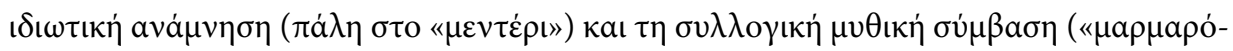

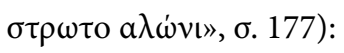

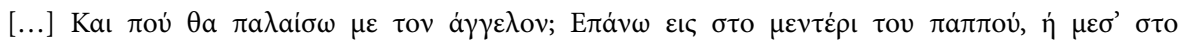

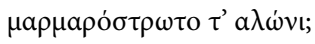

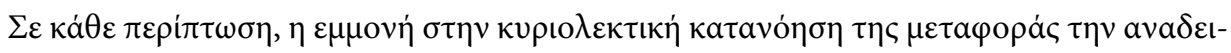

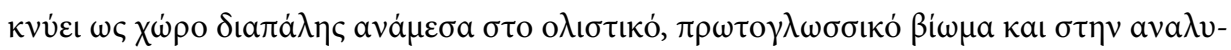

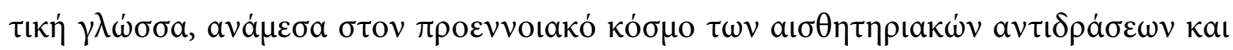

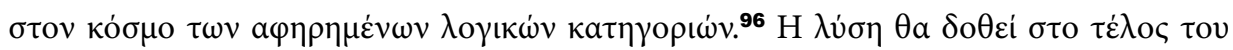

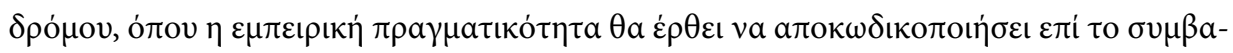

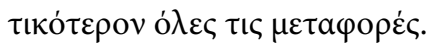

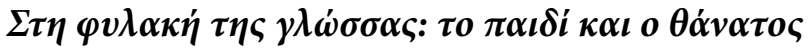

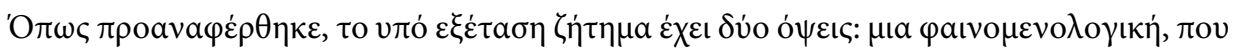

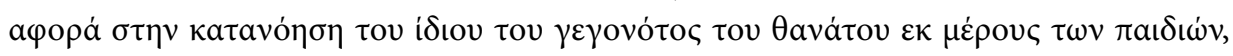

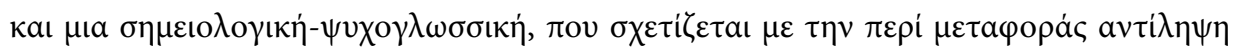

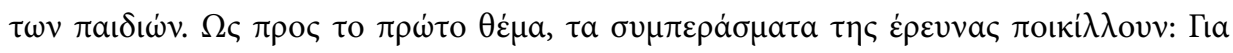

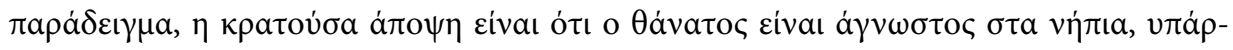

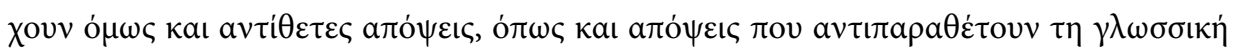

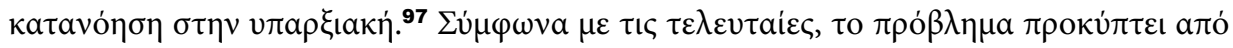

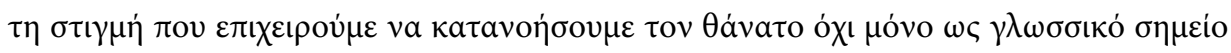

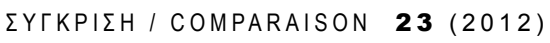




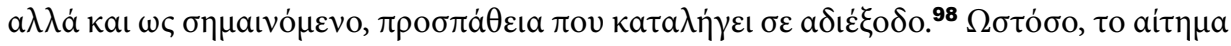

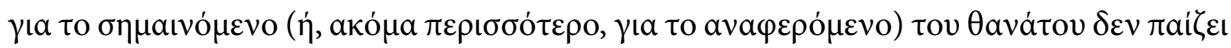

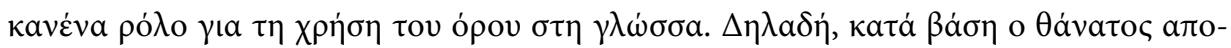

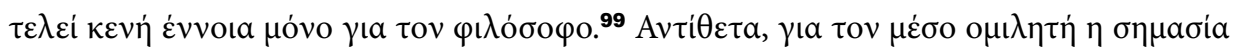

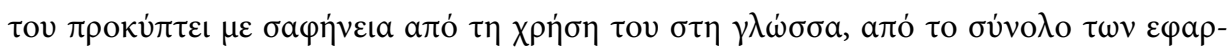

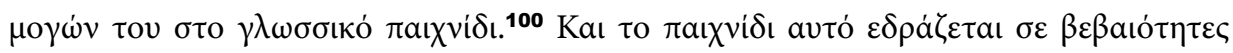

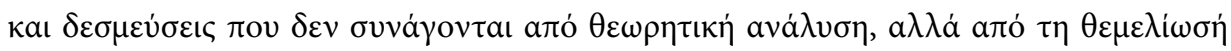

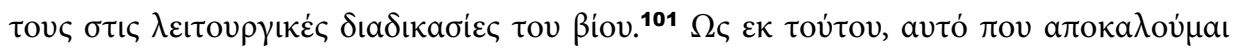

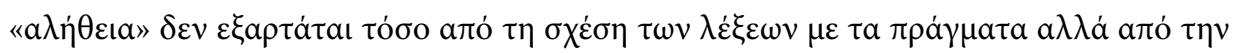

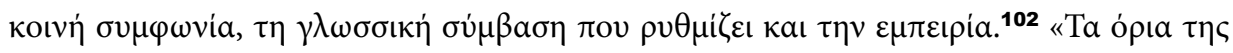

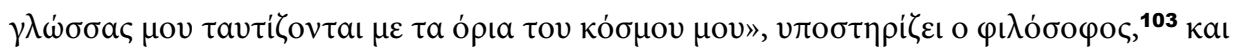

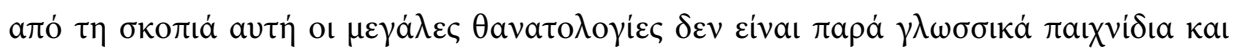

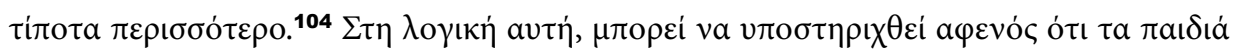

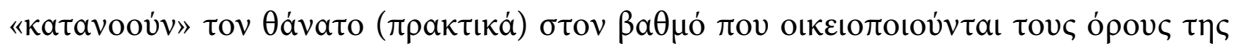

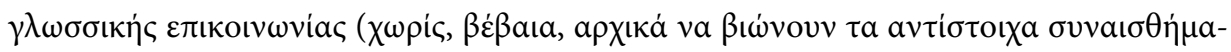

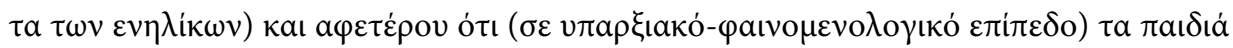

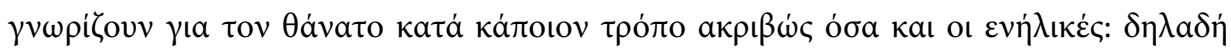
тілота. ${ }^{105}$

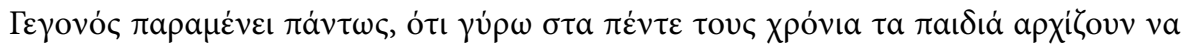

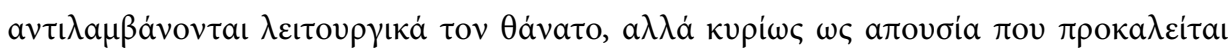

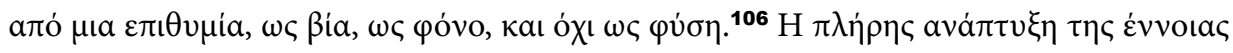

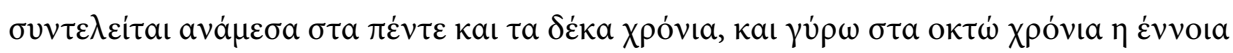

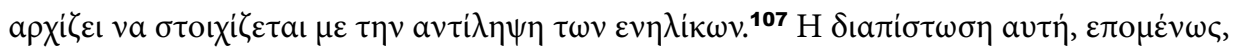

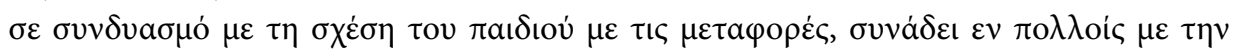

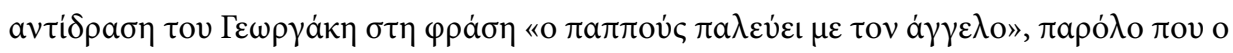

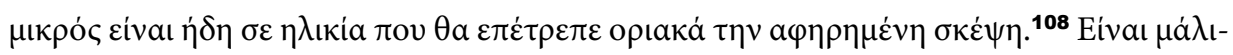

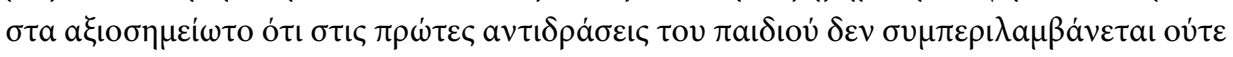

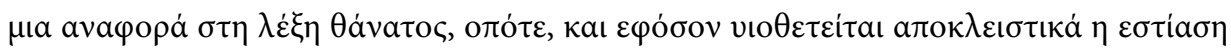

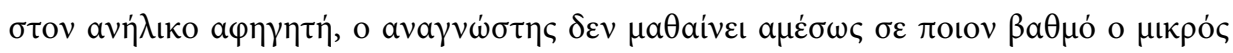

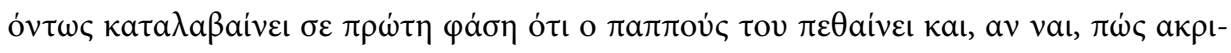

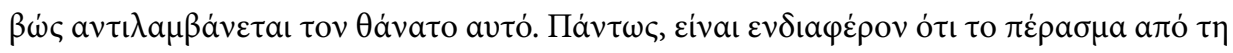

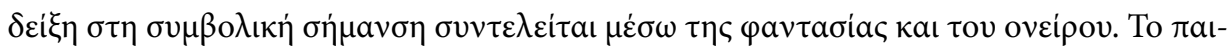

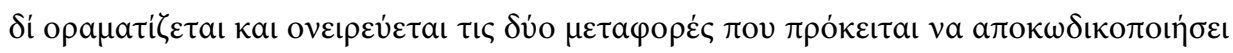

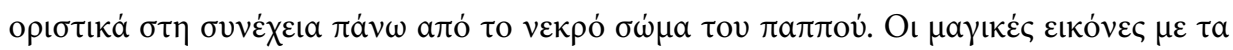

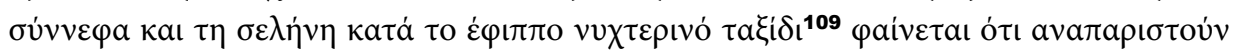

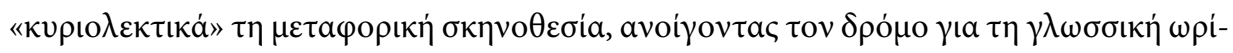

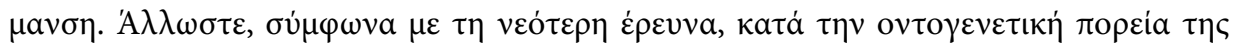




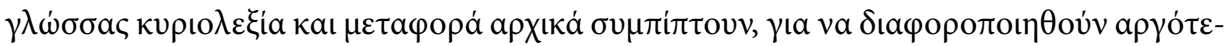

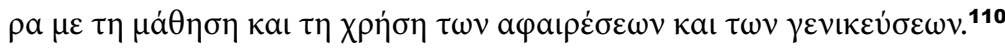

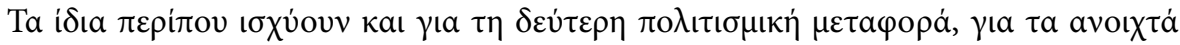

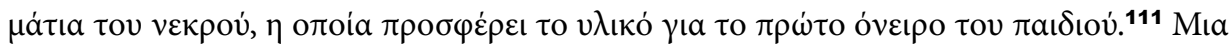

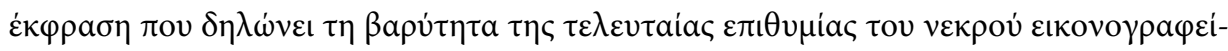

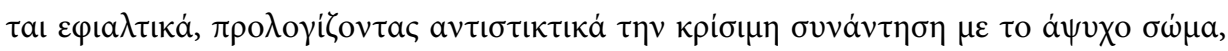

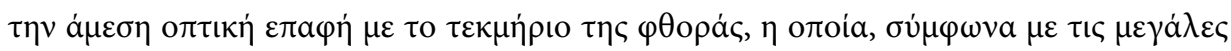

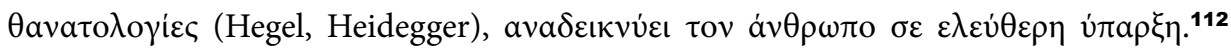

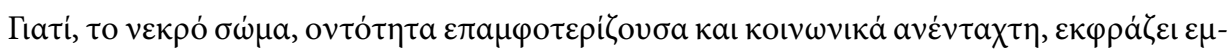

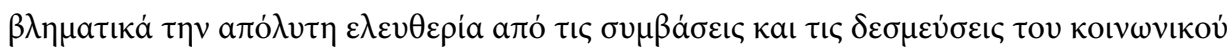

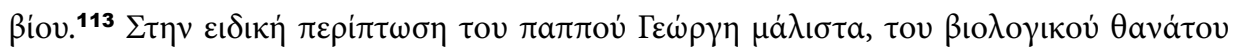

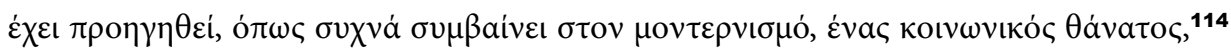

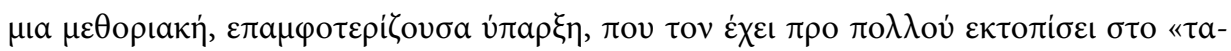

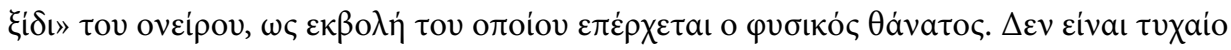

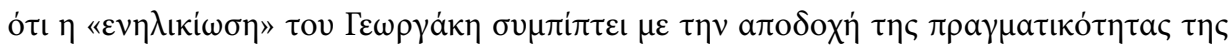

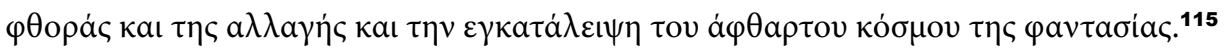

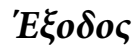

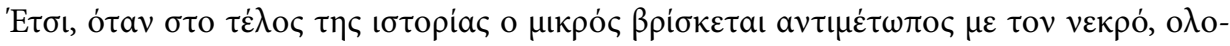

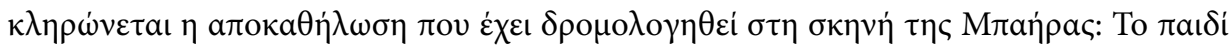

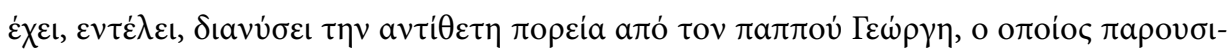

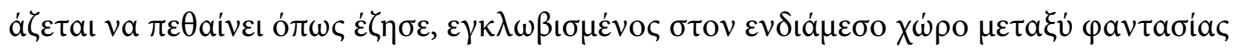

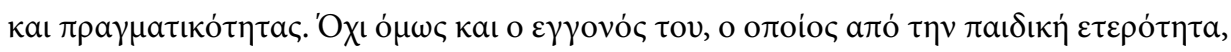

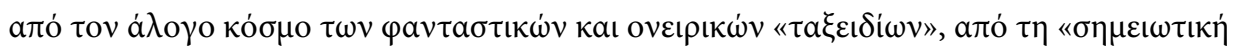

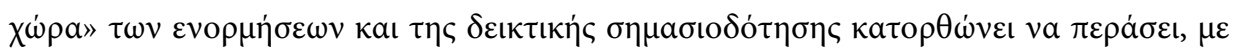

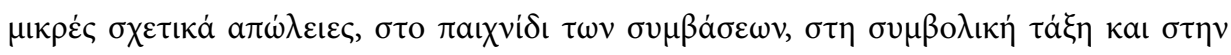

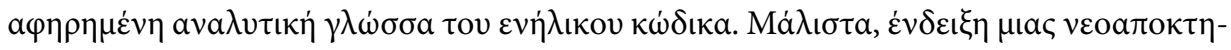
$\theta \varepsilon i \sigma \alpha \varsigma$ ع

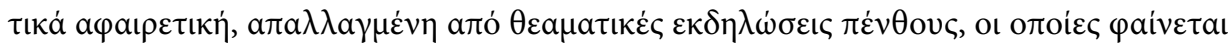

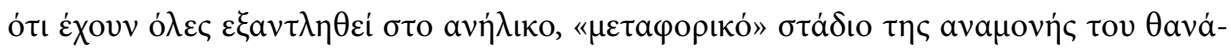

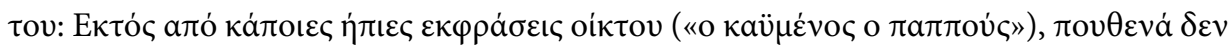

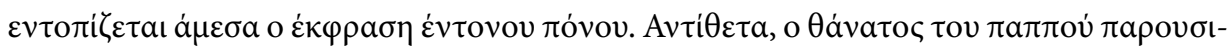

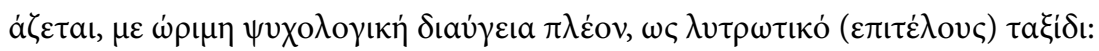

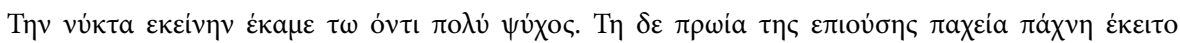

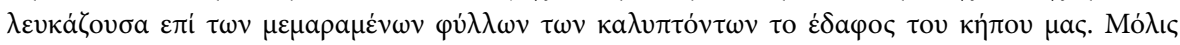

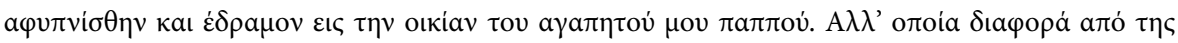

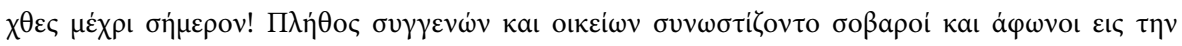

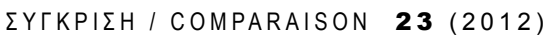




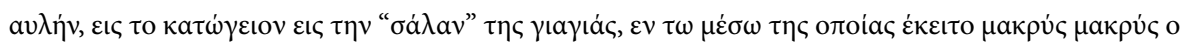

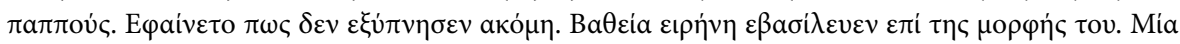

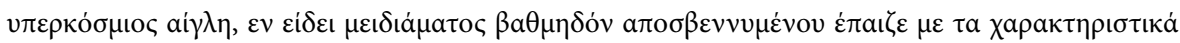

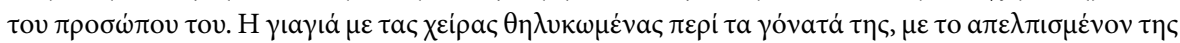

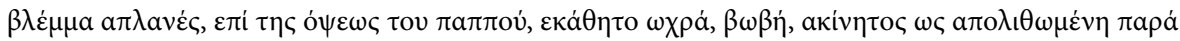

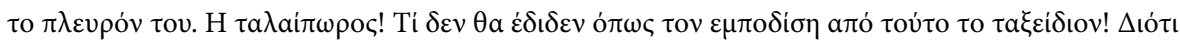

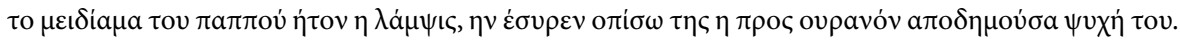

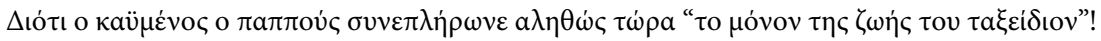

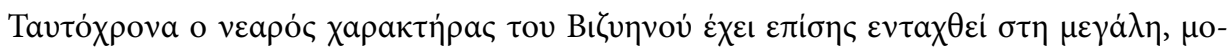

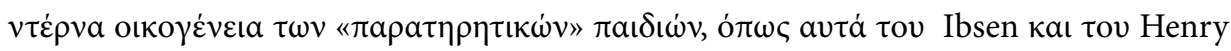

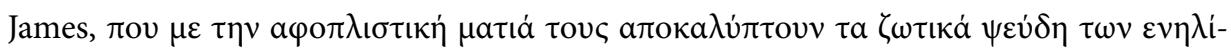

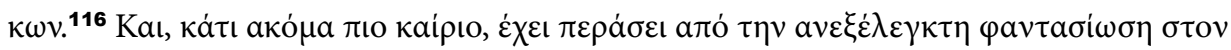

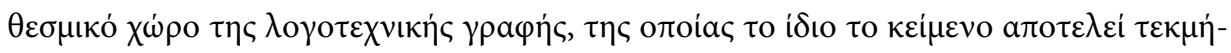

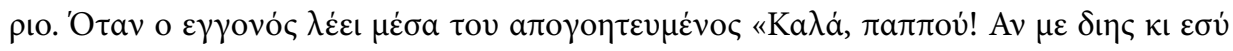

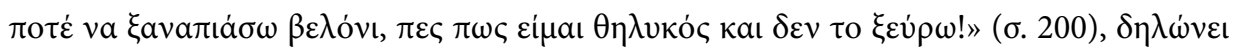

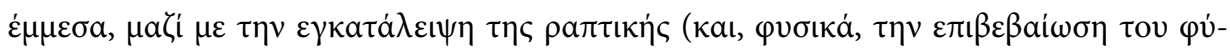

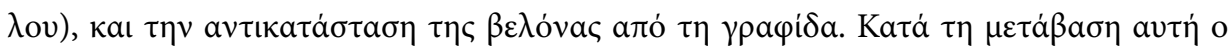

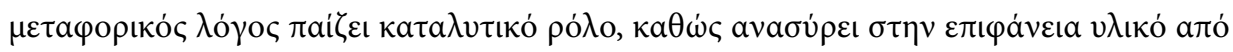

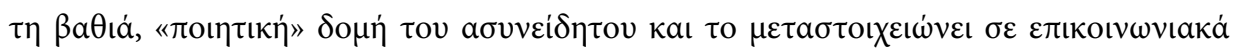

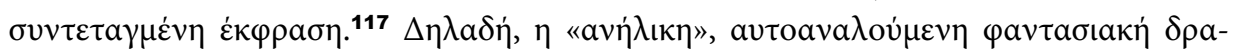

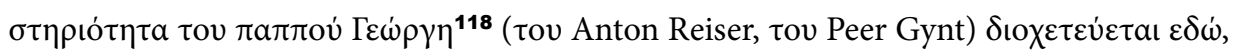

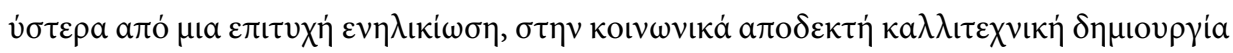

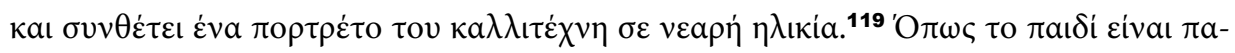

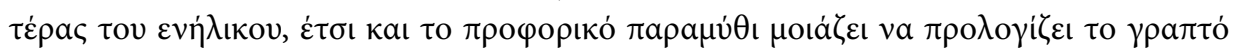

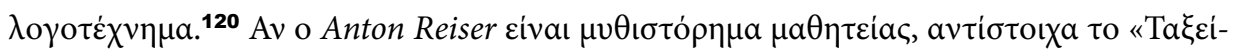

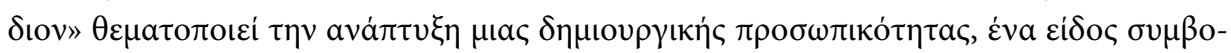

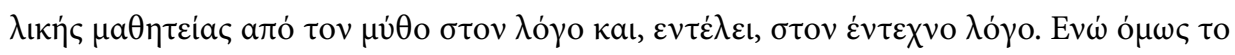

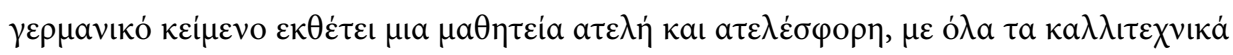

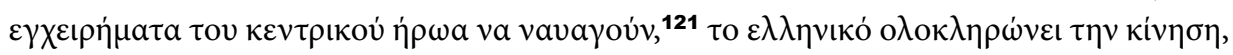

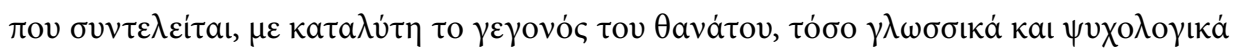

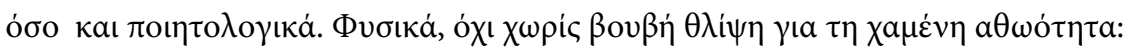

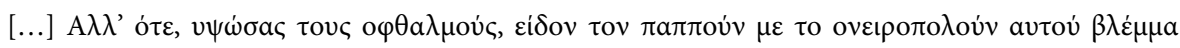

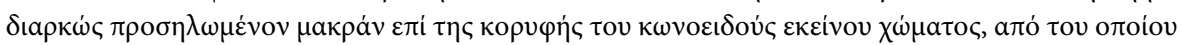

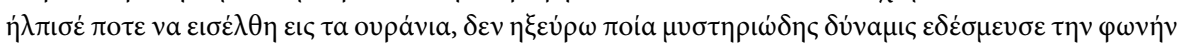

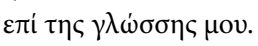

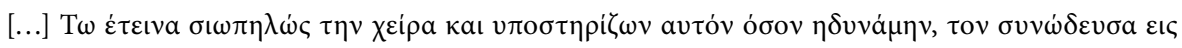

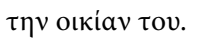




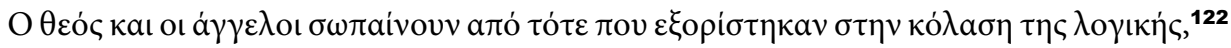

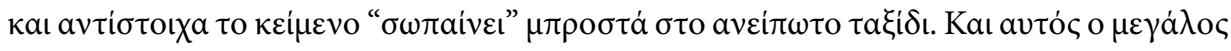

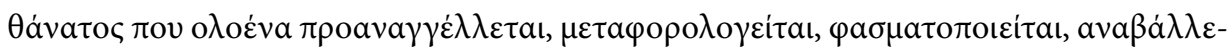

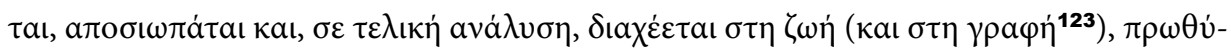

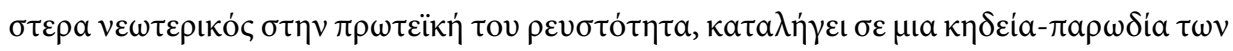

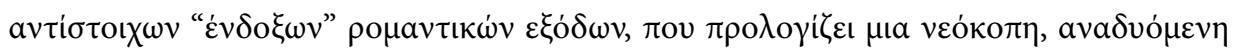

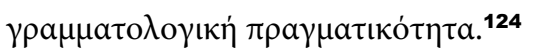

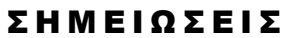

1 "Die Altväter, so abgeschmackt und abenteuerlich oft ihre Geschichte sein mochte, waren für Anton die würdigsten Muster zur Nachahmung, und er kannte eine Zeitlang keinen höhern Wunsch, als seinem großen Namensgenossen, dem heiligen Antonius, ähnlich zu werden und wie dieser Vater und Mutter zu verlassen und in eine Wüste zu fliehen, die er nicht weit vom Tore zu finden hoffte, und wohin er einmal wirklich eine Reise antrat, indem er sich über hundert Schritte weit von der Wohnung seiner Eltern entfernte und vielleicht noch weiter gegangen wäre, wenn die Schmerzen an seinem Fuße ihn nicht genötigt hätten, wieder zurückzukehren." (K. P. Moritz, Anton Reiser. Ein psychologischer Roman,

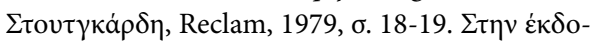

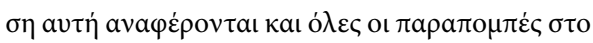

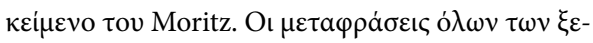

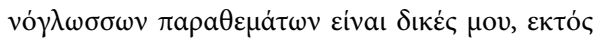

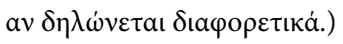

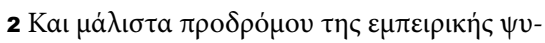

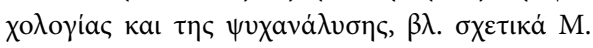
Wagner-Egelhaaf, Die Melancholie der Literatur.

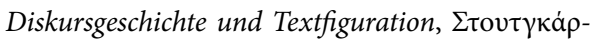

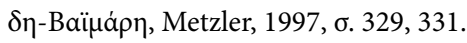

3 В $\lambda$. Г.М. Вı孔

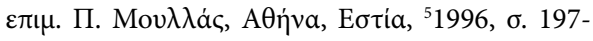

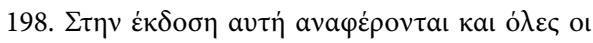

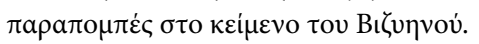

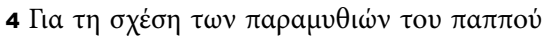

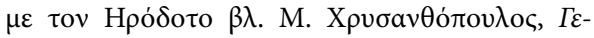

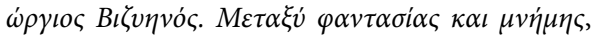

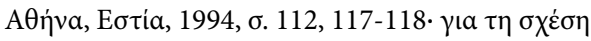

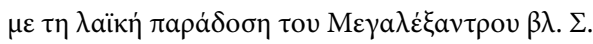

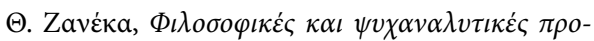

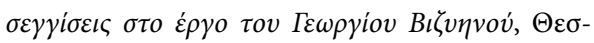

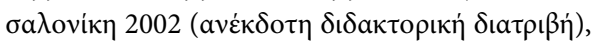
б. 283-284.

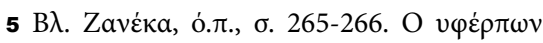

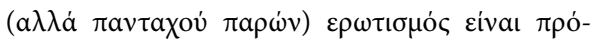

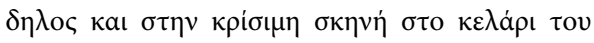

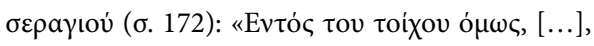

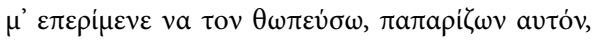

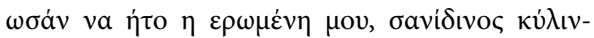

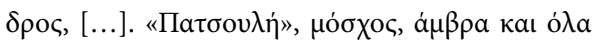

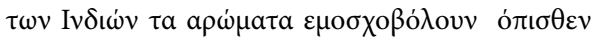

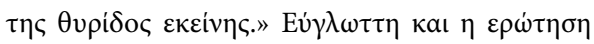

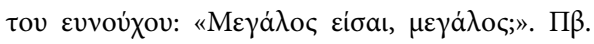

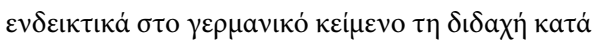

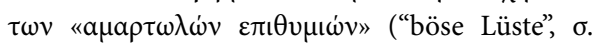

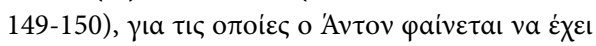

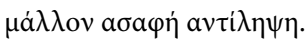

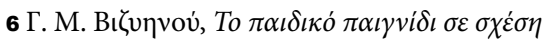

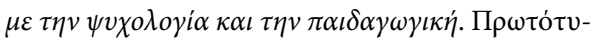

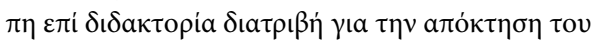

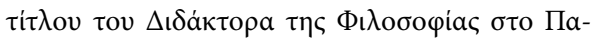

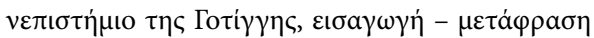

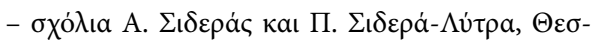

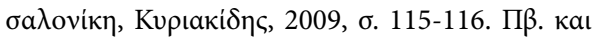

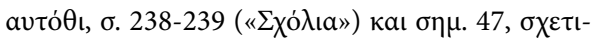




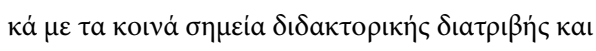

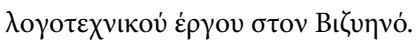

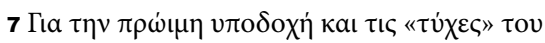

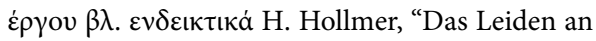
der Kunst. Ein Moritz-Thema und seine Folgen für die Herzensergießungen eines kunstliebenden Klosterbruders", Text+Kritik. Zeitschrift für Lite-

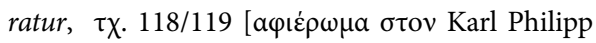
Moritz] (1993) 107-117.

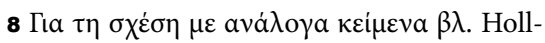

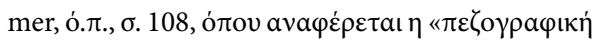

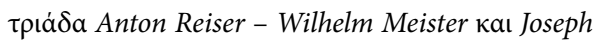

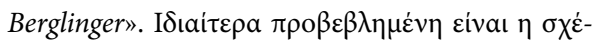

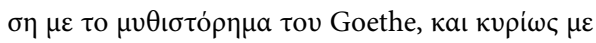

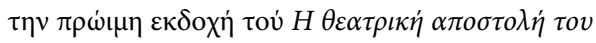

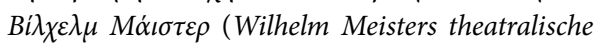

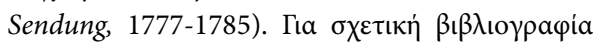

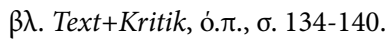

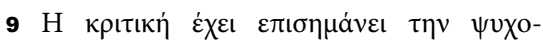

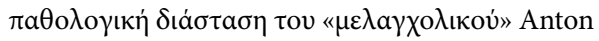

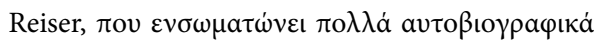

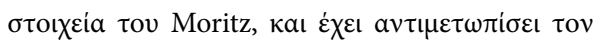

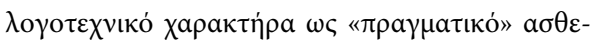

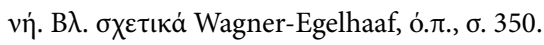

10 Wagner-Egelhaaf, ó.đ., $\sigma .388$.

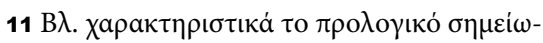

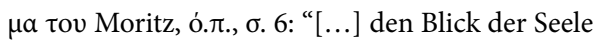

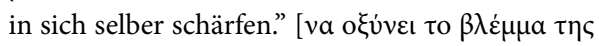

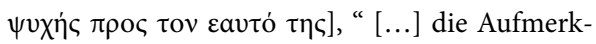
samkeit des Menschen mehr auf den Menschen selbst zu heften, und ihm sein individuelles Da-

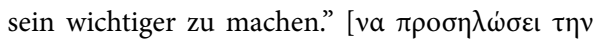

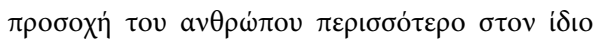

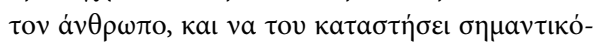

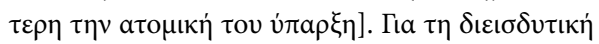

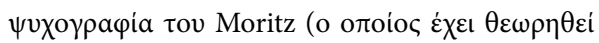

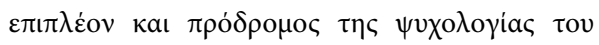

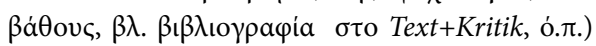

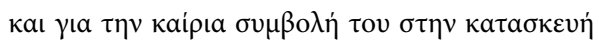

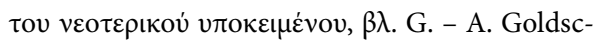
midt, "Die beflügelte Wahrnehmung des Leidens. Zu Karl Philipp Moritz' Roman Anton Reiser",

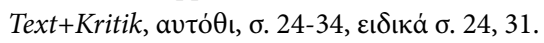

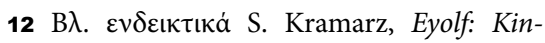
der und Kinderschicksale im Werk Henrik Ibsens,

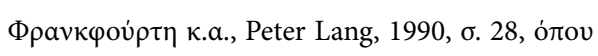

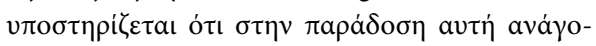

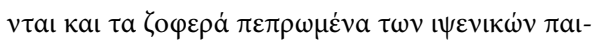

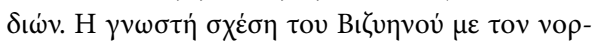

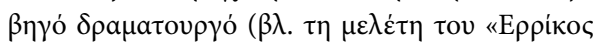

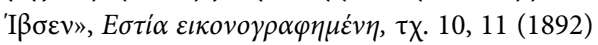

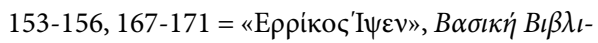

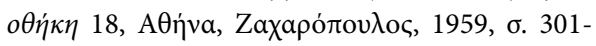

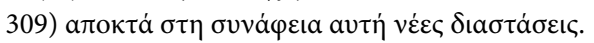

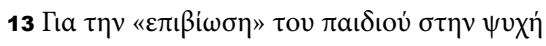

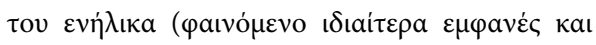

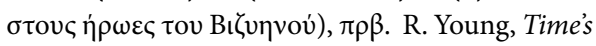
disinherited children. Childhood, regression and sacrifice in the plays of Henrik Ibsen, Nópyouıc,

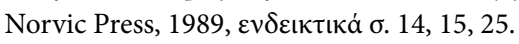

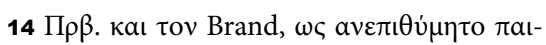

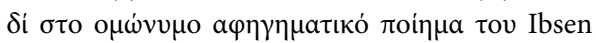

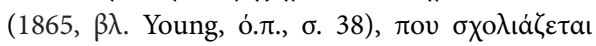

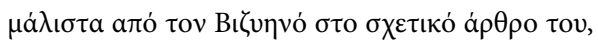

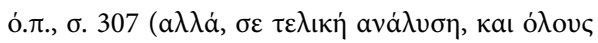

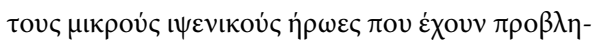

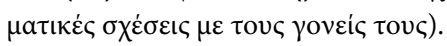

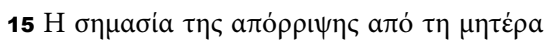

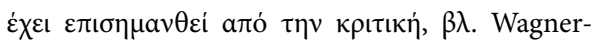
Egelhaaf, ó.đ., $\sigma .350$.

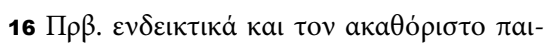

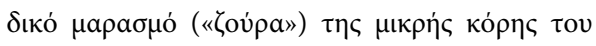

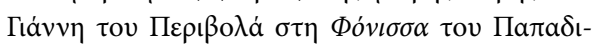

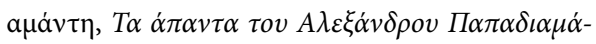

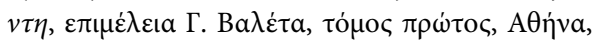

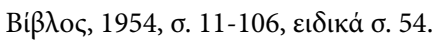

17 Eívaı a

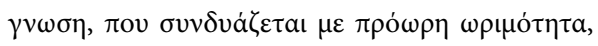

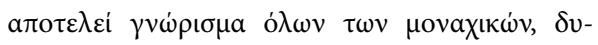

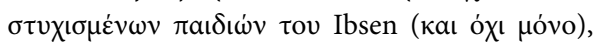

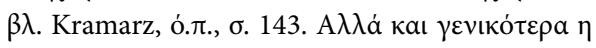
$\pi \rho о \sigma \varphi v \gamma \eta \dot{~ \sigma \tau o v ~ к o ́ \sigma \mu о ~ \tau \eta ৎ ~ \lambda о \gamma о \tau \varepsilon \chi v i ́ a \varsigma ~ к а ı ~ \tau \eta \varsigma ~}$

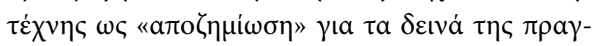

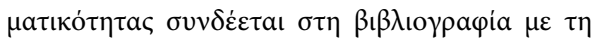
$\mu \varepsilon \lambda \alpha \gamma \chi \mathrm{o} \lambda \mathrm{i} a, \beta \lambda$. Wagner-Egelhaaf, ó. $\pi ., \quad \sigma .27,327$, $349,350,392$.

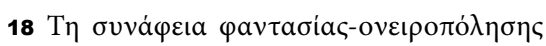

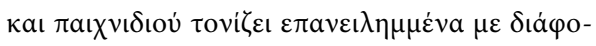

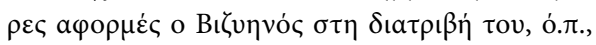

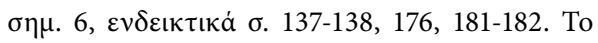




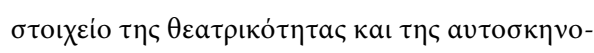

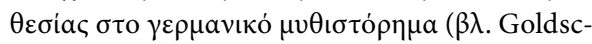

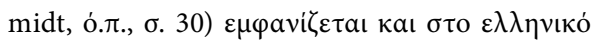

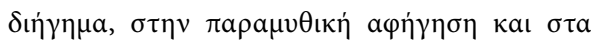
óveıрa.

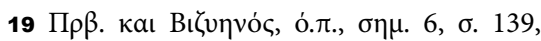

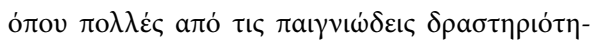

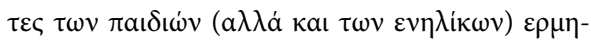

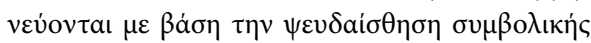

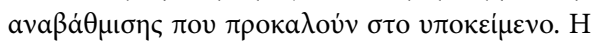

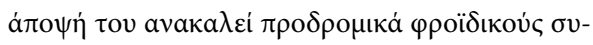

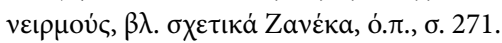

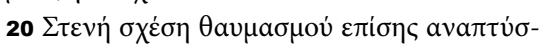

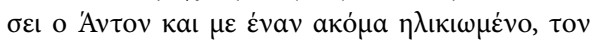

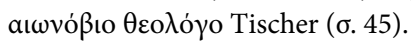

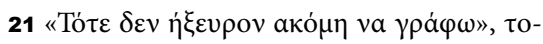

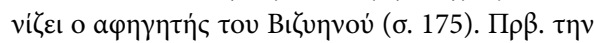
$\varepsilon เ \sigma a \gamma \omega \gamma \eta \dot{~ \tau o v ~ \Pi . ~ M o v \lambda \lambda a ́, ~ B ı \zeta u \eta v o ́ \varsigma, ~ o ́ . \pi ., ~ \sigma \eta \mu . ~ 3, ~}$

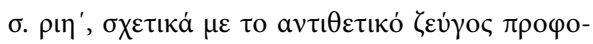

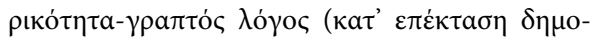

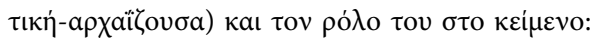

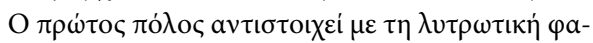

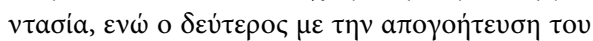

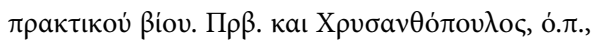

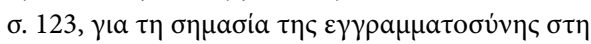

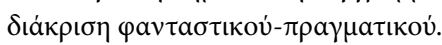

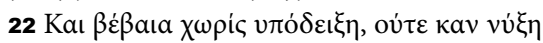

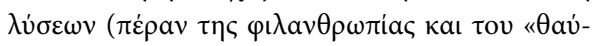

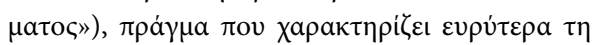

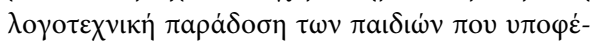

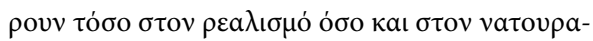

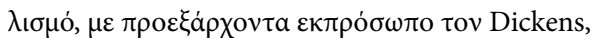

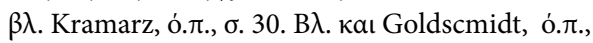

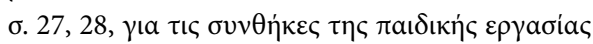

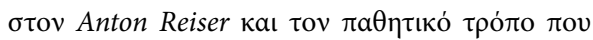

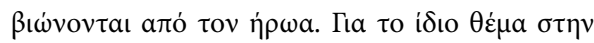

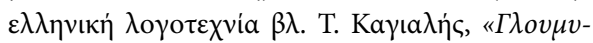

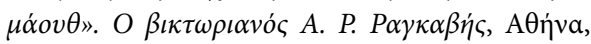

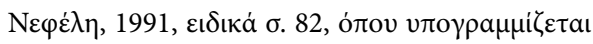
$\eta$ $а \pi о \varphi v \gamma \eta \dot{~ \kappa a \tau \alpha \gamma \gamma \varepsilon \lambda i ́ a \varsigma ~ \tau \omega v ~ v \pi \varepsilon v \theta u ́ v \omega v . ~ O ı ~} \beta \mathrm{l}-$

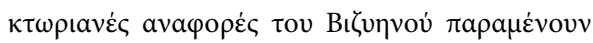
$\theta \dot{\varepsilon} \mu \alpha \pi \rho \circ \varsigma \delta \varepsilon \rho \varepsilon \dot{v} \eta \sigma \eta$.

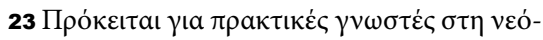

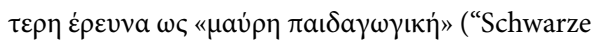

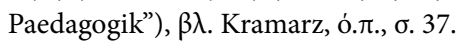

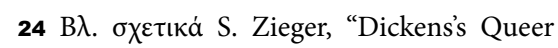
Children", Literature Interpretation Theory, 20

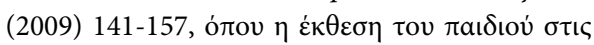

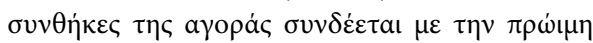

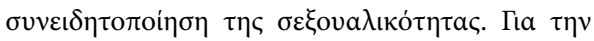

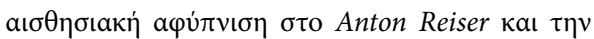

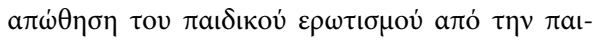

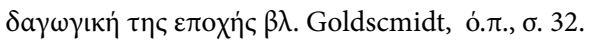

25 B $\lambda$. A. Rassidakis, "Labyrinth-Figurationen: Eine absolute Metapher und ihre rhizomatischen Auswüchse", Mythologica. Düsseldorfer Jahrbuch für interdisziplinäre Mythosforschung, 8

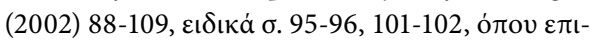

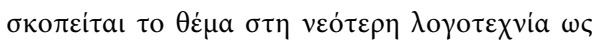

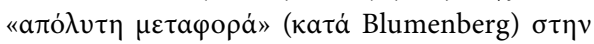

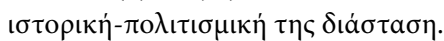

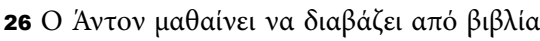

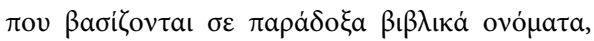

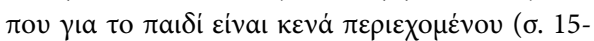

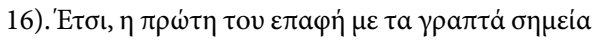

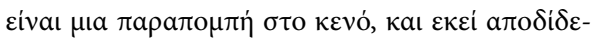

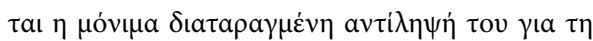

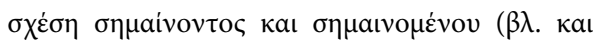
$\pi \alpha \rho \alpha \kappa a ́ \tau \omega, \sigma \eta \mu .45)$.

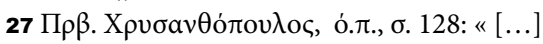

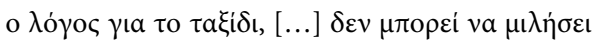

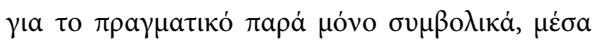

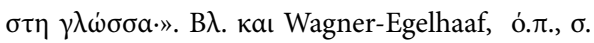

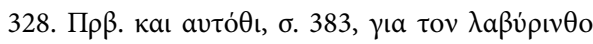

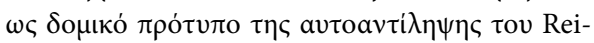

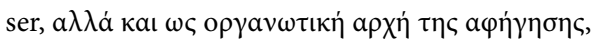

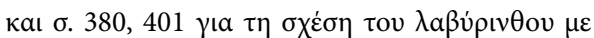

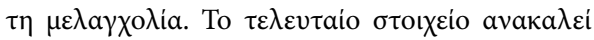

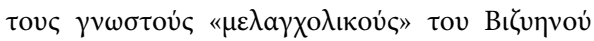

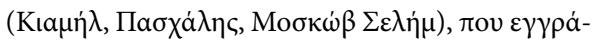

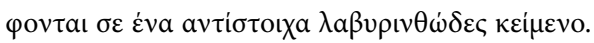

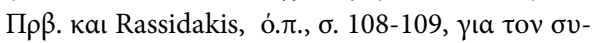

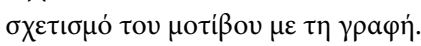

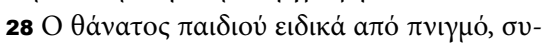

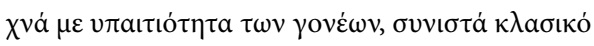

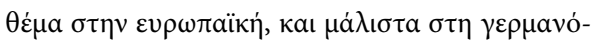

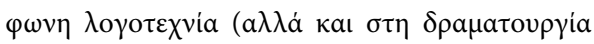

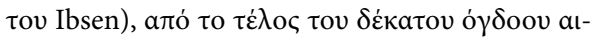

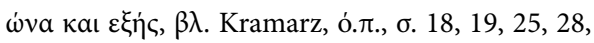
200. 


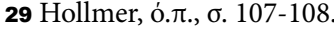

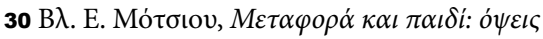

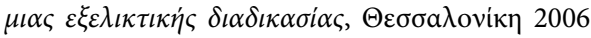

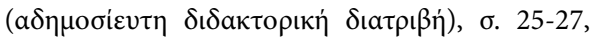

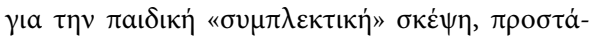

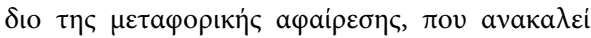

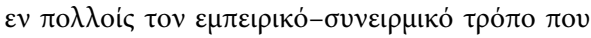

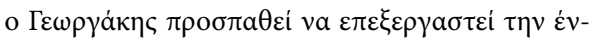

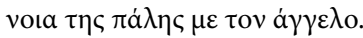

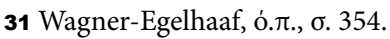

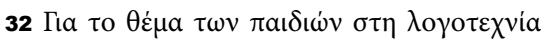

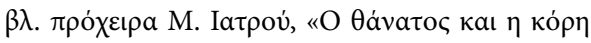

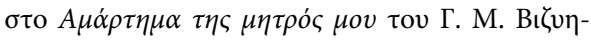

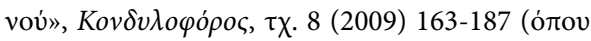

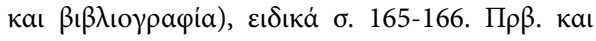
Krammarz, ó. $\pi .$, б. 28-39.

$33 \mathrm{~B} \lambda . \varepsilon v \delta \varepsilon เ \kappa \tau \iota \kappa \alpha \dot{~ A . ~ S i m o n i s, ~ K i n d h e i t ~ i n ~ R o-~}$ manen um 1800, M $\pi \dot{i} \lambda \varepsilon \varphi \varepsilon \lambda \nu \tau$, Aisthesis, 1993, $\sigma$. 13, 25-26, 31.

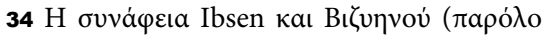

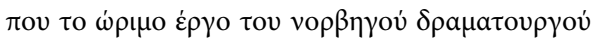

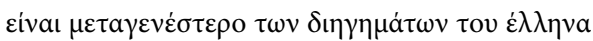

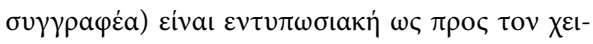


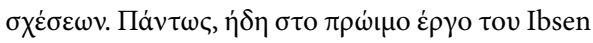

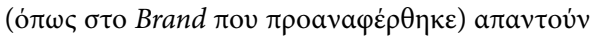

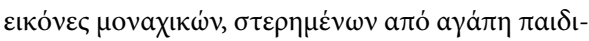

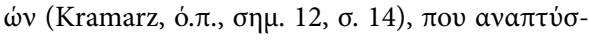

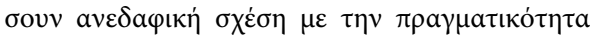

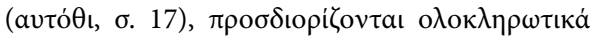

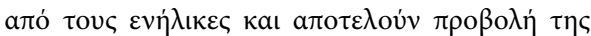

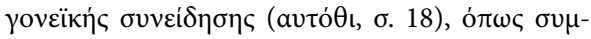

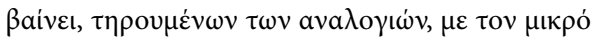

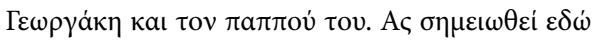

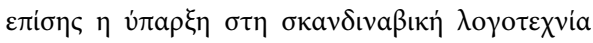

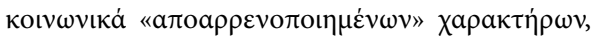

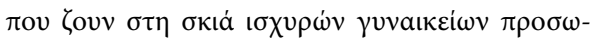

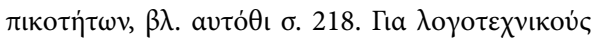

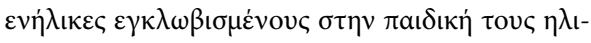

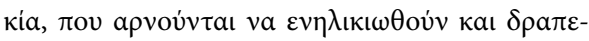

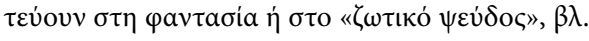

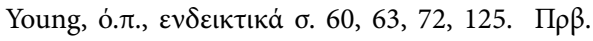

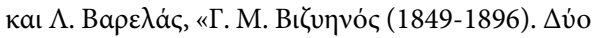

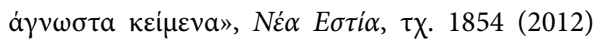

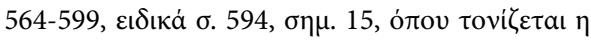

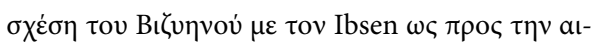

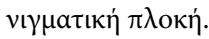

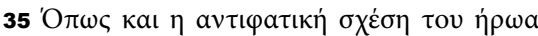

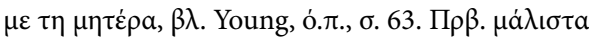

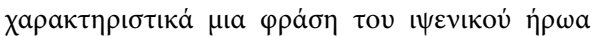

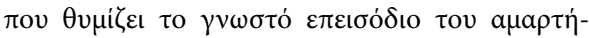

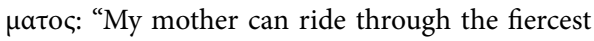

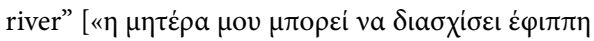

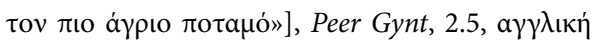

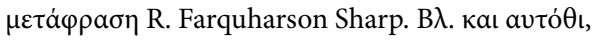

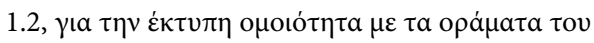

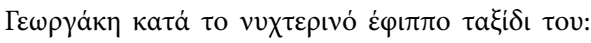
"What a curious cloud! That bit's like a horse, / And there is its rider and saddle and bridle,/ And behind them an old crone is riding a broomstick."

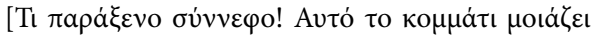

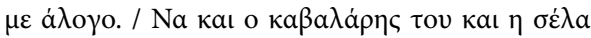

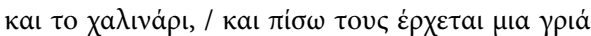

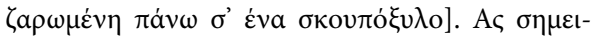

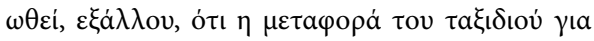

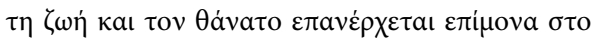

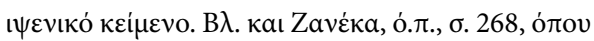

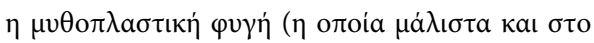

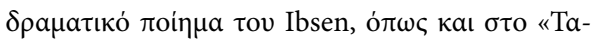

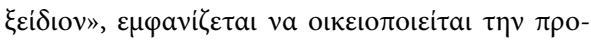

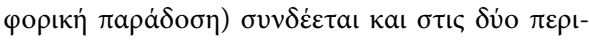
$\pi \tau \dot{\omega} \sigma \varepsilon เ \varsigma \mu \varepsilon \tau \eta \nu \alpha v \alpha \zeta \dot{\eta} \tau \eta \sigma \eta \lambda \dot{\tau} \tau \rho \omega \sigma \eta \varsigma \sigma \tau \eta \nu \tau \dot{\varepsilon} \chi \nu \eta$.

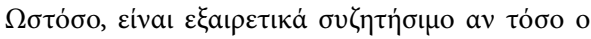

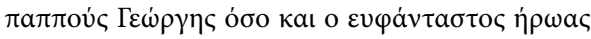

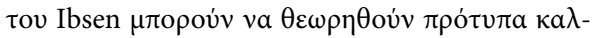

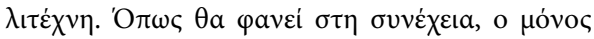

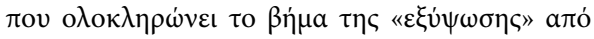

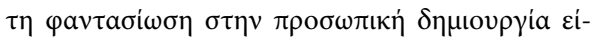

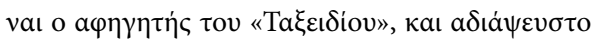
ix

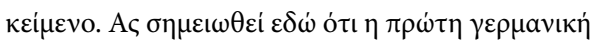

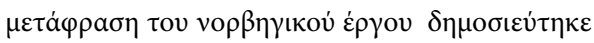

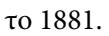

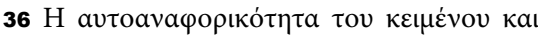

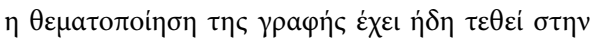

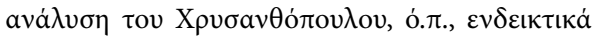

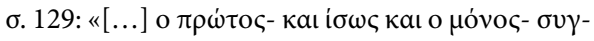

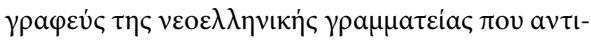

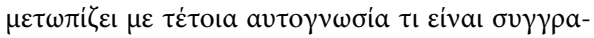

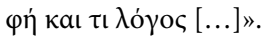

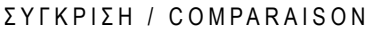

23 


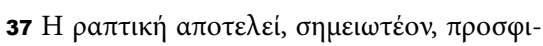

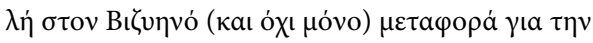

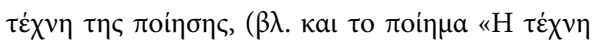

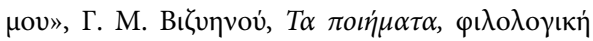

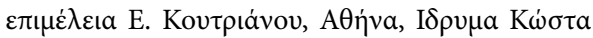

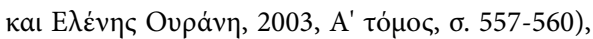

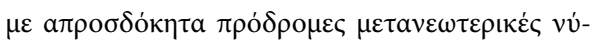

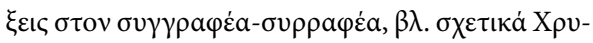

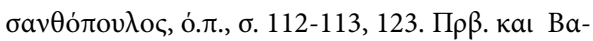

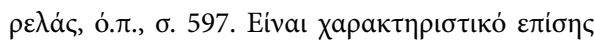

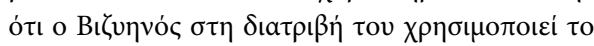

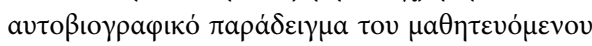

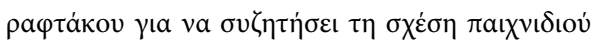

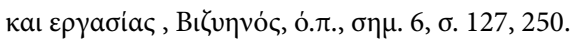

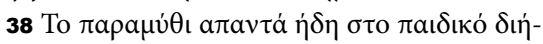

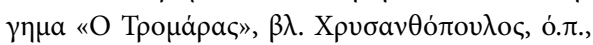

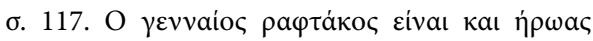
$\pi \alpha \rho \alpha \mu v \theta ı$ เov $\tau \omega \nu$ a $\delta \varepsilon \lambda \varphi \omega \dot{\nu}$ Grimm ("Das tapfere Schneiderlein" í "Vom klugen Schneiderlein”),

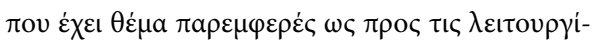

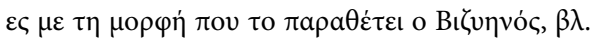

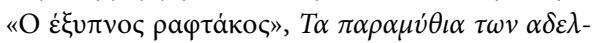

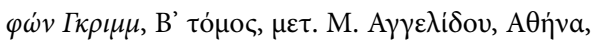

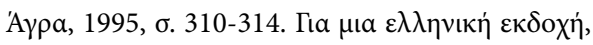

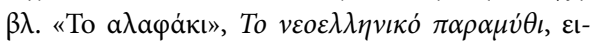

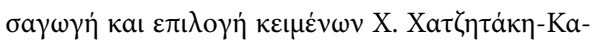

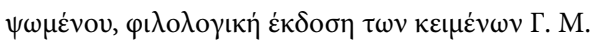

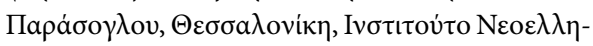

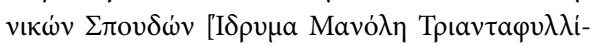

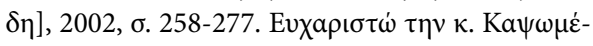

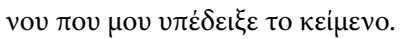

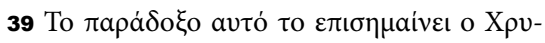

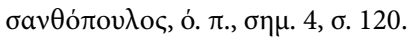

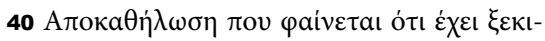

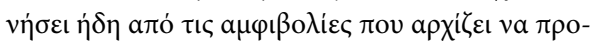

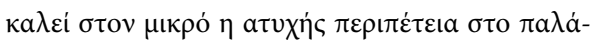

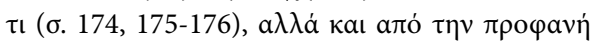

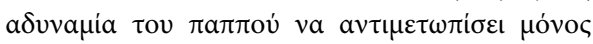

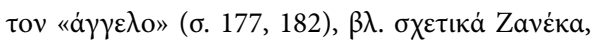

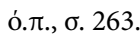

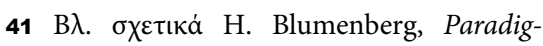

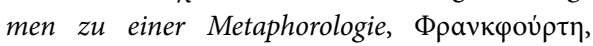

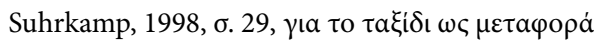

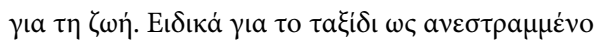

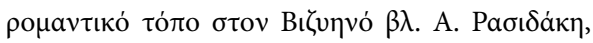

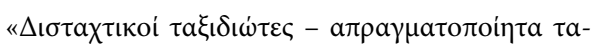

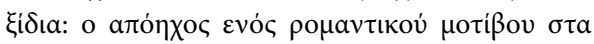

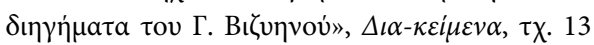

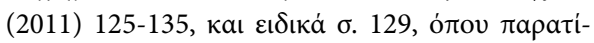

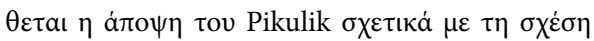

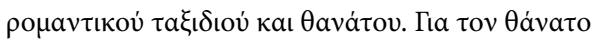

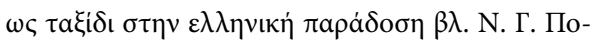

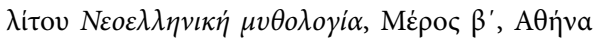

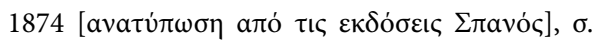
264. П $\beta$. каı В. Bultinck, Metaphors we die by: conceptualizations of death in English and their

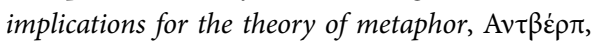
Universiteit Anwerpen, Universitaire Instelling Antwerpen, Department Germaanse, Afdeling

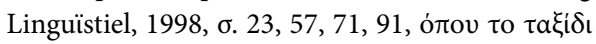

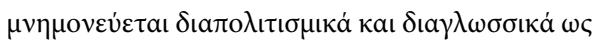

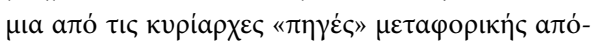

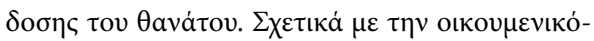

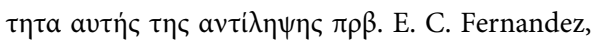
"The language of death: euphemism and conceptual metaphorization in Victorian obituaries", SKY

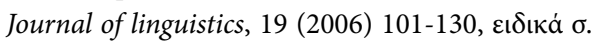
113 (ó

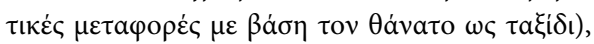

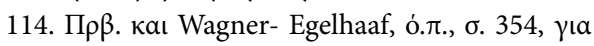

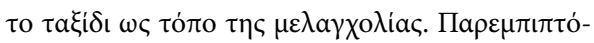

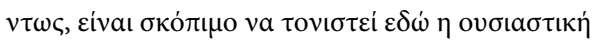
a

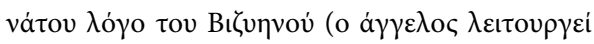

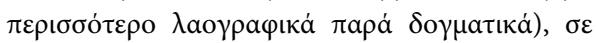

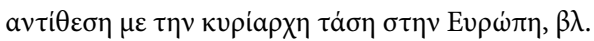

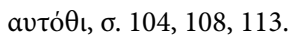

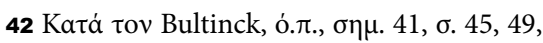

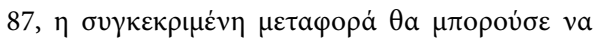

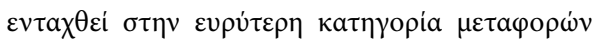

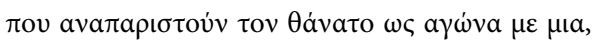

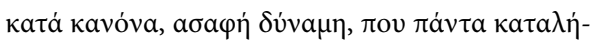

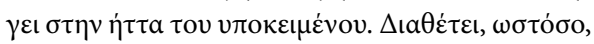

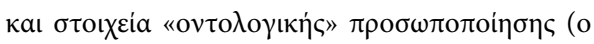

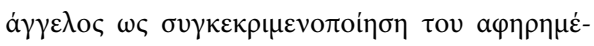
vov $\theta$ avátov), $\beta \lambda$. avтó $\theta \mathrm{l}, \sigma .55$.

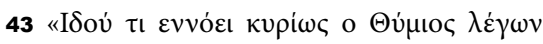

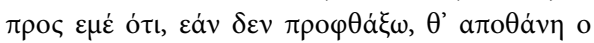

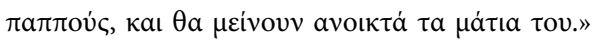
(б. 180) 


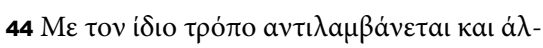

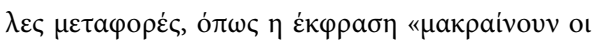

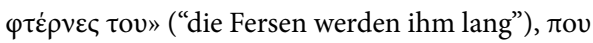

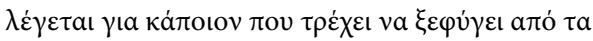

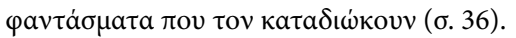

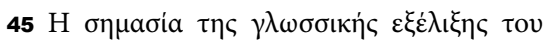

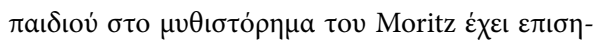

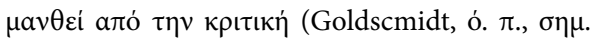

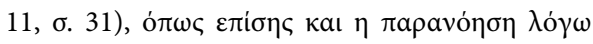

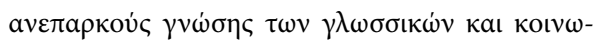

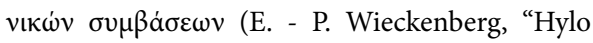

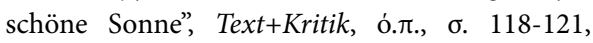

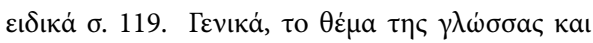

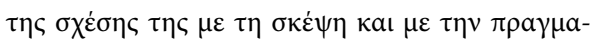

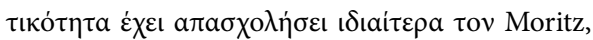

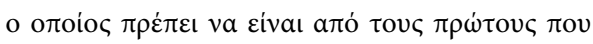

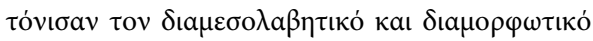

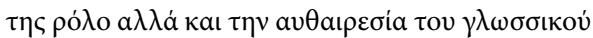

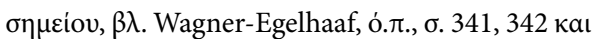
H. Smidt, "Karl Philipp Moritz, der Linguist", Text

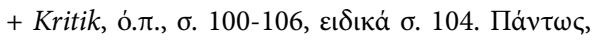

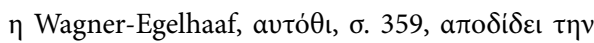

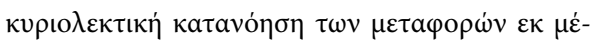

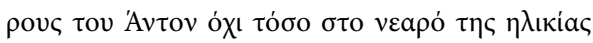

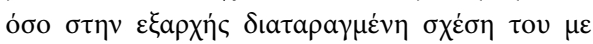

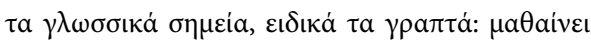

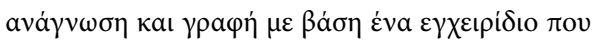

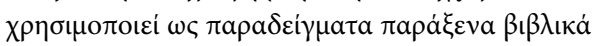

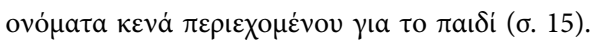

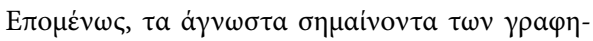

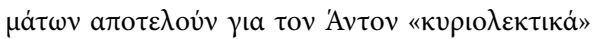

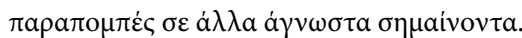

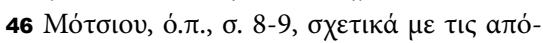

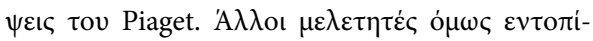

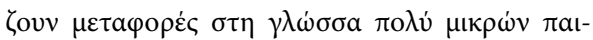

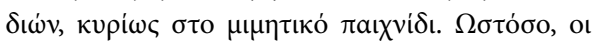

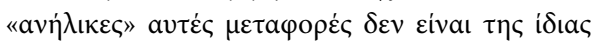

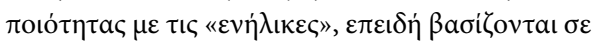

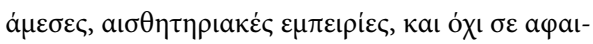

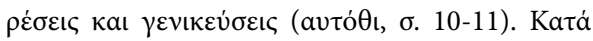

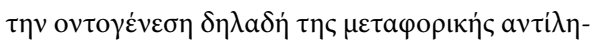

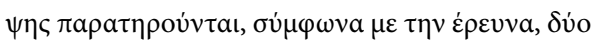

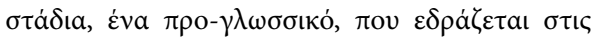

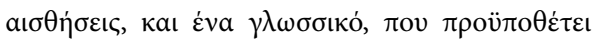

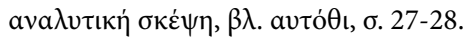

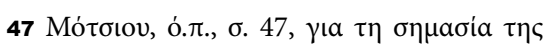

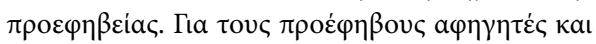

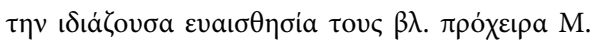

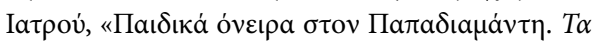

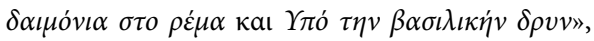

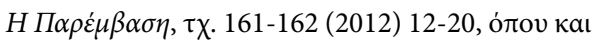
$\beta$ เ $\beta$ เоррачі́а.

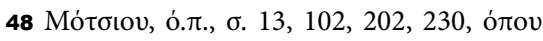

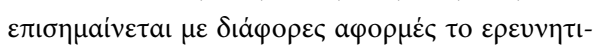

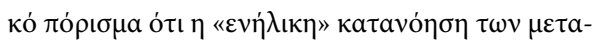

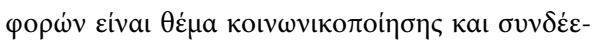

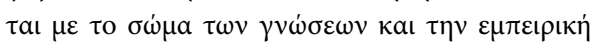

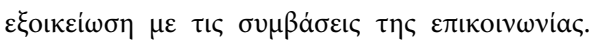

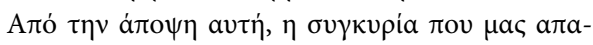

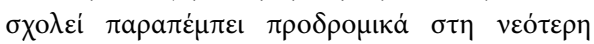

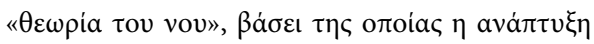

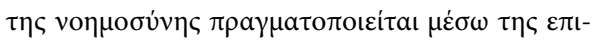

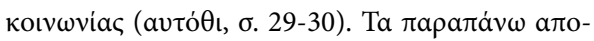

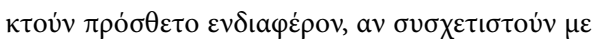

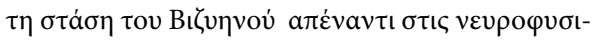

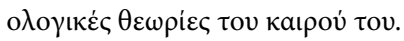

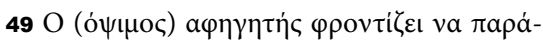

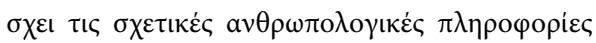

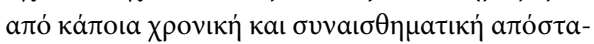

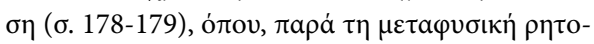

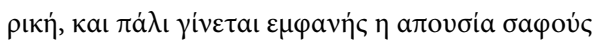

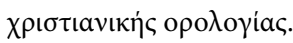

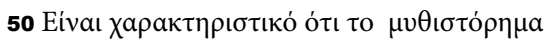

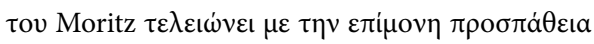

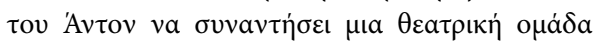

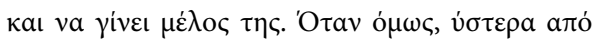

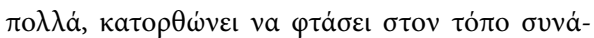

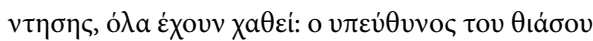

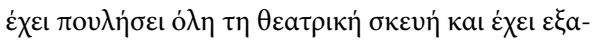

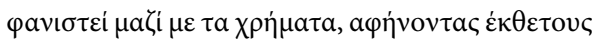

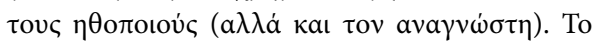

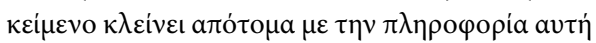

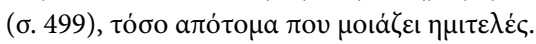

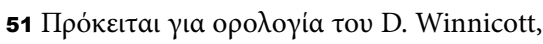

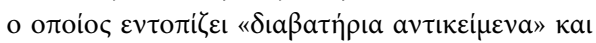

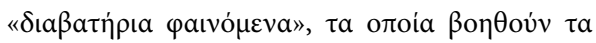

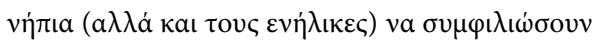

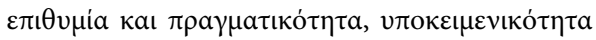

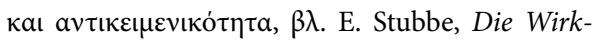
lichkeit der Engel in Literatur, Kunst und Religion,

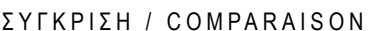

$23(2012)$ 


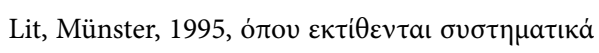

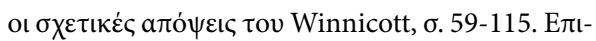

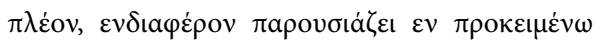

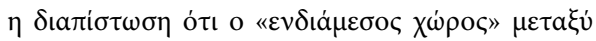

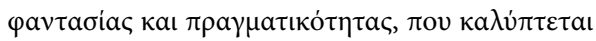

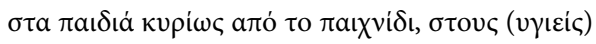

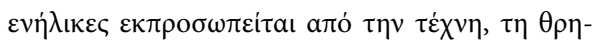

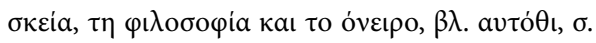
61,64 .

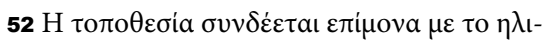

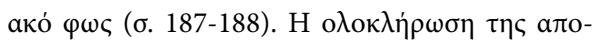

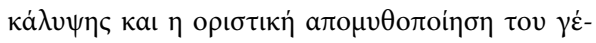

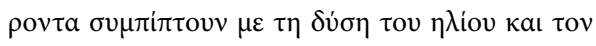
Өávato (б. 196-197, 200).

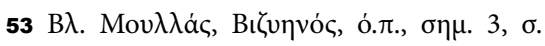

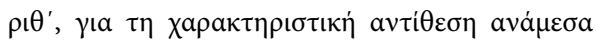

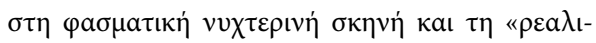

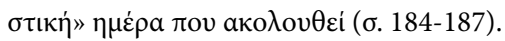

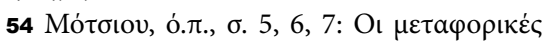

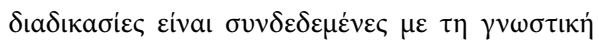

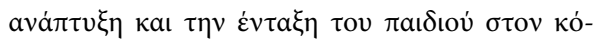

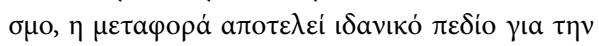

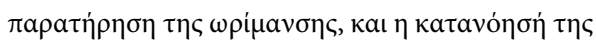

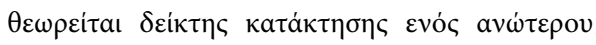

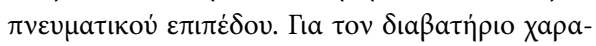

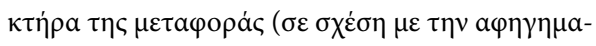

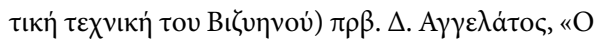

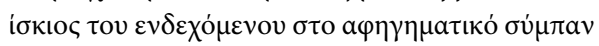

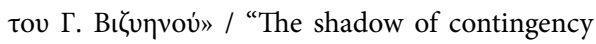

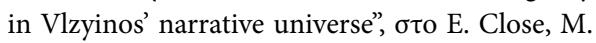
Tsianikas каı G. Couvalis ( $\varepsilon \pi \mu$.), Greek Research in Australia: Proceedings of the Sixth Biennial International Conference of Greek Studies, Flinders University June 2005, Flinders University Department of Languages - Modern Greek, A $\delta \varepsilon$ -

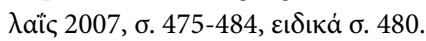

$55 \mathrm{~B} \lambda . \varepsilon \nu \delta \varepsilon \iota \kappa \tau \iota \kappa \alpha ́$ J. Sexton, "The semantics of death and dying: Metaphor and mortality", et $\mathrm{Ce}$ -

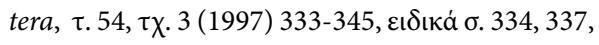

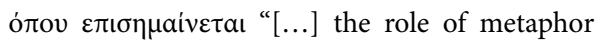
in providing a foundation for our understand-

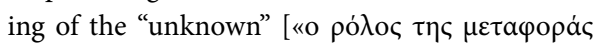

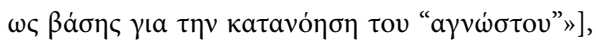

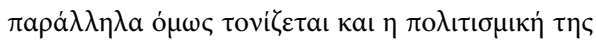

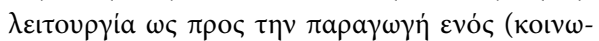

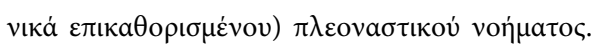

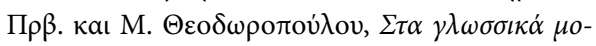

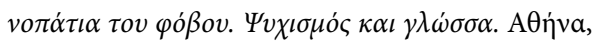

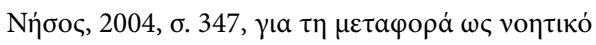

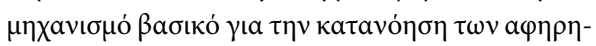

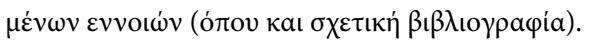

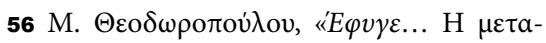

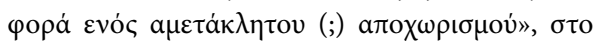

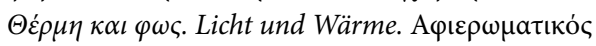

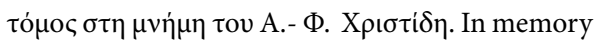

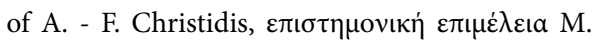

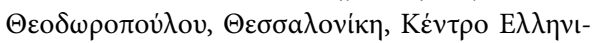

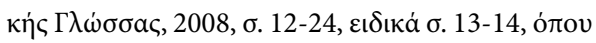

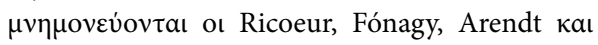

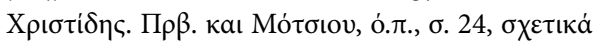

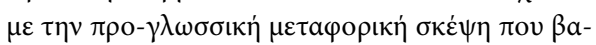

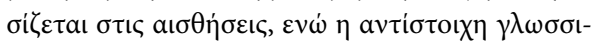

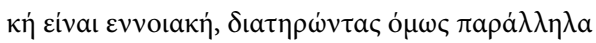

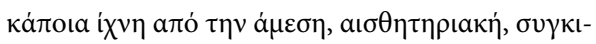

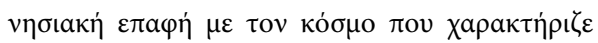
$\tau \eta \nu \pi \rho о \gamma \varepsilon v \varepsilon \dot{\sigma} \sigma \varepsilon \rho \eta \dot{~ \tau \eta ऽ ~ \kappa a \tau \alpha ́ \sigma \tau a \sigma \eta . ~ П \rho \beta . ~ \alpha v \tau o ́ \theta ı ~} \sigma$.

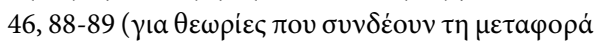

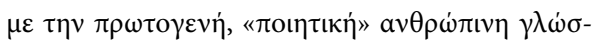

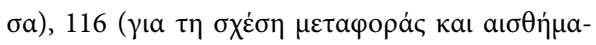

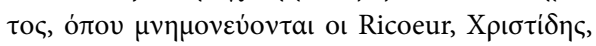

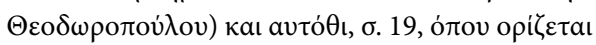

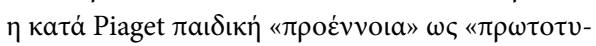

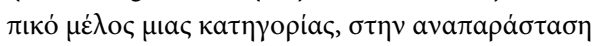

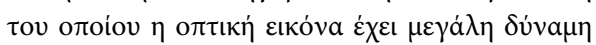

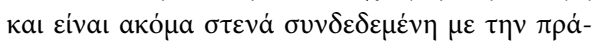

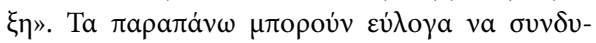

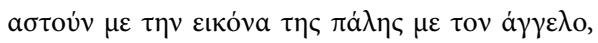

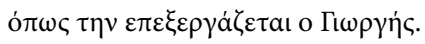

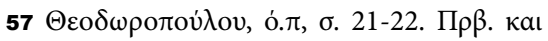
Fernandez, ó. $\pi, \sigma .116$, ó

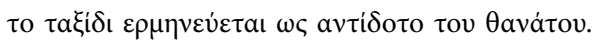

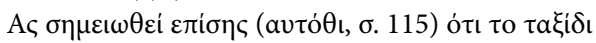

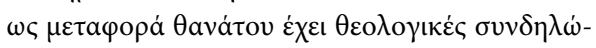

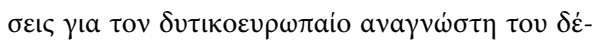

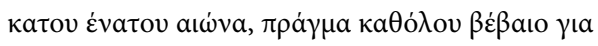

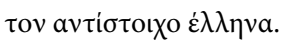

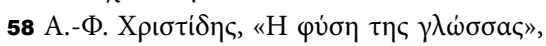

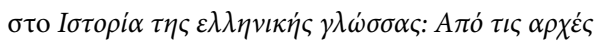

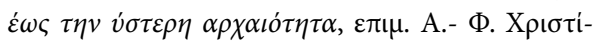

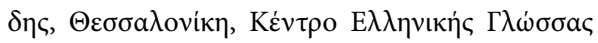




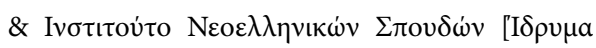

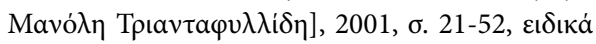

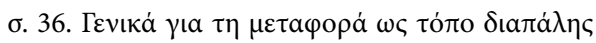

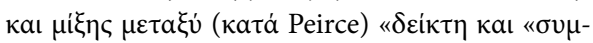

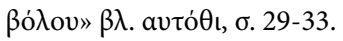

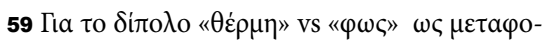

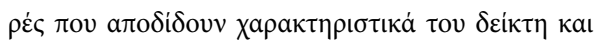

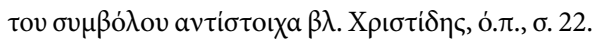

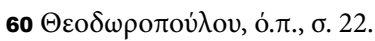

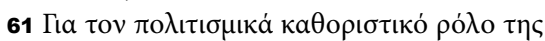

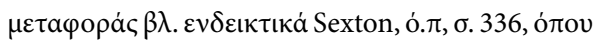

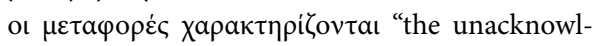

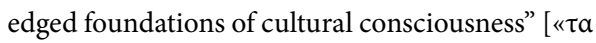

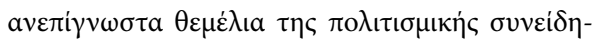

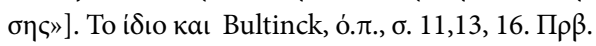

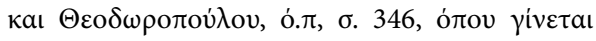
ava

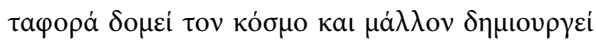

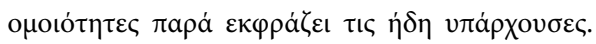

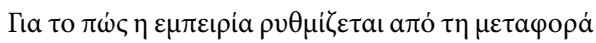

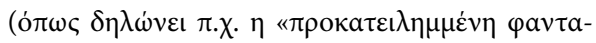

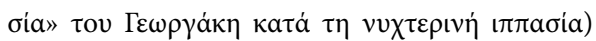

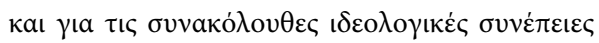

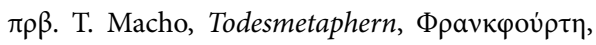
Suhrkamp, 1987, б. 145, 148.

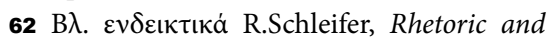
death. The language of modernism and postmod-

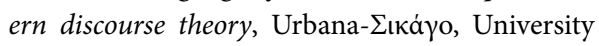

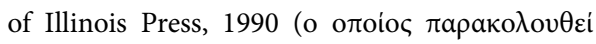
$\tau \eta v \kappa \rho i \sigma \eta \tau \omega v v \pi \varepsilon \rho \beta a \tau \iota \kappa \omega \dot{v} \alpha \xi \iota \dot{\omega} v \kappa a ı ~ \tau \eta v ~ \kappa \alpha \tau \alpha \dot{\rho}-$

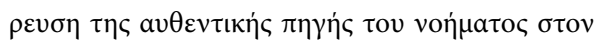

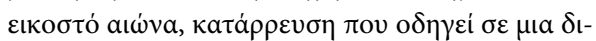

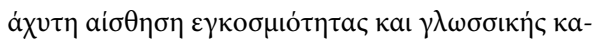

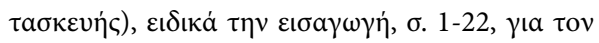

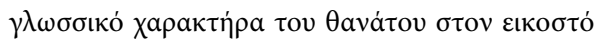

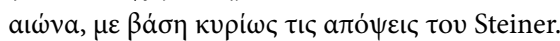

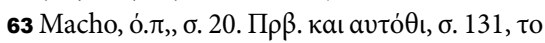

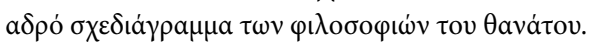

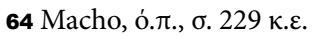

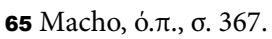

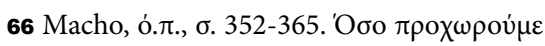

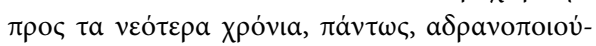

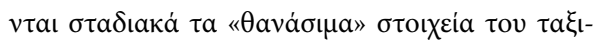

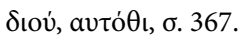

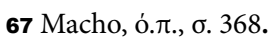

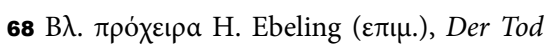

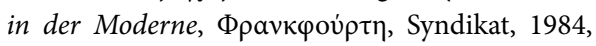
б. 16-19.

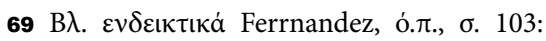
"The name of death is death. The only effective way to ameliorate the taboo is silence" [ "To óvo $\mu \alpha$ tov

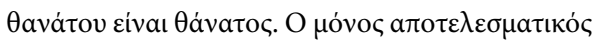

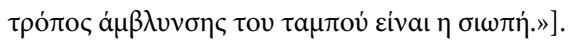

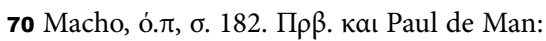
"Death is a displaced name for a linguistic predic-

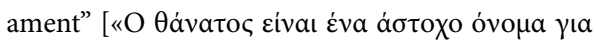

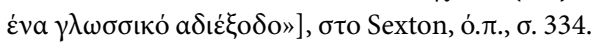

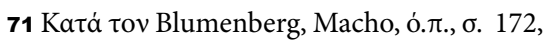

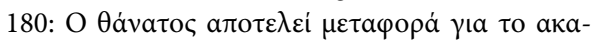

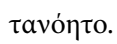

72 Macho, ó.đ., б. 183-184.

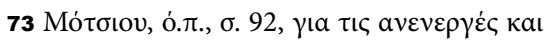

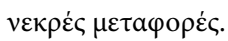

74 Macho, ó.đ., $\sigma .188$.

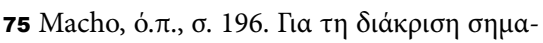

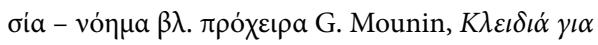

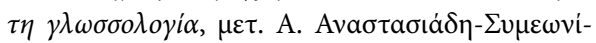

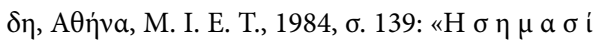

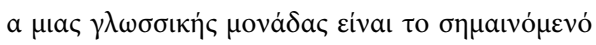

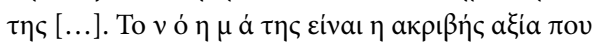

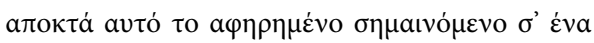
$\mu$

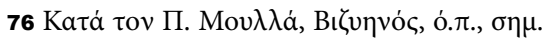
3, б.

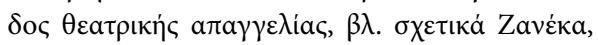

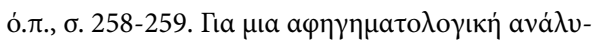

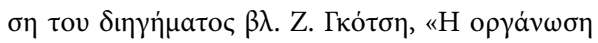

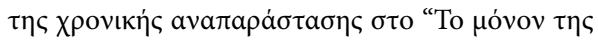

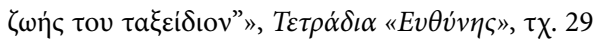
(1988) 151-158.

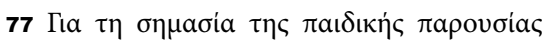

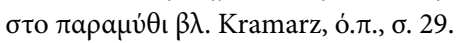

$78 \mathrm{~B} \lambda$. J. Pierrot, Le rêve de Milton aux surréa-

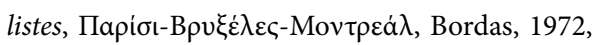

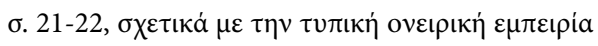

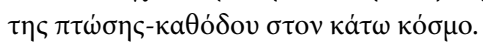

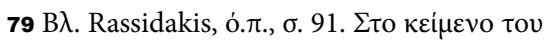

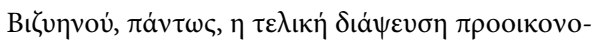

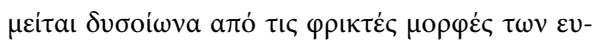

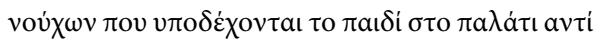

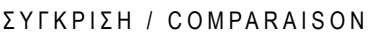

$23(2012)$ 


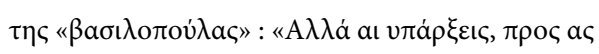

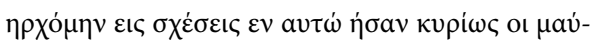

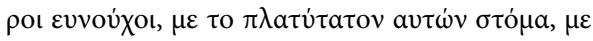

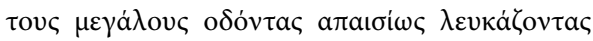

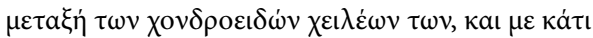

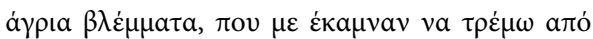

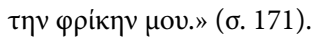

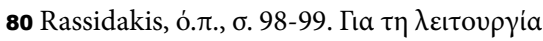

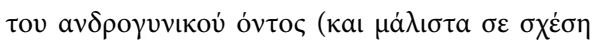

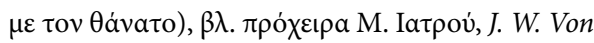

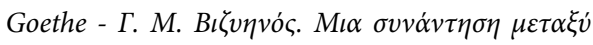

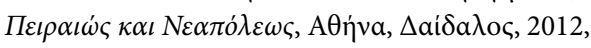

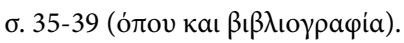

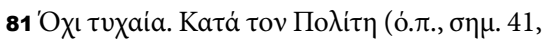

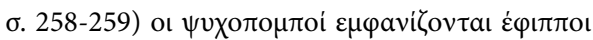

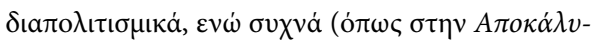

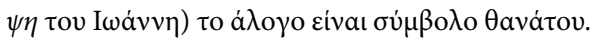

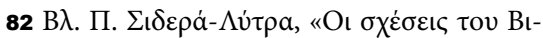

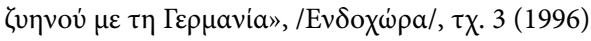

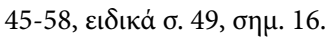

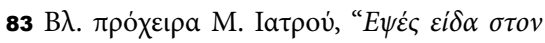

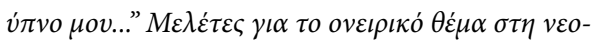
$\varepsilon \lambda \lambda \eta v \iota \kappa \eta \dot{~ \pi o i \eta ~} \sigma \eta, \Theta \varepsilon \sigma \sigma \alpha \lambda$ ovín, University Studio Press, 2011, б. 111-112.

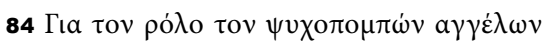

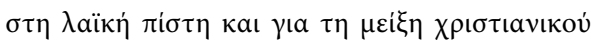

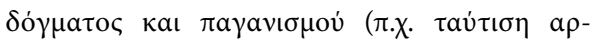

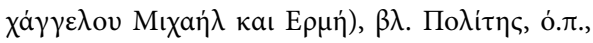

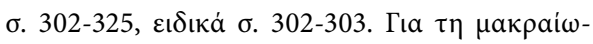

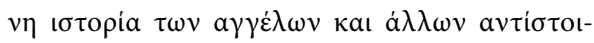

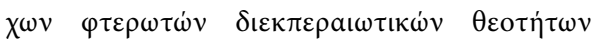

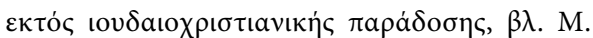
Schmitz-Emans, "Engel-ein Steckbegriff", $\sigma \tau \mathrm{\tau o}$

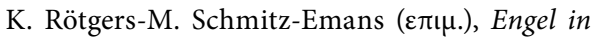
der Literatur-, Philosophie- und Kulturgeshichte,

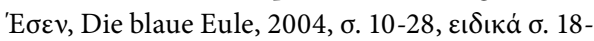
19. П $\beta$. каı M. Schönenborn, "Engel müssen weinen. Zur Form und Funktion des Engelbegriffes im dramatischen Sprachgebrauch des 18. Jahr-

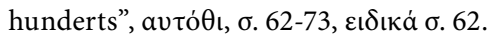

85 Schmitz-Emans, ó. $\pi$., $\sigma .28$.

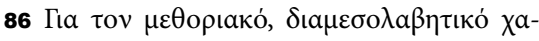

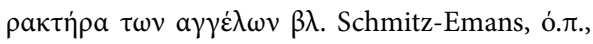

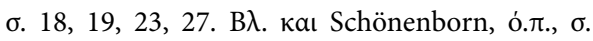
62. Пр $\beta$. каı P. Brandes, "Engel, Allegorien. Zu

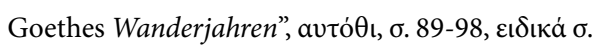
89, S. Hartwig, "Der sterbende Engel. Mallarmés

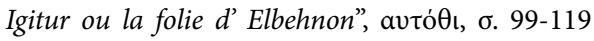
каı M. Schmitz-Emans, "Schwarze Engel. Engel der Erinnerung und des Vergessens bei Antonio Tabucchi und Milan Kundera", avtó $\theta$ l, $\sigma$. 135-155,

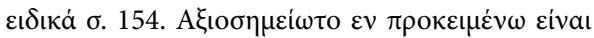

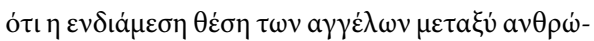

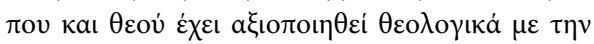

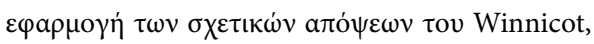

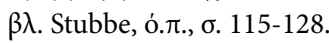

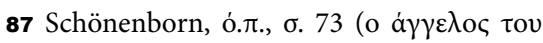

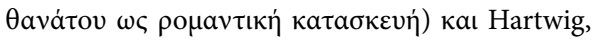

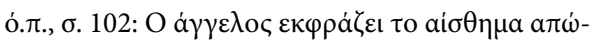

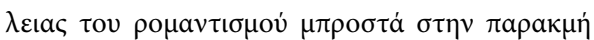

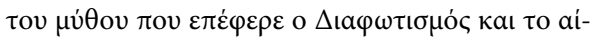

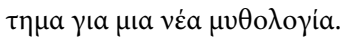

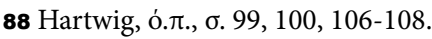

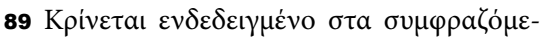

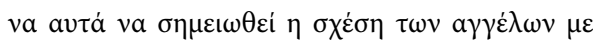

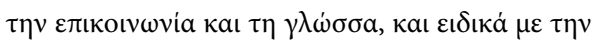

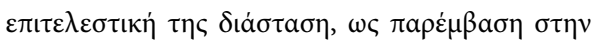

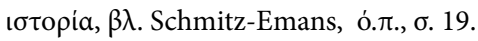

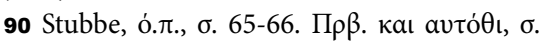
122: "Menschen kommen nicht an der Anstrengung vorbei, innere und äussere Realität zueinander in Beziehung zu setzen. Engel und Übergangsobjekte stellen einen Zwischenbereich zur Verfügung [...] der vorübergehende Befreiung von dieser Anstrengung ermöglicht. Das Selbst entfaltet sich zwischen Schutz und Bedrohung, Sein und Vernichtung"

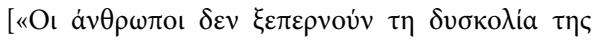

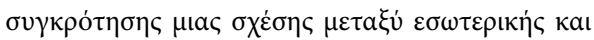

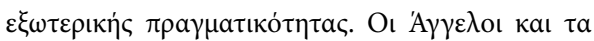

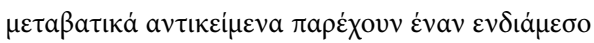

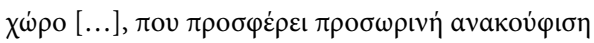

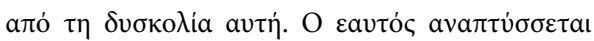

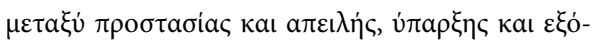
$v \tau \omega \sigma \eta \zeta . »]$.

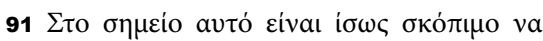

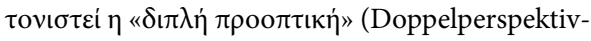

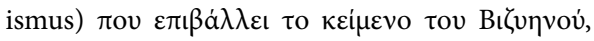

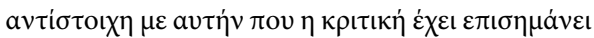

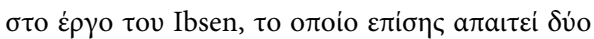

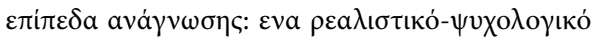




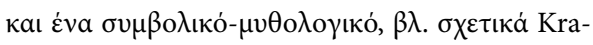
marz, ó.л., $\sigma .24,132,133-134$.

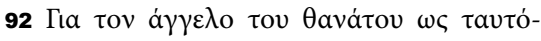

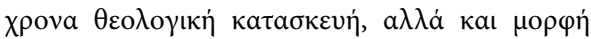

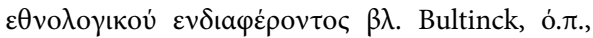

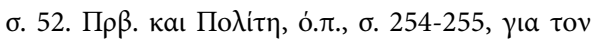

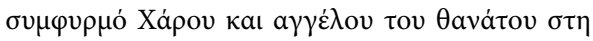
$\lambda \alpha \ddot{\kappa} \eta \dot{~ \pi \alpha \rho a ́ \delta o \sigma \eta . ~}$

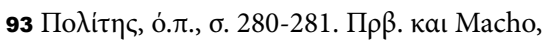

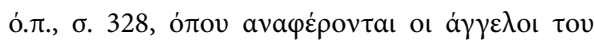

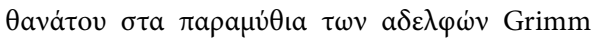

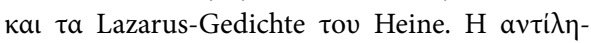

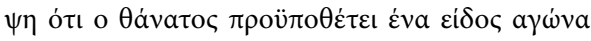

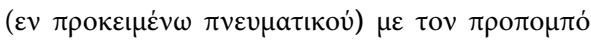

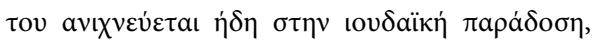
$\beta \lambda$. $\sigma \chi \varepsilon \tau \iota \kappa \alpha$ E. Diamond, "Wrestling the Angel of Death. Form and Meaning in Rabbinic Tales of Death and Dying", Journal for the Study of Judaism in the Persian, Hellenistic and Roman Period, $\tau \chi$.

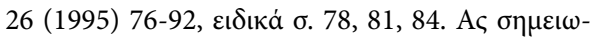

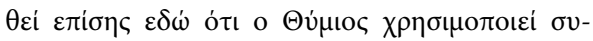

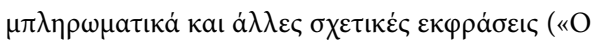

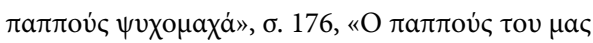

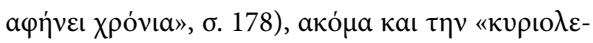

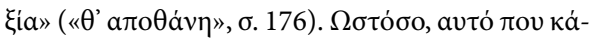

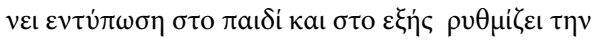

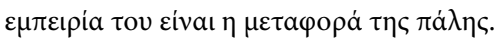

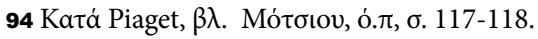

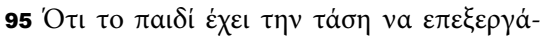

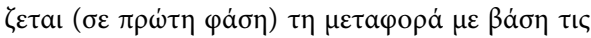

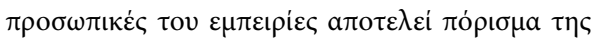

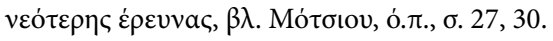

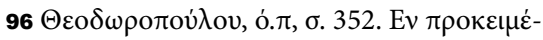

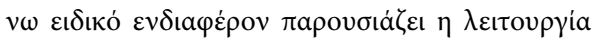

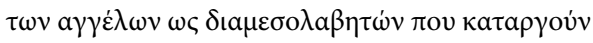

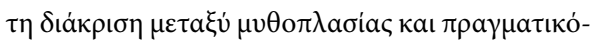

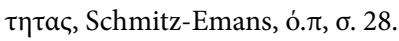

97 Macho, ó. $\pi$, б. 167.

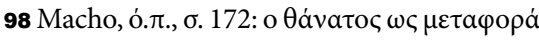

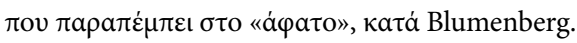

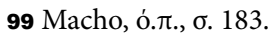

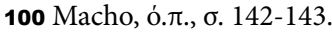

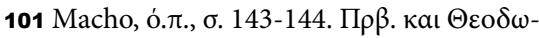

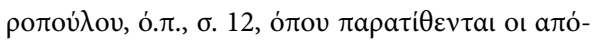

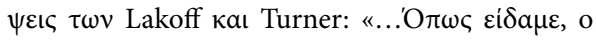

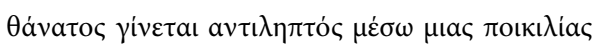

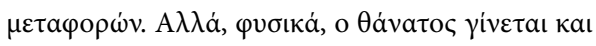

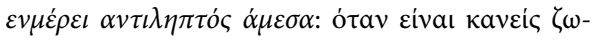

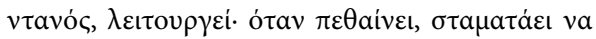

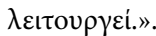

102 Macho, ó.đ., $\sigma .145$.

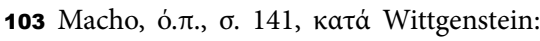
"Die Grenzen meiner Sprache bedeuten die Grenzen meiner Welt".

104 Macho, ó.đ., $\sigma .153$.

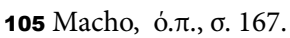

106 Macho, ó.đ., $\sigma .168$.

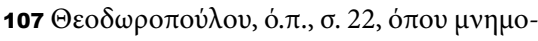

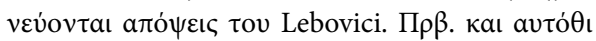

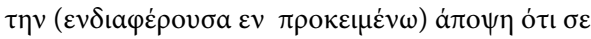

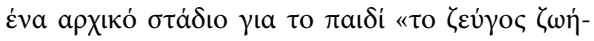

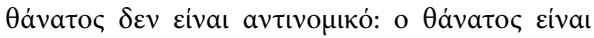

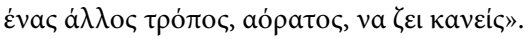

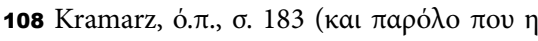

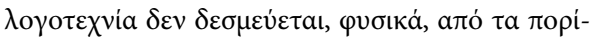

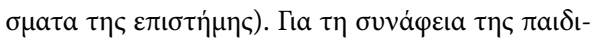

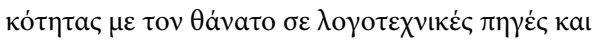

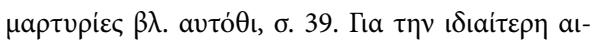

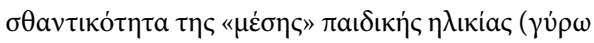

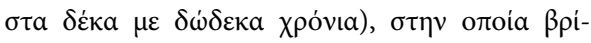

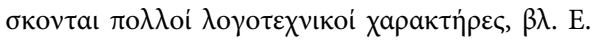
Cobb, "The ecology of imagination in childhood",

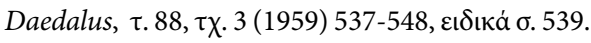

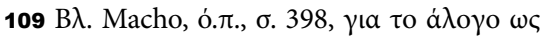

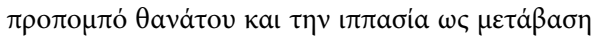

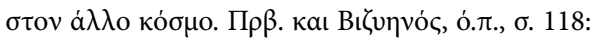

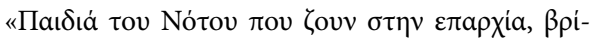

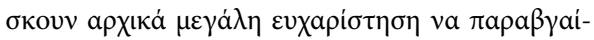

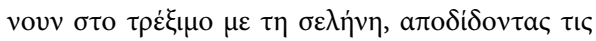

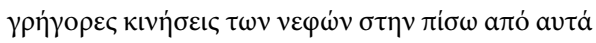

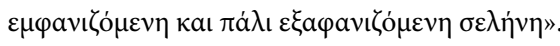

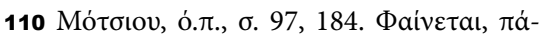

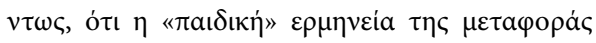

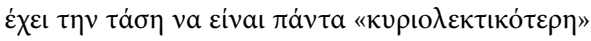

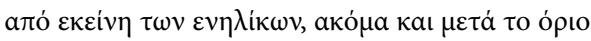

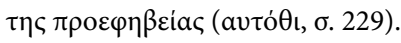

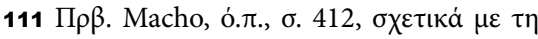

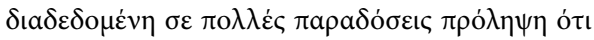

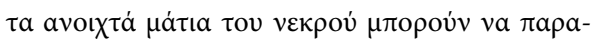

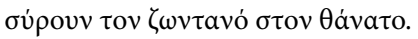

$\Sigma Y \Gamma K P I \Sigma H$ / COMPARAISON

$23(2012)$ 


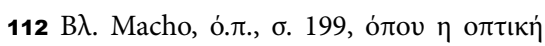

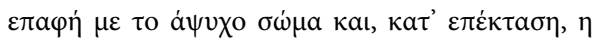

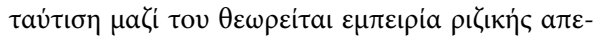

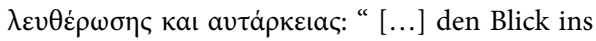
Antlitz der Leiche zu riskieren und ihren Blick auf

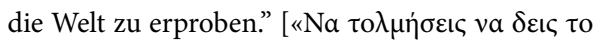

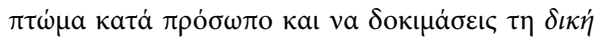

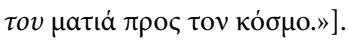

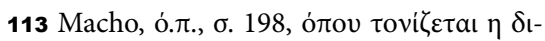

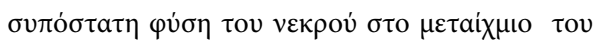

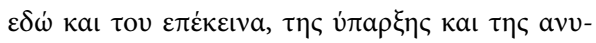

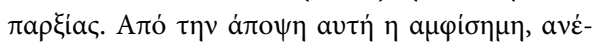

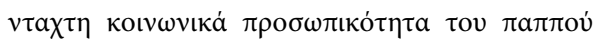

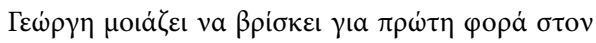

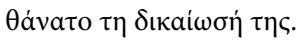

114 П $\beta$. Macho, ó.., б. 223: "In der Grenzerfahrung des sozialen Todes ist die Lokalisierbarkeit der Individuen aufgehoben. Die 'Reise'

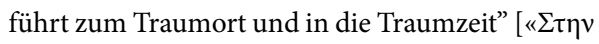

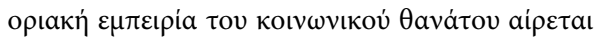
$\eta \varepsilon v \tau$ то

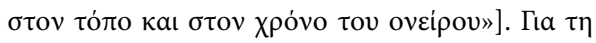

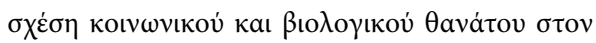

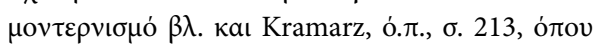

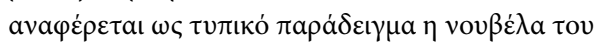

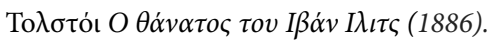

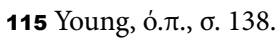

116 Kramarz, ó.đ., $\sigma .142$.

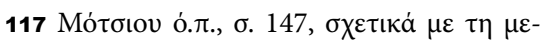

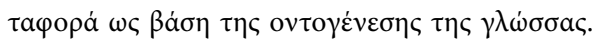

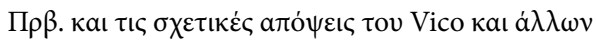

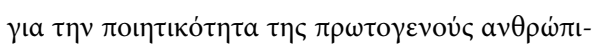

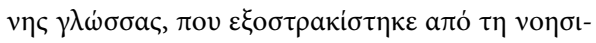

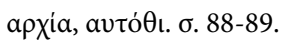

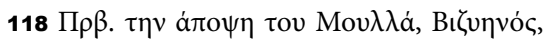

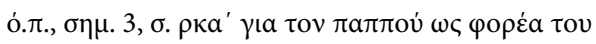

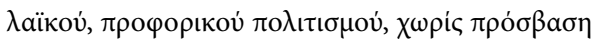

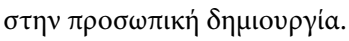

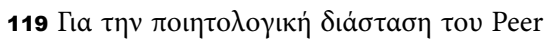
Gynt, $\beta \lambda$. Young, ó.л., $\sigma .58,61$.

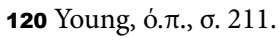

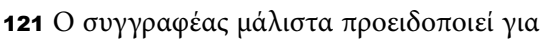

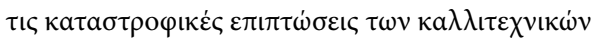

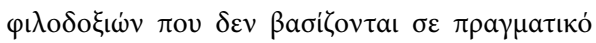
$\tau \alpha \lambda \varepsilon^{\prime} v \tau o$ ( $\left.\sigma .382-383\right)$.

122 Macho, ó.đ., б. 180.

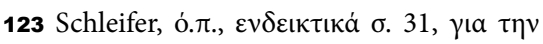

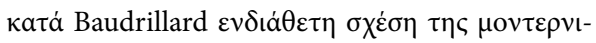

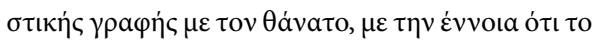

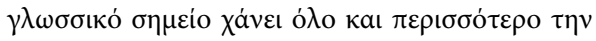

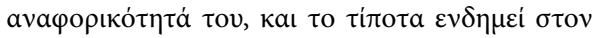

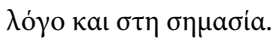

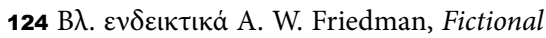

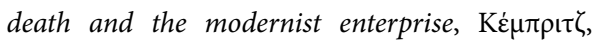
Cambridge University Press, 1995, б. 31-46 ("Climactic death") кaı 71-86 ("Dying in bed"). П $\beta$.

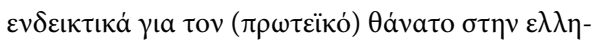

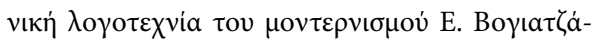

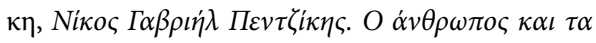

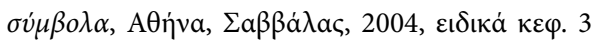
( $\mathrm{O} \pi \varepsilon \theta \alpha \mu \varepsilon \dot{v o \varsigma} \kappa a \iota ~ \eta \alpha v a ́ \sigma \tau \alpha \sigma \eta »)$.

\section{RÉ S U MÉ}

MARIA IATROU: G.M. Vizyinos, «Le seul voyage de sa vie»: les chemins des textes et les métaphores de la mort.

Ce travail est divisé en deux parties: la première examine le rapport entre le récit de Vizyinos et le roman autobiographique Anton Reiser (1785-1790) de Karl Philipp Moritz (1756-1793), écrivain, pédagogue et psychologue allemand de lépoque tardive des Lumières. La deuxième partie explore le thème des métaphores de la mort et leur rôle du catalyseur par rapport à la progression de l'intrigue du récit et, plus largement, à la production de sens. La perception enfantine de la métaphore fait

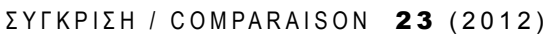


le lien entre les deux unités, car on la retrouve dans les deux textes: les deux héros sont mineurs et comprennent les métaphores littéralement.

Dans la première partie de ce travail sont repérés les éléments thématiques communs entre le texte grec et le texte allemand. Ils reflètent l'intérêt croissant que le XIXème siècle porte à l'enfance. Puis, à travers l'expression «le grand-père se bat avec l'ange» (sens figuré pour quelqu'un qui est en train de mourir), nous examinerons le thème de la perception enfantine de la métaphore en relation avec la linguistique moderne et la psychologie du développement. Les métaphores de la mort et le rapport des enfants avec celle-ci sont également examinés dans ce même cadre. À partir de là, nous proposerons une lecture du «Voyage» en tant que récit de la transition linguistique de l'espace enfantin, de l'imagination et de l'impulsion à l'ordre symbolique et rationnel des adultes et, par extension, du fantasme anarchiste et socialement dysfonctionnel à la production littéraire socialement acceptée. Cette étude constituera le quatrième chapitre d'une monographie sur Vizyinos. 
